\title{
A thermodynamic model of mixed organic-inorganic aerosols to predict activity coefficients
}

\author{
A. Zuend, C. Marcolli, B. P. Luo, and T. Peter \\ Institute for Atmospheric and Climate Science, ETH Zurich, Switzerland \\ Received: 20 February 2008 - Published in Atmos. Chem. Phys. Discuss.: 26 March 2008 \\ Revised: 20 June 2008 - Accepted: 8 July 2008 - Published: 6 August 2008
}

\begin{abstract}
Tropospheric aerosols contain mixtures of inorganic salts, acids, water, and a large variety of organic compounds. Interactions between these substances in liquid mixtures lead to discrepancies from ideal thermodynamic behaviour. By means of activity coefficients, non-ideal behaviour can be taken into account. We present here a thermodynamic model named AIOMFAC (Aerosol InorganicOrganic Mixtures Functional groups Activity Coefficients) that is able to calculate activity coefficients covering inorganic, organic, and organic-inorganic interactions in aqueous solutions over a wide concentration range. This model is based on the activity coefficient model LIFAC by Yan et al (1999) that we modified and reparametrised to better describe atmospherically relevant conditions and mixture compositions. Focusing on atmospheric applications we considered $\mathrm{H}^{+}, \mathrm{Li}^{+}, \mathrm{Na}^{+}, \mathrm{K}^{+}, \mathrm{NH}_{4}^{+}, \mathrm{Mg}^{2+}, \mathrm{Ca}^{2+}, \mathrm{Cl}^{-}, \mathrm{Br}^{-}$, $\mathrm{NO}_{3}^{-}, \mathrm{HSO}_{4}^{-}$, and $\mathrm{SO}_{4}^{2-}$ as cations and anions and a wide range of alcohols/polyols composed of the functional groups $\mathrm{CH}_{\mathrm{n}}$ and $\mathrm{OH}$ as organic compounds. With AIOMFAC, the activities of the components within an aqueous electrolyte solution are well represented up to high ionic strength. Most notably, a semi-empirical middle-range parametrisation of direct organic-inorganic interactions in alcohol+water+salt solutions strongly improves the agreement between experimental and modelled activity coefficients. At room temperature, this novel thermodynamic model offers the possibility to compute equilibrium relative humidities, gas/particle partitioning and liquid-liquid phase separations with high accuracy. In further studies, other organic functional groups will be introduced. The model framework is not restricted to specific ions or organic compounds and is therefore also applicable for other research topics.
\end{abstract}

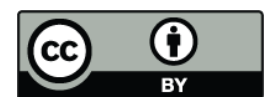

Correspondence to: A. Zuend (andreas.zuend@env.ethz.ch)

\section{Introduction}

Tropospheric aerosols are composed of many different organic and inorganic substances originating from direct emission of particles and from condensation of gas phase species (Kanakidou et al., 2005). Field measurements show that organics are not just traces in individual aerosol particles, but rather that $30 \%$ to more than $80 \%$ of the aerosol mass in the free troposphere are carbonaceous material. Most of this carbonaceous material is organic (Murphy et al., 2006). The abundance of organics in aerosols is comparable to the other well-known tropospheric aerosol components such as sulphuric acid and ammonia. Single particle measurements suggest that organic and inorganic species are mostly internally mixed, especially far away from local sources (Murphy and Thomson, 1997; Middlebrook et al., 1998; Lee et al., 2002; Murphy et al., 2006). This assumption of aerosols as internal mixtures of organics and inorganics is also supported by gas phase diffusion considerations of semi-volatile species (Marcolli et al., 2004). While the prevalent inorganic aerosol constituents are relatively small in number, the organic fraction is highly complex, containing hundreds of compounds with a large fraction still unidentified (Rogge et al., 1993). Such a wide variety of organic compounds in the liquid and solid aerosol phases requires some classification. This is often done considering different functional groups implying that semi-volatile, oxidised organics tend to contain a high degree of functionality, including hydroxyl, carboxyl, and carbonyl groups (Decesari et al., 2000; Maria et al., 2004).

While the thermodynamics of aqueous inorganic systems at atmospheric temperatures is well established, little is known about the physicochemistry of mixed organicinorganic particles. Salting-out and salting-in effects result from organic-inorganic interactions and are used to improve industrial separation processes. In the atmosphere, they may influence the aerosol phases. Phase separations into a mainly polar (aqueous) and a less polar organic phase

Published by Copernicus Publications on behalf of the European Geosciences Union. 
as simulated by Erdakos and Pankow (2004) and Chang and Pankow (2006), may considerably influence the gas/particle partitioning of semi-volatile substances compared to a single phase estimation. Recent experiments show that the interactions between inorganic ions and organic compounds in aerosol particles may induce a liquid-liquid phase separation during humidity cycles (Marcolli and Krieger, 2006). Thus, a thermodynamic model is required that predicts the phase partitioning of organic compounds between the gas and the condensed phases, as well as the compositions of the possible liquid and solid phases at thermodynamic equilibrium.

Non-ideal thermodynamic behaviour in mixtures is usually described by an expression for the excess Gibbs energy $G^{e x}\left(p, T, n_{j}\right)$, as the characteristic state variables of experiments are usually pressure $p$ and temperature $T$. The corresponding activity coefficients $\gamma_{j}$ of the species with amount of moles $n_{j}$ in the mixture, are related to $G^{e x}$ by:

$$
\ln \gamma_{j}=\left(\frac{\partial G^{e x} / R T}{\partial n_{j}}\right)_{T, p, n_{j^{\prime} \neq j}} .
$$

For aqueous electrolyte solutions, Pitzer ion-interaction models are well-known for their ability to calculate activity coefficients in aqueous electrolyte solutions, ranging up to high concentrations (Pitzer, 1991; Carslaw et al., 1995; Clegg et al., 1998a). For non-electrolyte liquid mixtures, the substance specific UNIQUAC (UNIversal QUAsiChemical) model (Abrams and Prausnitz, 1975) and its group-contribution version UNIFAC (UNIquac Functional group Activity Coefficients) (Fredenslund et al., 1975) are widely used for the prediction of liquid-phase activity coefficients of organic species and water. The model LIQUAC (Li et al., 1994) and its group-contribution version LIFAC by Yan et al. (1999) merge a Pitzer-like approach with a UNIQUAC/UNIFAC model to calculate the activity coefficients of mixed organic-inorganic systems. To resolve the problem of liquid-liquid equilibria (LLE) calculations when using variable reference states in mixed solutions, a modified version of LIQUAC/LIFAC with fixed reference states was proposed recently (Kiepe et al., 2006). Such models enable the computation of chemical potentials and the Gibbs energy of mixed systems, and therefore possible phase separations. The original LIFAC model was developed for chemical engineering purposes, which differ mainly in the selection of chemical species, the concentration, and temperature ranges from the needs of aerosol science.

In this study, we present a modified LIFAC model to describe atmospherically relevant aqueous solutions up to high ionic concentrations at room temperature. This activity coefficient model named AIOMFAC (Aerosol Inorganic-Organic Mixtures Functional groups Activity Coefficients) explicitly accounts for molecular interaction effects between solution constituents, both organic and inorganic. In comparison, the ZSR mixing rule (Zdanovskii, 1936, 1948; Stokes and Robinson, 1966) and models based on such rules do not ex- plicitly consider organic-inorganic interactions. The careful choice of reference and standard states (see below) for the neutral and ionic species allows to compute vapour-liquid (VLE), liquid-liquid (LLE) and solid-liquid (SLE) equilibria within one framework.

In the atmosphere, the relative humidity $(\mathrm{RH})$ varies over a wide range and thus affects the concentrations and stable phases in aerosol particles. Compared with bulk solutions, in liquid aerosol droplets much higher supersaturations (metastabilities) with respect to crystalline phases can be reached. For this reason, AIOMFAC was parametrised taking such high ionic strengths into account by using also data from electrodynamic balance (EDB) measurements of single levitated particles. Besides choosing more appropriate reference and standard states and accounting for high ionic strength, other differences compared to the original LIFAC model concern the introduction of additional electrolyte species such as sulphuric acid and ammonium bisulphate. Organic compounds used in this study comprise a wide range of alcohols and polyols, represented by the functional groups $\mathrm{OH}$ and $\mathrm{CH}_{\mathrm{n}}(\mathrm{n}=0,1,2,3)$. The presented modular framework allows to include further functional groups, e.g. carboxyl, carbonyl or aromatic groups, in future studies.

\section{Model framework}

\subsection{General considerations}

The liquid mixtures considered in the present study are composed of different inorganic salts, inorganic acids, organic compounds, and water at room temperature (298 K). Organics are constrained to alcohols and polyols. As we are primarily interested in describing natural aerosols with their tendency to stay fully liquid despite supersaturations with respect to various associated crystalline states, the formation of solid salts or hydrates is prevented on purpose, enabling the formation of metastable solutions. The mixtures are treated as homogeneous bulk solutions excluding curvature effects, which become only important for aerosol droplet radii smaller than $50 \mathrm{~nm}$. Using the terminology of Yan et al. (1999), organic components and water are called "solvents" and the term "solute" refers to ions. All salts and acids in the liquid mixture are treated as completely dissociated into ions, except for the second dissociation stage of sulphuric acid $\left(\mathrm{HSO}_{4}^{-} \rightleftharpoons \mathrm{H}^{+}+\mathrm{SO}_{4}^{2-}\right.$ ) which is explicitly taken into account. Strictly speaking, assuming complete dissociation is valid only at very low solute concentrations because even strong electrolytes associate to a certain amount at higher concentrations (Heyrovska, 2006). However, ion association effects on solution thermodynamics are taken into account by the activity coefficients of the solutes and solvents, thereby justifying the present approach. 


\subsubsection{Group-contribution concept}

Following the idea of UNIFAC, a group-contribution concept is used to describe interaction effects of organic compounds and water in a solution, thereby covering a large number of organics by means of just a few functional groups. For the use in the different model parts, the functional groups of a chemical species are further divided into socalled (functional) main groups and subgroups. For example, the alkyl groups $\mathrm{CH}_{3}, \mathrm{CH}_{2}, \mathrm{CH}$ and $\mathrm{C}$ are different subgroups classified into the main group $\mathrm{CH}_{\mathrm{n}}$. The hydroxyl group $\mathrm{OH}$ is the only subgroup of the main group $\mathrm{OH}$. Therefore, 1-propanol $\left(\mathrm{CH}_{3}-\mathrm{CH}_{2}-\mathrm{CH}_{2}-\mathrm{OH}\right)$ consists of $3 \times \mathrm{CH}_{\mathrm{n}}+1 \times \mathrm{OH}$ in terms of main groups - or when resolved into subgroups of $1 \times \mathrm{CH}_{3}+2 \times \mathrm{CH}_{2}+1 \times \mathrm{OH}$.

The group-contribution concept can be extended to electrolyte solutions by the inclusion of ions as put forward by e.g., extended UNIFAC or the LIFAC models. AIOMFAC is based on LIFAC and uses the same group-contribution concept. In the cases of water and inorganic ions, main groups, subgroups, and chemical species are identical and the terms are used according to the context. Consequently, the category "solvent main groups" of an aqueous organic-inorganic solution includes the different main groups of organic solvents as well as water.

\subsubsection{Reference states}

To avoid problems when using the AIOMFAC model to calculate liquid-liquid phase separations, the reference and standard states of the solvents and solutes should be chosen appropriately. The chemical potential $\mu_{j}\left(\mathrm{~J} \mathrm{~mol}^{-1}\right)$ of component $j$ in the solution is:

$\mu_{j}=\mu_{j}^{\circ}+R T \ln a_{j}$,

where $\mu_{j}^{\circ}$ is the chemical potential of $j$ with respect to a standard state, $R\left(\mathrm{~J} \mathrm{~K}^{-1} \mathrm{~mol}^{-1}\right)$ the universal gas constant, $T(\mathrm{~K})$ the temperature, and $a_{j}$ the activity of species $j$. Using indices $i$ for ions and $s$ for solvent components, the mole fraction of $j$ ( $j$ used for solvent or solute species) in terms of number of moles $n_{j}$ is:

$x_{j}=\frac{n_{j}}{\sum_{i} n_{i}+\sum_{s} n_{s}}$.

On the mole fraction scale the activity coefficient $\gamma_{j}^{(x)}$ is related to $a_{j}^{(x)}$ by:

$a_{j}^{(x)}=\gamma_{j}^{(x)} \frac{x_{j}}{x_{j}^{\circ}}$,

where the superscript $(x)$ denotes the mole fraction basis and $x_{j}^{\circ}$ is the standard state mole fraction of $j$.
For solvent components we choose the symmetric convention with the standard state of the pure liquid $\left(x_{s}^{\circ}=1\right)$ and the reference state of $\gamma_{s}^{(x)} \rightarrow 1$ as $x_{s} \rightarrow 1$. For ions a pure liquid (of cations or anions) is of course inconceivable. To use the symmetric convention for ions, one would therefore have to choose pure fused salts as the reference states (Erdakos et al., 2006). However, having more than one species of both cations and anions in a mixture, the reference basis of pure fused salt becomes ambiguous (Pitzer, 1991). To avoid such conditions (and to make use of an experimentally preferred scale), we chose the unsymmetrical convention on the molality basis for the ions.

Molality $m_{i}\left(\mathrm{~mol} \mathrm{~kg}^{-1}\right)$ of ion $i$ in a solution with solvent components $s$ is defined as:

$m_{i}=\frac{n_{i}}{\sum_{s} n_{s} M_{s}}$,

here $n_{i}$ and $n_{s}$ are the number of moles of the ionic and solvent components, respectively, and $M_{S}\left(\mathrm{~kg} \mathrm{~mol}^{-1}\right)$ is the molar mass of compound $s$. Similar to Eq. (4), the relation for the activity coefficient on the molality basis $(m)$ is:

$a_{i}^{(m)}=\gamma_{i}^{(m)} \frac{m_{i}}{m_{i}^{\circ}}$,

with $m_{i}^{\circ}$ being the standard state molality (conventionally defined as unit molality, i.e. $m_{i}^{\circ}=1 \mathrm{~kg} \mathrm{~mol}^{-1}$ ). For LLE calculations it is very useful to have the same fixed standard state in all coexisting (liquid) phases of different composition. For atmospheric aerosol systems it makes sense to choose water as the reference solvent. In the AIOMFAC model, the reference state of ions is therefore the infinitely diluted solution of ion $i$ in water: $\gamma_{i}^{(m)} \rightarrow 1$ as $x_{w} \rightarrow 1, \sum_{s \neq w} x_{s} \rightarrow 0$, and $m_{i} \rightarrow 0$, $I \rightarrow 0$, where $I$ is the ionic strength (Eq. 10). In contrast to the symmetric mole fraction convention, where reference state and standard state are equal, in the unsymmetric convention the standard state is the hypothetical ideal aqueous solution of unit molality at standard pressure and temperature.

\subsubsection{Non-ideal thermodynamics}

The excess Gibbs energy $G^{e x}(J)$ characterises for the nonideality of a thermodynamic system. Different types of interactions involving charged and non-charged solution species, interacting over different geometric ranges, can be identified. The total excess Gibbs energy of a multicomponent mixture in the AIOMFAC model is expressed in terms of three contributions from long-range (LR), middle-range (MR) and shortrange (SR) interactions:

$G^{e x}=G_{\mathrm{LR}}^{e x}+G_{\mathrm{MR}}^{e x}+G_{\mathrm{SR}}^{e x}$.

A detailed description of typical expressions for interaction potentials, which play a role in inorganic mixtures or in organic-inorganic mixtures has been given by, e.g. Pitzer 


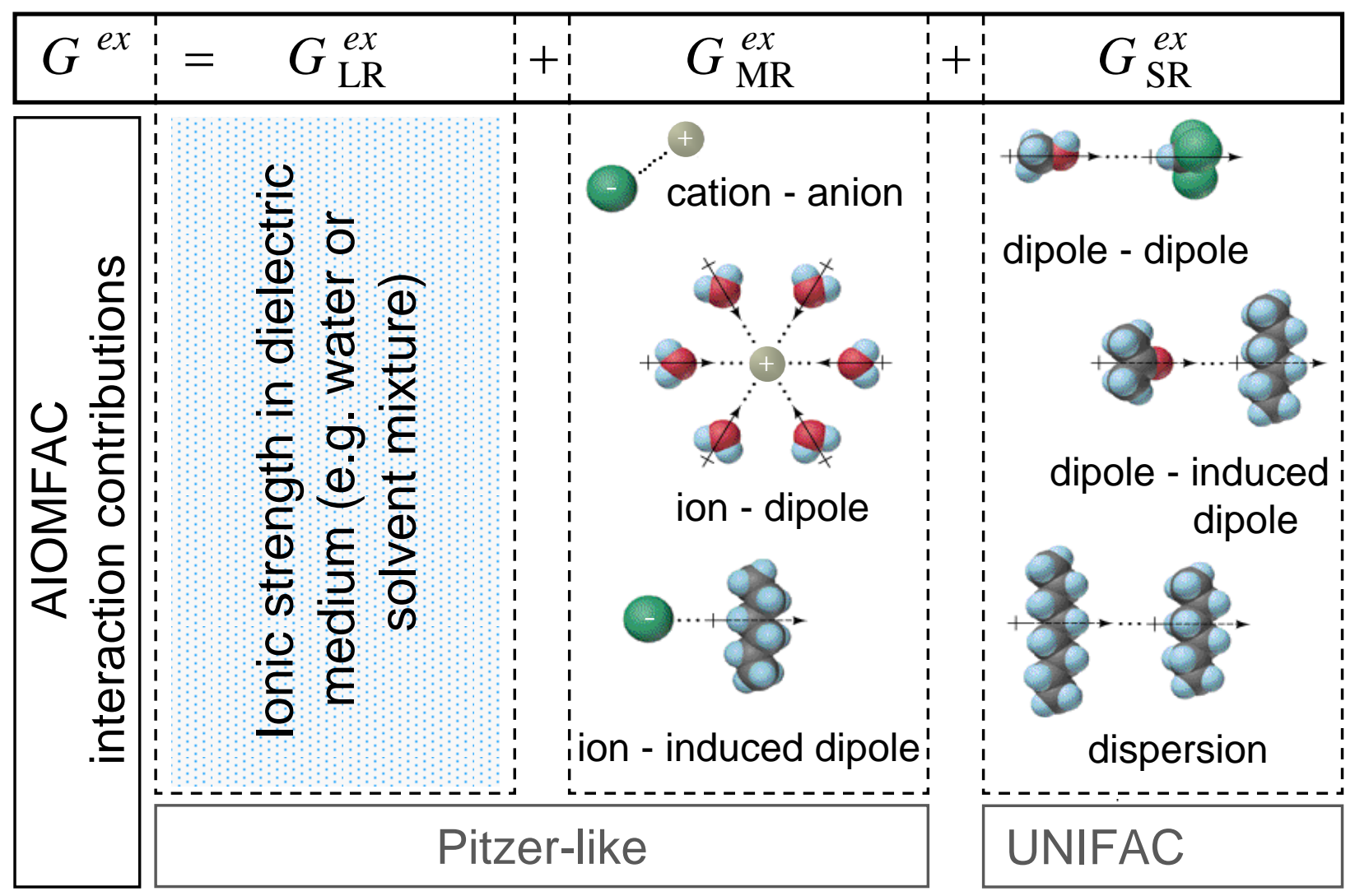

Fig. 1. Three major terms represent different types of molecular interactions in a solution and add up to the excess Gibbs energy $\left(\mathrm{G}^{\text {ex }}\right.$ ) of a certain system in the AIOMFAC model. Dispersion forces, also called London forces, are present in any mixture and denote induced dipole-induced dipole interactions. Long-range forces between ions are described by only taking the electric charge interactions into account while neglecting other ion specific properties (e.g. the different radii).

(1991) and Li et al. (1994), respectively. Figure 1 schematically shows the three interaction ranges considered in AIOMFAC. Long-range and middle-range interactions are described within a Pitzer-like part, in which the former are described by an extended Debye-Hückel term. Short-range interactions of non-charged components are calculated in the UNIFAC part. Note that when no electrolytes are in the mixture, AIOMFAC reduces to UNIFAC. In the following sections, the LR, MR, and SR model parts are explained in more detail.

\subsection{Long-range contribution}

The $G_{\mathrm{LR}}^{e x}$ term represents the LR interaction contribution caused by Coulomb electrostatic forces between the permanently charged ions, moderated by the presence of the dielectric solvent medium. The Debye-Hückel theory was the first approach to successfully describe the electrolyte effects in highly diluted solutions (Debye and Hückel, 1923). This theory treats the solutes as electrical charges in a solvent medium of a specific density and dielectric constant and was shown to be correct in the limit of infinite dilution. In this study, we use the extended Debye-Hückel theory modified as by Fowler and Guggenheim (1949). As a consequence of the choice of the reference solvent water for inorganic ions, the Debye-Hückel expression is different from the one in original LIFAC. Instead of using mixing rules to estimate the density and dielectric constant of the solvent mixture, we use water properties for all solvent components. Similar assumptions were made for the LR part of other mixed solvent models (Iliuta et al., 2000). With this constraint, the corresponding LR activity coefficient expressions for the solvents $\gamma_{s}^{\mathrm{LR},(\mathrm{x})}$ and the ions $\gamma_{i}^{\mathrm{LR},(\mathrm{x}), \infty}$ are:

$$
\begin{aligned}
\ln \gamma_{s}^{\mathrm{LR},(\mathrm{x})}= & \frac{2 A M_{s}}{b^{3}}\left[1+b \sqrt{I}-\frac{1}{1+b \sqrt{I}}\right. \\
& -2 \ln (1+b \sqrt{I})] \\
\ln \gamma_{i}^{\mathrm{LR},(\mathrm{x}), \infty}= & \frac{-z_{i}^{2} A \sqrt{I}}{1+b \sqrt{I}} .
\end{aligned}
$$

Equation (9) gives the activity coefficient of ion $i$ in the mole fraction basis $(x)$ with the reference state of infinite dilution 


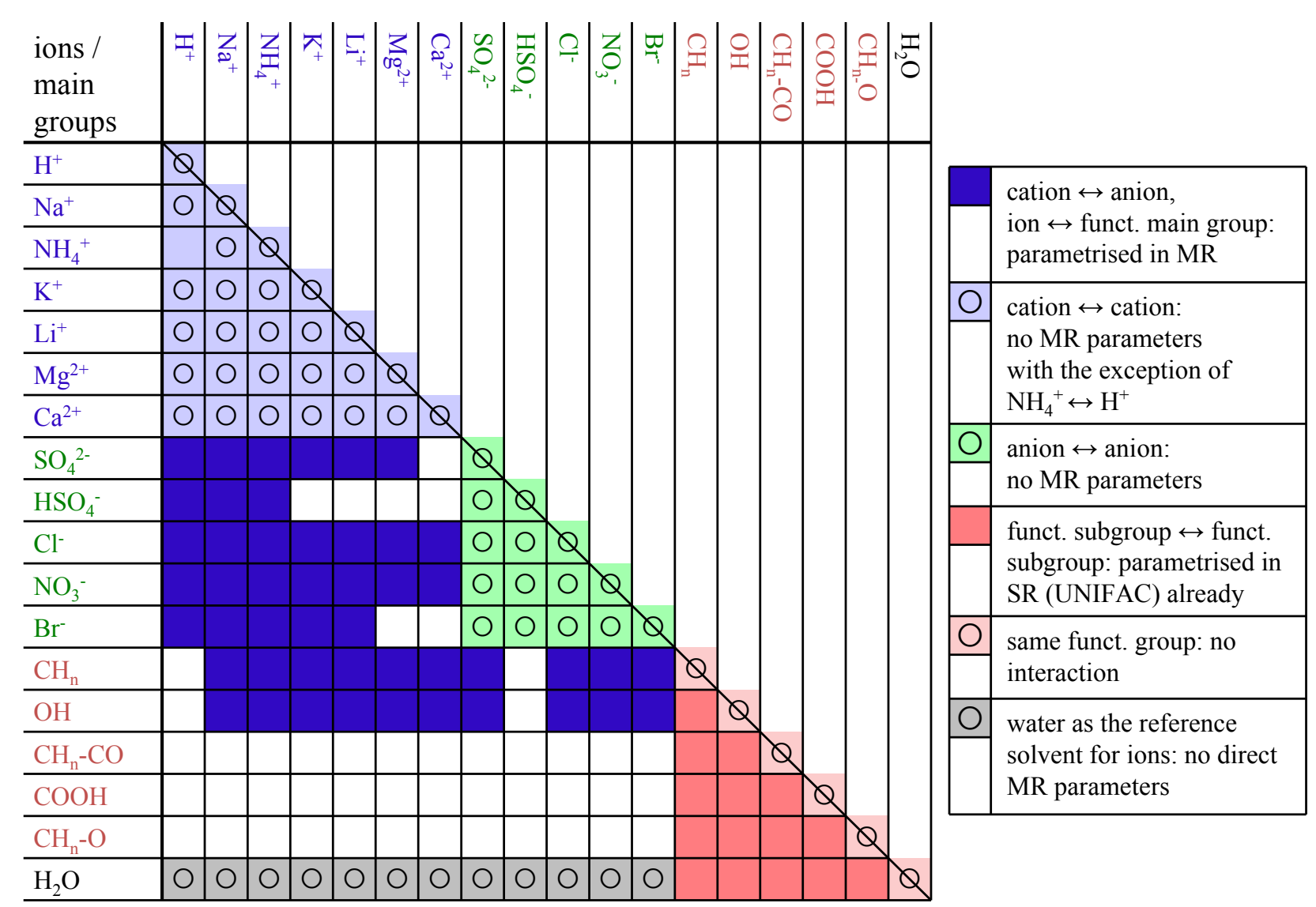

Fig. 2. Scheme of the currently parametrised interactions in the MR and SR part. Fit parameters for ion-ion and ion-organic main group interactions are all incorporated in the MR part and set to zero in the SR (UNIFAC) part. $\mathrm{CH}_{\mathrm{n}}-\mathrm{CO}, \mathrm{COOH}$, and $\mathrm{CH}_{\mathrm{n}}-\mathrm{O}$ present further important organic main groups whose MR interaction parameters are not estimated so far.

in water, indicated by superscript $\infty . M_{s}$ is the molar mass of solvent $s, z_{i}$ the number of elementary charges of ion $i$, and the ionic strength $I\left(\mathrm{~mol} \mathrm{~kg}^{-1}\right)$ is:

$I=\frac{1}{2} \sum_{i} m_{i} z_{i}^{2}$

The Debye-Hückel parameters $A\left(\mathrm{~kg}^{1 / 2} \mathrm{~mol}^{-1 / 2}\right)$ and $b$ $\left(\mathrm{kg}^{1 / 2} \mathrm{~mol}^{-1 / 2}\right)$, depend on temperature $T(\mathrm{~K})$, density $\rho_{w}$ $\left(\mathrm{kg} \mathrm{m}^{-3}\right.$ ), and relative static permittivity $\epsilon_{w}$ (dimensionless) of water, as calculated based on a distance of closest approach of $0.4 \mathrm{~nm}$ between ions:

$A=1.327757 \cdot 10^{5} \frac{\sqrt{\rho_{w}}}{\left(\epsilon_{w} T\right)^{3 / 2}}$,

$b=6.359696 \frac{\sqrt{\rho_{w}}}{\sqrt{\epsilon_{w} T}}$,

with all variables expressed in SI units as mentioned above. The simplification to a water-properties based expression for LR activity coefficients implicates the advantage of not having to estimate unknown dielectric constants of certain organic compounds (Raatikainen and Laaksonen, 2005) and maintains the thermodynamic consistency regarding the chosen reference states. In a real mixture solvents have densities and dielectric properties different from those of pure water, which was the reason for other authors to avoid applying this simplification. We compensate inaccuracies stemming from this simplification in the semi-empirical MR part (see below). Also, since the physical validity of the Debye-Hückel equation is limited to highly dilute ionic solutions, the main effect of the LR part and the involved approximations to describe a mixture's behaviour holds only in that concentration range (typically $<0.1 \mathrm{~mol} \mathrm{~kg}^{-1}$ ).

\subsection{Middle-range contribution}

The $G_{\mathrm{MR}}^{e x}$ term, as illustrated in Fig. 1, is the contribution of the interaction effects involving ions and permanent or induced dipoles. Moreover, the semi-empirical character of the MR part, containing most of the adjustable parameters, can be regarded as the model part, which describes all the interaction effects involving ions not considered by the LR and SR contributions. This includes corrections to assumptions made in the LR and SR parts with respect to approximations 
Table 1. Relative van der Waals subgroup volume $\left(R_{t}^{H}\right)$ and surface area. $\left(Q_{t}^{H}\right)$ parameters for cations and anions considering dynamic hydration.

\begin{tabular}{lrrrrrr}
\hline Ion & $r_{c}(\mathrm{pm})^{\mathrm{a}}$ & $N^{\mathrm{ADH} \mathrm{b}}$ & $R_{t}$ & $Q_{t}$ & $R_{t}^{H \mathrm{c}}$ & $Q_{t}^{H \mathrm{c}}$ \\
\hline $\mathrm{H}^{+}$ & 0 & 1.93 & 0.00 & 0.00 & 1.78 & 2.70 \\
$\mathrm{Li}^{+}$ & 76 & 0.58 & 0.07 & 0.17 & 0.61 & 0.99 \\
$\mathrm{Na}^{+}$ & 102 & 0.22 & 0.18 & 0.31 & 0.38 & 0.62 \\
$\mathrm{~K}^{+}$ & 138 & 0.00 & 0.44 & 0.58 & 0.44 & 0.58 \\
$\mathrm{NH}_{4}^{+}$ & 161 & 0.00 & 0.69 & 0.78 & 0.69 & 0.78 \\
$\mathrm{Mg}^{2+}$ & 72 & 5.85 & 0.06 & 0.16 & 5.44 & 8.35 \\
$\mathrm{Ca}^{2+}$ & 123 & 2.10 & 0.31 & 0.46 & 2.24 & 3.40 \\
$\mathrm{Cl}^{-}$ & 181 & 0.00 & 0.99 & 0.99 & 0.99 & 0.99 \\
$\mathrm{Br}^{-}$ & 196 & 0.00 & 1.25 & 1.16 & 1.25 & 1.16 \\
$\mathrm{NO}_{3}^{-}$ & 179 & 0.00 & 0.95 & 0.97 & 0.95 & 0.97 \\
$\mathrm{HSO}_{4}^{-}$ & 215 & 0.00 & 1.65 & 1.40 & 1.65 & 1.40 \\
$\mathrm{SO}_{4}^{2-}$ & 215 & 1.83 & 1.65 & 1.40 & 3.34 & 3.96 \\
\hline
\end{tabular}

a The unhydrated (crystal) radii taken from Kiriukhin and Collins (2002) and for $\mathrm{NO}_{3}^{-}$and $\mathrm{Br}^{-}$from Achard et al. (1994). The radius of bisulphate $\left(\mathrm{HSO}_{4}^{-}\right)$was assumed to be the same as the one for sulphate $\left(\mathrm{SO}_{4}^{2-}\right)$.

b The apparent dynamic hydration numbers $\left(N^{\mathrm{ADH}}\right)$ at $303.15 \mathrm{~K}$ and $0.1 \mathrm{M}$ taken from Kiriukhin and Collins (2002). Values of $N^{\mathrm{ADH}}=0$ are assigned to the ions, which act as chaotropes (where dynamic hydration is not significant).

${ }^{\mathrm{c}}$ Calculated using Eqs. (26) and (27), respectively.

of physical parameters. MR interactions of solvent compounds (organics and water) with ions are calculated using functional main groups.

The expression for $G_{\mathrm{MR}}^{e x}$ of a mixture containing $n_{k}$ moles of solvent main groups $k$ (main groups of organics and water), with molar masses $M_{k}$, and $n_{i}$ moles of ions $i$ is:

$$
\begin{aligned}
\frac{G_{\mathrm{MR}}^{e x}}{R T} & =\frac{1}{\sum_{k} n_{k} M_{k}} \sum_{k} \sum_{i} B_{k, i}(I) n_{k} n_{i} \\
& +\frac{1}{\sum_{k} n_{k} M_{k}} \sum_{c} \sum_{a} B_{c, a}(I) n_{c} n_{a} \\
& +\frac{1}{\sum_{k} n_{k} M_{k}} \sum_{c} \sum_{a} C_{c, a}(I) n_{c} n_{a} \sum_{i} \frac{n_{i}\left|z_{i}\right|}{\sum_{k} n_{k} M_{k}} \\
& +\frac{1}{\sum_{k} n_{k} M_{k}} \sum_{c} \sum_{c^{\prime} \geq c} R_{c, c^{\prime}} n_{c} n_{c^{\prime}} \\
& +\frac{1}{\left(\sum_{k} n_{k} M_{k}\right)^{2}} \sum_{c} \sum_{c^{\prime} \geq c} \sum_{a} Q_{c, c^{\prime}, a} n_{c} n_{c^{\prime}} n_{a} .
\end{aligned}
$$

$n_{c}$ and $n_{c^{\prime}}$ are moles of cations, $n_{a}$ are moles of anions, and $I$ is the ionic strength (Eq. 10). $B_{k, i}(I)\left(\mathrm{kg} \mathrm{mol}^{-1}\right)$ and $B_{c, a}(I)$
Table 2. Relative van der Waals subgroup volume $\left(R_{t}\right)$ and surface area $\left(Q_{t}\right)$ parameters for solvent subgroups (Hansen et al., 1991).

\begin{tabular}{llll}
\hline Main group $k$ & Subgroup $t$ & $R_{t}$ & $Q_{t}$ \\
\hline $\mathrm{CH}_{\mathrm{n}}(\mathrm{n}=0,1,2,3)$ & $\mathrm{CH}_{3}$ & 0.9011 & 0.848 \\
& $\mathrm{CH}_{2}$ & 0.6744 & 0.540 \\
& $\mathrm{CH}$ & 0.4469 & 0.228 \\
& $\mathrm{C}$ & 0.2195 & 0 \\
$\mathrm{OH}$ & $\mathrm{OH}$ & 1.0000 & 1.200 \\
$\mathrm{H}_{2} \mathrm{O}$ & $\mathrm{H}_{2} \mathrm{O}$ & 0.9200 & 1.400 \\
\hline
\end{tabular}

$\left(\mathrm{kg} \mathrm{mol}^{-1}\right)$ are binary interaction coefficients between solvent main groups and ions, and between cations and anions, respectively. $C_{c, a}(I)\left(\mathrm{kg}^{2} \mathrm{~mol}^{-2}\right)$ are interaction coefficients between cation-anion pairs with respect to the total charge concentration. The coefficients $R_{c, c^{\prime}}\left(\mathrm{kg} \mathrm{mol}^{-1}\right)$ and $Q_{c, c^{\prime}, a}$ $\left(\mathrm{kg}^{2} \mathrm{~mol}^{-2}\right)$ describe binary and ternary interactions involving two different cations. These latter two interaction coefficients were introduced to improve the description of systems containing the ion combinations $\mathrm{NH}_{4}^{+}, \mathrm{H}^{+}$or $\mathrm{NH}_{4}^{+}, \mathrm{H}^{+}$, $\mathrm{SO}_{4}^{2-}$ (e.g., sulphuric acid-ammonium sulphate solutions), especially at very high ionic strength. Hence, the last two terms of Eq. (13) vanish in other cases.

Equation (13) could be extended by terms accounting for interactions between two different anions, two different anions and a cation, and so on. We found that it is not necessary to introduce such higher order interaction terms for the solutions studied. The first three interaction coefficients are parametrised as functions of ionic strength $I$. In contrast to LIFAC, in AIOMFAC we use expressions, which are similar to the ones used for the Pitzer model of Knopf et al. (2003):

$$
\begin{aligned}
& B_{k, i}(I)=b_{k, i}^{(1)}+b_{k, i}^{(2)} e^{-b_{k, i}^{(3)} \sqrt{I}}, \\
& B_{c, a}(I)=b_{c, a}^{(1)}+b_{c, a}^{(2)} e^{-b_{c, a}^{(3)} \sqrt{I}}, \\
& C_{c, a}(I)=c_{c, a}^{(1)} e^{-c_{c, a}^{(2)} \sqrt{I}},
\end{aligned}
$$

where $b_{k, i}^{(1)}, b_{k, i}^{(2)}, b_{c, a}^{(1)}, b_{c, a}^{(2)}, b_{c, a}^{(3)}, c_{c, a}^{(1)}$, and $c_{c, a}^{(2)}$ are adjustable parameters, which are determined by fitting AIOMFAC activity coefficients to experimental data sets. The parameter $b_{c, a}^{(3)}$ was found to describe most aqueous salt solutions when assuming a fixed value of $0.8 \mathrm{~kg}^{1 / 2} \mathrm{~mol}^{-1 / 2}$. In cases where this value did not result in a satisfactory data fit, $b_{c, a}^{(3)}$ was allowed to vary. The parameter $b_{k, i}^{(3)}$ was fixed for all mixed organic-inorganic solutions assuming a value of $1.2 \mathrm{~kg}^{1 / 2} \mathrm{~mol}^{-1 / 2}$. All interaction coefficients in the MR part are symmetric, i.e. $B_{c, a}(I)=B_{a, c}(I)$.

The MR activity coefficients are obtained by differentiating Eq. (13) with respect to the number of moles of solvent main groups, cations, and anions respectively. For a specific solvent main group $k^{*}$ the related expression is: 
Table 3. Continued.

Table 3. Data types, number of data points (N), and references of aqueous inorganic solution data. Binary data was used to fit and ternary to validate the AIOMFAC model at room temperature.

\begin{tabular}{|c|c|c|c|}
\hline Inorganic solutes & Data type $^{\mathrm{a}}$ & $\mathrm{N}^{\mathrm{b}}$ & Reference \\
\hline \multicolumn{4}{|c|}{ binary mixtures (1 salt/acid + water $)$} \\
\hline \multirow[t]{2}{*}{$\mathrm{HCl}$} & $\gamma_{ \pm}$ & 29 & Robinson and Stokes (2002) \\
\hline & $a_{w}$ & 23 & Robinson and Stokes (2002) \\
\hline \multirow[t]{2}{*}{$\mathrm{HBr}$} & $\gamma_{ \pm}$ & 22 & Robinson and Stokes (2002) \\
\hline & $a_{w}$ & 17 & Robinson and Stokes (2002) \\
\hline \multirow{2}{*}{$\mathrm{HNO}_{3}$} & $\gamma_{ \pm}$ & 17 & Robinson and Stokes (2002) \\
\hline & $a_{w}$ & 17 & Robinson and Stokes (2002) \\
\hline \multirow[t]{4}{*}{$\mathrm{H}_{2} \mathrm{SO}_{4}$} & $\alpha_{\mathrm{HSO}_{4}^{-}}$ & 4 & Knopf et al. (2003) \\
\hline & $\alpha_{\mathrm{HSO}_{4}^{-}}$ & 11 & Myhre et al. (2003) \\
\hline & $a_{w}$ & 81 & Staples (1981) \\
\hline & $a_{w}$ & 64 & Robinson and Stokes (2002) \\
\hline \multirow[t]{4}{*}{$\mathrm{LiCl}$} & $\gamma_{ \pm}$ & 43 & Hamer and Wu (1972) \\
\hline & $\gamma_{ \pm}$ & 37 & Robinson and Stokes (2002) \\
\hline & $a_{w}$ & 43 & Hamer and Wu (1972) \\
\hline & $a_{w}$ & 37 & Robinson and Stokes (2002) \\
\hline \multirow[t]{4}{*}{$\mathrm{LiBr}$} & $\gamma_{ \pm}$ & 37 & Robinson and Stokes (2002) \\
\hline & $\gamma_{ \pm}$ & 43 & Hamer and Wu (1972) \\
\hline & $a_{w}$ & 37 & Robinson and Stokes (2002) \\
\hline & $a_{w}$ & 43 & Hamer and Wu (1972) \\
\hline \multirow[t]{4}{*}{$\mathrm{LiNO}_{3}$} & $\gamma_{ \pm}$ & 30 & Robinson and Stokes (2002) \\
\hline & $\gamma_{ \pm}$ & 43 & Hamer and Wu (1972) \\
\hline & $a_{w}$ & 30 & Robinson and Stokes (2002) \\
\hline & $a_{w}$ & 43 & Hamer and Wu (1972) \\
\hline \multirow[t]{2}{*}{$\mathrm{LiSO}_{4}$} & $\gamma_{ \pm}$ & 17 & Robinson and Stokes (2002) \\
\hline & $a_{w}$ & 17 & Robinson and Stokes (2002) \\
\hline \multirow[t]{5}{*}{$\mathrm{NaCl}$} & $\gamma_{ \pm}$ & 30 & Hamer and Wu (1972) \\
\hline & $a_{w}$ & 35 & Robinson and Stokes (2002) \\
\hline & $a_{w}$ & 30 & Hamer and Wu (1972) \\
\hline & $a_{w}$ & 26 & Tang (1997) \\
\hline & $a_{w}$ & 10 & Ha et al. (2000) \\
\hline \multirow[t]{4}{*}{$\mathrm{NaBr}$} & $\gamma_{ \pm}$ & 32 & Hamer and Wu (1972) \\
\hline & $\gamma_{ \pm}$ & 19 & Robinson and Stokes (2002) \\
\hline & $a_{w}$ & 32 & Hamer and Wu (1972) \\
\hline & $a_{w}$ & 19 & Robinson and Stokes (2002) \\
\hline \multirow[t]{4}{*}{$\mathrm{NaNO}_{3}$} & $\gamma_{ \pm}$ & 34 & Hamer and Wu (1972) \\
\hline & $a_{w}$ & 23 & Robinson and Stokes (2002) \\
\hline & $a_{w}$ & 99 & Tang and Munkelwitz (1994) \\
\hline & $a_{w}$ & 19 & Ha et al. (2000) \\
\hline \multirow[t]{3}{*}{$\mathrm{Na}_{2} \mathrm{SO}_{4}$} & $\gamma_{ \pm}$ & 19 & Robinson and Stokes (2002) \\
\hline & $a_{w}$ & 19 & Robinson and Stokes (2002) \\
\hline & $a_{w}$ & 68 & Tang and Munkelwitz (1994) \\
\hline \multirow[t]{5}{*}{$\mathrm{KCl}$} & $\gamma_{ \pm}$ & 27 & Hamer and Wu (1972) \\
\hline & $\gamma_{ \pm}$ & 21 & Robinson and Stokes (2002) \\
\hline & $a_{w}$ & 27 & Hamer and Wu (1972) \\
\hline & $a_{w}$ & 20 & Robinson and Stokes (2002) \\
\hline & $a_{w}$ & 24 & Tang (1997) \\
\hline \multirow[t]{4}{*}{$\mathrm{KBr}$} & $\gamma_{ \pm}$ & 28 & Hamer and Wu (1972) \\
\hline & $\gamma_{ \pm}$ & 22 & Robinson and Stokes (2002) \\
\hline & $a_{w}$ & 28 & Hamer and Wu (1972) \\
\hline & $a_{w}$ & 22 & Robinson and Stokes (2002) \\
\hline \multirow[t]{3}{*}{$\mathrm{KNO}_{3}$} & $\gamma_{ \pm}$ & 24 & Hamer and Wu (1972) \\
\hline & $a_{w}$ & 24 & Hamer and Wu (1972) \\
\hline & $a_{w}$ & 18 & Robinson and Stokes (2002) \\
\hline
\end{tabular}

\begin{tabular}{|c|c|c|c|}
\hline Inorganic solutes & Data type $^{\mathrm{a}}$ & $\mathrm{N}^{\mathrm{b}}$ & Reference \\
\hline \multicolumn{4}{|c|}{ binary mixtures (1 salt/acid + water) } \\
\hline \multirow[t]{2}{*}{$\mathrm{K}_{2} \mathrm{SO}_{4}$} & $\gamma_{ \pm}$ & 7 & Robinson and Stokes (2002) \\
\hline & $a_{w}$ & 7 & Robinson and Stokes (2002) \\
\hline \multirow[t]{5}{*}{$\mathrm{NH}_{4} \mathrm{Cl}$} & $\gamma_{ \pm}$ & 23 & Robinson and Stokes (2002) \\
\hline & $\gamma_{ \pm}$ & 31 & Hamer and Wu (1972) \\
\hline & $a_{w}$ & 23 & Robinson and Stokes (2002) \\
\hline & $a_{w}$ & 31 & Hamer and Wu (1972) \\
\hline & $a_{w}$ & 54 & Ha et al. (2000) \\
\hline \multirow[t]{2}{*}{$\mathrm{NH}_{4} \mathrm{Br}$} & $\gamma_{ \pm}$ & 23 & Covington and Irish (1972) \\
\hline & $a_{w}$ & 23 & Covington and Irish (1972) \\
\hline \multirow[t]{5}{*}{$\mathrm{NH}_{4} \mathrm{NO}_{3}$} & $\gamma_{ \pm}$ & 37 & Robinson and Stokes (2002) \\
\hline & $\gamma_{ \pm}$ & 49 & Hamer and Wu (1972) \\
\hline & $a_{w}$ & 37 & Robinson and Stokes (2002) \\
\hline & $a_{w}$ & 49 & Hamer and Wu (1972) \\
\hline & $a_{w}$ & 71 & Chan et al. (1992) \\
\hline \multirow[t]{4}{*}{$\left(\mathrm{NH}_{4}\right)_{2} \mathrm{SO}_{4}$} & $\gamma_{ \pm}$ & 19 & Robinson and Stokes (2002) \\
\hline & $a_{w}$ & 22 & Robinson and Stokes (2002) \\
\hline & $a_{w}$ & 54 & Clegg et al. (1995) \\
\hline & $a_{w}$ & 18 & Tang and Munkelwitz (1994) \\
\hline \multirow[t]{3}{*}{$\mathrm{MgCl}_{2}$} & $\gamma_{ \pm}$ & 21 & Robinson and Stokes (2002) \\
\hline & $a_{w}$ & 21 & Robinson and Stokes (2002) \\
\hline & $a_{w}$ & 60 & Ha and Chan (1999) \\
\hline \multirow[t]{3}{*}{$\mathrm{Mg}\left(\mathrm{NO}_{3}\right)_{2}$} & $\gamma_{ \pm}$ & 21 & Robinson and Stokes (2002) \\
\hline & $a_{w}$ & 21 & Robinson and Stokes (2002) \\
\hline & $a_{w}$ & 60 & Ha and Chan (1999) \\
\hline \multirow[t]{4}{*}{$\mathrm{MgSO}_{4}$} & $\gamma_{ \pm}$ & 17 & Robinson and Stokes (2002) \\
\hline & $a_{w}$ & 16 & Guendouzi et al. (2003) \\
\hline & $a_{w}$ & 17 & Robinson and Stokes (2002) \\
\hline & $a_{w}$ & 62 & Ha and Chan (1999) \\
\hline
\end{tabular}

$$
\begin{aligned}
\ln \gamma_{k^{\star}}^{\mathrm{MR},(\mathrm{x})}=\sum_{i} B_{k^{\star}, i}(I) m_{i} \\
-\frac{M_{k^{\star}}}{M_{a v}} \sum_{k} \sum_{i}\left[B_{k, i}(I)+I B_{k, i}^{\prime}(I)\right] x_{k}^{\prime} m_{i} \\
-M_{k^{\star}} \sum_{c} \sum_{a}\left[B_{c, a}(I)+I B_{c, a}^{\prime}(I)\right] m_{c} m_{a} \\
-M_{k^{\star}}\left(\sum_{i} m_{i}\left|z_{i}\right|\right) \sum_{c} \sum_{a}\left[2 C_{c, a}(I)\right. \\
\left.+I C_{c, a}^{\prime}(I)\right] m_{c} m_{a} \\
-M_{k^{\star}} \sum_{c} \sum_{c^{\prime} \geq c} R_{c, c^{\prime}} m_{c} m_{c^{\prime}} \\
-M_{k^{\star}} \sum_{c} \sum_{c^{\prime} \geq c} \sum_{a} 2 Q_{c, c^{\prime}, a} m_{c} m_{c^{\prime}} m_{a},
\end{aligned}
$$

where $m_{i}, m_{c}, m_{a}$ are the molalities of ions, cations, and anions respectively, $x_{k}^{\prime}$ are the salt-free mole fractions of solvent main groups $k$, and $M_{a v}=\sum_{s} x_{s}^{\prime} M_{s}$ is the average molar mass of the solvent mixture. $M_{k}^{*}$ is the molar mass of main group $k^{*}$, calculated from the molar masses of the corresponding subgroups and their partial 
Table 3. Continued.

\begin{tabular}{|c|c|c|c|}
\hline Inorganic solutes & Data type ${ }^{a}$ & $\mathrm{~N}^{\mathrm{b}}$ & Reference \\
\hline \multirow[t]{3}{*}{$\mathrm{CaCl}_{2}$} & $\gamma_{ \pm}$ & 23 & Robinson and Stokes (2002) \\
\hline & $a_{w}$ & 31 & Robinson and Stokes (2002) \\
\hline & $a_{w}$ & 14 & Guendouzi et al. (2001) \\
\hline \multirow[t]{2}{*}{$\mathrm{Ca}\left(\mathrm{NO}_{3}\right)_{2}$} & $\gamma_{ \pm}$ & 23 & Robinson and Stokes (2002) \\
\hline & $a_{w}$ & 23 & Robinson and Stokes (2002) \\
\hline \multicolumn{4}{|c|}{ ternary and higher multicomponent mixtures $\mathrm{c}$} \\
\hline $\mathrm{NaHSO}_{4}\left(\hat{=} \mathrm{Na}_{2} \mathrm{SO}_{4}+\mathrm{H}_{2} \mathrm{SO}_{4}[1: 1]\right)$ & $a_{w}$ & 32 & Tang and Munkelwitz (1994) \\
\hline $\mathrm{NH}_{4} \mathrm{HSO}_{4}$ & $\alpha_{\mathrm{HSO}_{4}^{-}}$ & 15 & Irish and Chen (1970) \\
\hline \multirow[t]{5}{*}{$\left(\hat{=}\left(\mathrm{NH}_{4}\right)_{2} \mathrm{SO}_{4}+\mathrm{H}_{2} \mathrm{SO}_{4}[1: 1]\right)$} & $\alpha_{\mathrm{HSO}_{4}^{-}}$ & 9 & Young et al. (1959) \\
\hline & $\alpha_{\mathrm{HSO}_{4}^{-}}$ & 7 & Dawson et al. (1986) \\
\hline & $a_{w}$ & 12 & Tang and Munkelwitz (1977) \\
\hline & $a_{w}$ & 40 & Spann (1984) \\
\hline & $a_{w}$ & 23 & Kim et al. (1994) \\
\hline$\left(\mathrm{NH}_{4}\right)_{2} \mathrm{SO}_{4}+\mathrm{H}_{2} \mathrm{SO}_{4}[1: 2]$ & $a_{w}$ & 33 & Kim et al. (1994) \\
\hline \multirow[t]{2}{*}{$\left(\mathrm{NH}_{4}\right)_{2} \mathrm{SO}_{4}+\mathrm{H}_{2} \mathrm{SO}_{4}[2: 1]$} & $a_{w}$ & 12 & this study (bulk) \\
\hline & $a_{w}$ & 33 & this study $(\mathrm{EDB})$ \\
\hline$\left(\mathrm{NH}_{4}\right)_{3} \mathrm{H}\left(\mathrm{SO}_{4}\right)_{2}[3: 1]$ & $a_{w}$ & 9 & Tang and Munkelwitz (1994) \\
\hline$\left(\mathrm{NH}_{4}\right)_{2} \mathrm{SO}_{4}+\mathrm{H}_{2} \mathrm{SO}_{4}[0.4824: 1]$ & $a_{w}$ & 36 & Clegg et al. (1996) \\
\hline$\left(\mathrm{NH}_{4}\right)_{2} \mathrm{SO}_{4}+\mathrm{H}_{2} \mathrm{SO}_{4}[1.947: 1]$ & $a_{w}$ & 35 & Clegg et al. (1996) \\
\hline $\mathrm{Mg}\left(\mathrm{NO}_{3}\right)_{2}+\mathrm{MgSO}_{4}[1: 1]$ & $a_{w}$ & 57 & Ha and Chan (1999) \\
\hline $\mathrm{MgCl}_{2}+\mathrm{MgSO}_{4}[1: 1]$ & $a_{w}$ & 62 & Ha and Chan (1999) \\
\hline $\mathrm{MgCl}_{2}+\mathrm{Mg}\left(\mathrm{NO}_{3}\right)_{2}[1: 1]$ & $a_{w}$ & 29 & Ha and Chan (1999) \\
\hline $\mathrm{MgCl}_{2}+\mathrm{Mg}\left(\mathrm{NO}_{3}\right)_{2}[3: 1]$ & $a_{w}$ & 26 & Ha and Chan (1999) \\
\hline $\mathrm{MgCl}_{2}+\operatorname{Mg}\left(\mathrm{NO}_{3}\right)_{2}[1: 3]$ & $a_{w}$ & 27 & Ha and Chan (1999) \\
\hline $\mathrm{MgCl}_{2}+\mathrm{Mg}\left(\mathrm{NO}_{3}\right)_{2}+\mathrm{MgSO}_{4}[1: 1: 1]$ & $a_{w}$ & 62 & Ha and Chan (1999) \\
\hline $\mathrm{MgCl}_{2}+\mathrm{Mg}\left(\mathrm{NO}_{3}\right)_{2}+\mathrm{MgSO}_{4}[1: 1: 5]$ & $a_{w}$ & 62 & Ha and Chan (1999) \\
\hline $\mathrm{NH}_{4} \mathrm{Cl}+\left(\mathrm{NH}_{4}\right)_{2} \mathrm{SO}_{4}[1: 1]$ & $a_{w}$ & 64 & Ha et al. (2000) \\
\hline $\mathrm{NH}_{4} \mathrm{Cl}+\mathrm{NH}_{4} \mathrm{NO}_{3}[1: 1]$ & $a_{w}$ & 58 & Ha et al. (2000) \\
\hline $\mathrm{NaCl}+\mathrm{NH}_{4} \mathrm{Cl}[1: 1]$ & $a_{w}$ & 73 & Ha et al. (2000) \\
\hline $\mathrm{NaCl}+\mathrm{NH}_{4} \mathrm{Cl}[3: 1]$ & $a_{w}$ & 73 & Ha et al. (2000) \\
\hline \multirow[t]{2}{*}{$\mathrm{NaCl}+\mathrm{NH}_{4} \mathrm{NO}_{3}[1: 1]$} & $a_{w}$ & 62 & Ha et al. (2000) \\
\hline & $a_{w}$ & 13 & this study (bulk) \\
\hline $\mathrm{NaCl}+\mathrm{NH}_{4} \mathrm{NO}_{3}[3: 1]$ & $a_{w}$ & 62 & Ha et al. (2000) \\
\hline $\mathrm{NaNO}_{3}+\left(\mathrm{NH}_{4}\right)_{2} \mathrm{SO}_{4}[1: 1]$ & $a_{w}$ & 62 & Ha et al. (2000) \\
\hline $\mathrm{NaNO}_{3}+\left(\mathrm{NH}_{4}\right)_{2} \mathrm{SO}_{4}[3: 1]$ & $a_{w}$ & 64 & Ha et al. (2000) \\
\hline $\mathrm{NaNO}_{3}+\mathrm{NH}_{4} \mathrm{NO}_{3}[1: 1]$ & $a_{w}$ & 61 & Ha et al. (2000) \\
\hline $\mathrm{NaNO}_{3}+\mathrm{NH}_{4} \mathrm{NO}_{3}[3: 1]$ & $a_{w}$ & 49 & Ha et al. (2000) \\
\hline $\mathrm{NaNO}_{3}+\mathrm{Na}_{2} \mathrm{SO}_{4}[1: 1]$ & $a_{w}$ & 26 & Ha et al. (2000) \\
\hline $\mathrm{NaNO}_{3}+\mathrm{Na}_{2} \mathrm{SO}_{4}[3: 1]$ & $a_{w}$ & 26 & Ha et al. (2000) \\
\hline $\mathrm{NaCl}+\mathrm{KCl}+\mathrm{LiCl}[1: 1: 1]$ & $a_{w}$ & 19 & Dinane (2007) \\
\hline $\mathrm{NaCl}+\mathrm{KCl}+\mathrm{LiCl}[2: 1: 1]$ & $a_{w}$ & 16 & Dinane (2007) \\
\hline $\mathrm{NaCl}+\mathrm{KCl}+\mathrm{LiCl}[1: 2: 2]$ & $a_{w}$ & 16 & Dinane (2007) \\
\hline $\mathrm{NaCl}+\mathrm{Na}_{2} \mathrm{SO}_{4}+\mathrm{MgCl}_{2}[14.82: 1.00: 1.89]$ & $a_{w}$ & 10 & this study (bulk) \\
\hline $\mathrm{Na}_{2} \mathrm{SO}_{4}+\mathrm{MgCl}_{2}+\mathrm{MgSO}_{4}[1.49: 1.00: 1.26]$ & $a_{w}$ & 9 & this study (bulk) \\
\hline \multirow[t]{2}{*}{$\mathrm{NaCl}+\mathrm{MgSO}_{4}[1: 1]$} & $a_{w}$ & 8 & this study (bulk) \\
\hline & $a_{w}$ & 68 & Chan et al. (2000) \\
\hline
\end{tabular}

${ }^{\text {a }}$ Water activity $\left(a_{w}\right)$ data was calculated from listed osmotic coefficients and solute molalities when not given in the literature.

${ }^{\mathrm{b}}$ Data points by Tang and Munkelwitz (1994) were generated by using the given polynomials to their measurements.

${ }^{\mathrm{c}}$ In brackets the molar ratio of the salts or alternatively the ratio of ammonium sulphate to sulphuric acid. 
contributions to $k^{*} . \quad B_{k, i}^{\prime}(I), B_{c, a}^{\prime}(I)\left(\mathrm{kg}^{2} \mathrm{~mol}^{-2}\right)$, and $C_{c, a}^{\prime}(I)\left(\mathrm{kg}^{3} \mathrm{~mol}^{-3}\right)$ are the partial derivatives with respect to $I$, e.g. $B_{c, a}^{\prime}(I)=\partial B_{c, a}^{\prime}(I) / \partial I$. The activity coefficient of solvent compound $s$ is then obtained from the main group contributions by:

$$
\ln \gamma_{s}^{\mathrm{MR},(\mathrm{x})}=\sum_{k} v_{k}^{(s)} \ln \gamma_{k}^{\mathrm{MR},(\mathrm{x})}
$$

where $v_{k}^{(s)}$ refers to the stoichiometric number of main groups $k$ in the solvent molecule $s$, e.g. $v_{\mathrm{CH}_{\mathrm{n}}}^{(1,2-\text { butanediol })}=4$ and $v_{\mathrm{OH}}^{(1,2-\text { butanediol })}=2$. In analogy to Eq. (17) the expressions for a specific cation $c^{*}$ are:

$$
\begin{aligned}
& \ln \gamma_{c^{\star}}^{\mathrm{MR},(\mathrm{x}), \infty}=\frac{1}{M_{a v}} \sum_{k} B_{k, c^{\star}}(I) x_{k}^{\prime} \\
& \quad+\frac{z_{c^{\star}}^{2}}{2 M_{a v}} \sum_{k} \sum_{i} B_{k, i}^{\prime}(I) x_{k}^{\prime} m_{i} \\
& \quad+\sum_{a} B_{c^{\star}, a}(I) m_{a}+\frac{z_{c^{\star}}^{2}}{2} \sum_{c} \sum_{a} B_{c, a}^{\prime}(I) m_{c} m_{a} \\
& +\sum_{a} C_{c^{\star}, a}(I) m_{a} \sum_{i} m_{i}\left|z_{i}\right| \\
& +\sum_{c} \sum_{a}\left[C_{c, a}(I)\left|z_{c^{\star}}\right|\right. \\
& \left.+C_{c, a}^{\prime}(I) \frac{z_{\mathcal{C}^{\star}}^{2}}{2} \sum_{i} m_{i}\left|z_{i}\right|\right] m_{c} m_{a} \\
& +\sum_{c} R_{c^{\star}, c} m_{c}+\sum_{c} \sum_{a} Q_{c^{\star}, c, a} m_{c} m_{a},
\end{aligned}
$$

and for anion $a^{*}$ :

$$
\begin{aligned}
& \ln \gamma_{a^{\star}}^{\mathrm{MR},(\mathrm{x}), \infty}=\frac{1}{M_{a v}} \sum_{k} B_{k, a^{\star}}(I) x_{k}^{\prime} \\
& \quad+\frac{z_{a^{\star}}^{2}}{2 M_{a v}} \sum_{k} \sum_{i} B_{k, i}^{\prime}(I) x_{k}^{\prime} m_{i} \\
& \quad+\sum_{c} B_{c, a^{\star}}(I) m_{c}+\frac{z_{a^{\star}}^{2}}{2} \sum_{c} \sum_{a} B_{c, a}^{\prime}(I) m_{c} m_{a} \\
& \quad+\sum_{c} C_{c, a^{\star}}(I) m_{c} \sum_{i} m_{i}\left|z_{i}\right| \\
& \quad+\sum_{c} \sum_{a}\left[C_{c, a}(I)\left|z_{a^{\star}}\right|\right. \\
& \left.\quad+C_{c, a}^{\prime}(I) \frac{z_{a^{\star}}^{2}}{2} \sum_{i} m_{i}\left|z_{i}\right|\right] m_{c} m_{a} \\
& +\sum_{c} \sum_{c^{\prime} \geq c} Q_{c, c^{\prime}, a^{\star}} m_{c} m_{c^{\prime}} .
\end{aligned}
$$

Specific interaction coefficients (and the corresponding fit parameters) between the reference solvent, i.e. water, and the inorganic ions are set to zero $\left(B_{k=w, i}(I)=0\right)$. Therefore, the unsymmetrical reference state condition for infinite dilution of ions in water $\left(\gamma_{i}^{\mathrm{MR}} \rightarrow 1\right)$ is indeed fulfilled and we write $\ln \gamma_{c^{*}}^{\mathrm{MR},(\mathrm{x}), \infty}$ (normalised) instead of $\ln \gamma_{c^{*}}^{\mathrm{MR},(\mathrm{x})}$. As a consequence of this definition, aqueous electrolyte solutions are described in a similar manner as in a conventional Pitzer model. All binary and ternary coefficients concerning interactions between cations and anions actually describe interactions of cations and anions dissolved in water, thus, including ionic interactions with water. Consequently, specific interaction coefficients between organic functional main groups and ions, the $B_{k, i}(I)$, actually describe the deviations from the interactions of the ions with water. In principle, a different reference solvent could be defined, as discussed in Kiepe et al. (2006), but most tabulated data, e.g. standard chemical potentials, are stated with respect to water as the reference solvent.

\subsection{Short-range contribution}

The SR contribution $G_{\mathrm{SR}}^{e x}$ to the total Gibbs excess energy is represented by the group-contribution method UNIFAC (Fredenslund et al., 1975). The UNIFAC parametrisations in AIOMFAC include some modifications to better meet the specific properties of atmospheric semi-volatile organics, which typically contain molecules carrying several strongly polar functional groups. Therefore, we implemented the more detailed descriptions of alcohol/polyol group interaction parameters published by Marcolli and Peter (2005). This UNIFAC parametrisation of alcohols/polyols distinguishes between three types of alkyl groups: (i) $\mathrm{CH}_{n}(\mathrm{n}=0,1,2)$ with a hydroxyl group, accounting for the induced polarity of alkyl groups directly connected to the electronegative hydroxyl group, (ii) $\mathrm{CH}_{\mathrm{n}}(\mathrm{n}=0,1,2,3)$ in hydrophobic tails, accounting for the non-polar nature of alkyl chains that easily agglomerate and form micelles in water, and (iii) $\mathrm{CH}_{\mathrm{n}}$ $(\mathrm{n}=0,1,2,3)$ in alcohols, which constitutes the general type of alkyl group that applies when the special conditions for the other two types are not fulfilled.

In UNIFAC the activity coefficient $\gamma_{j}$ of mixture component $j$ ( $j$ used for solute or solvent) is in general expressed as the contributions of a combinatorial part $(C)$, accounting for the geometrical properties of the molecule, and a residual part $(R)$, which reflects inter-molecular interactions:

$$
\ln \gamma_{j}^{\mathrm{SR}}=\ln \gamma_{j}^{C}+\ln \gamma_{j}^{R} .
$$

The expression for the combinatorial part of UNIFAC is (Fredenslund et al., 1975):

$$
\ln \gamma_{j}^{C}=\ln \frac{\Phi_{j}}{x_{j}}+\frac{z}{2} q_{j} \ln \frac{\Theta_{j}}{\Phi_{j}}+l_{j}-\frac{\Phi_{j}}{x_{j}} \sum_{j^{\prime}} x_{j^{\prime}} l_{j^{\prime}}
$$

where

$$
\Phi_{j}=\frac{r_{j} x_{j}}{\sum_{j^{\prime}} r_{j^{\prime}} x_{j^{\prime}}} ; \quad \Theta_{j}=\frac{q_{j} x_{j}}{\sum_{j^{\prime}} q_{j^{\prime}} x_{j^{\prime}}},
$$


with

$r_{j}=\sum_{t} v_{t}^{(j)} R_{t} ; \quad q_{j}=\sum_{t} v_{t}^{(j)} Q_{t}$,

and

$l_{j}=\frac{z}{2}\left(r_{j}-q_{j}\right)-\left(r_{j}-1\right)$.

Here, $j$ and $j^{\prime}$ denote mixture species (solvents or ions), $x_{j}$ is the mole fraction of component $j$, and $v_{t}^{(j)}$ is the number of subgroups of type $t$ in component $j . R_{t}$ and $Q_{t}$ are the relative van der Waals subgroup volume and surface area parameters, respectively. The lattice coordination number $z$, a constant, is set equal to 10 (Fredenslund et al., 1975). The relative van der Waals subgroup volume and surface area parameters, $R_{t}$ and $Q_{t}$, account for pure component properties. $R_{t}$ and $Q_{t}$ values for the ions can be estimated from the ionic radii. However, as Yan et al. (1999) point out, the very small radii of the cations significantly reduce the fitting capabilities of the SR contribution. Therefore we estimated $R_{t}$ and $Q_{t}$ values for the ions, taking hydration effects into account, which are especially prominent for the small cations having a high surface charge density. Using an empirical parametrisation, the hydrated group volume and surface area parameters $R_{t}^{H}$ and $Q_{t}^{H}$ are calculated by (Achard et al., 1994):

$R_{t}^{H}=R_{t}+N_{t}^{\mathrm{ADH}} \cdot R_{w}$,

$Q_{t}^{H}=Q_{t}+N_{t}^{\mathrm{ADH}} \cdot Q_{w}$,

where $R_{w}$ and $Q_{w}$ refer to the values of the water molecule and $N_{t}^{\mathrm{ADH}}$ are measured apparent dynamic hydration numbers at $303.15 \mathrm{~K}$ (Kiriukhin and Collins, 2002). $R_{t}^{H}$ and $Q_{t}^{H}$ values calculated with this assumptions are listed in Table 1. They are used as constant, ion-specific values over the whole concentration range. In the case of an ionic component, in Eq. (24), $R_{t}$ and $Q_{t}$ are replaced by $R_{t}^{H}$ and $Q_{t}^{H}$, respectively. The resulting SR contributions were found to be much better suited for an overall model fit compared to unhydrated parameters.

For neutral substances we took the relative subgroup volume and surface area parameters published by Hansen et al. (1991), listed in Table 2. The terms for the residual part of the activity coefficient of $j$ are:

$\ln \gamma_{j}^{R}=\sum_{t} v_{t}^{(j)}\left[\ln \Gamma_{t}-\ln \Gamma_{t}^{(j)}\right]$

where $\Gamma_{t}$ and $\Gamma_{t}^{(j)}$ are the group residual activity coefficients in the mixture and in a reference solution containing only compound $j$, a (hypothetical) pure liquid of $j$, respectively. The expression for the residual activity coefficient of subgroup $t$ is:

$\ln \Gamma_{t}=Q_{t}\left[1-\ln \left(\sum_{m} \Theta_{m} \Psi_{m, t}\right)-\sum_{m}\left(\frac{\Theta_{m} \Psi_{t, m}}{\sum_{n} \Theta_{n} \Psi_{n, m}}\right)\right]$ with

$\Theta_{m}=\frac{Q_{m} X_{m}}{\sum_{n} Q_{n} X_{n}} ; \quad \Psi_{m, n}=e^{-a_{m, n} / T}$,

where $\Theta_{m}$ is the relative surface area fraction of subgroup $m$, $X_{m}$ is the mole fraction of $m$ in the mixture, and $\Psi_{m, n}$ is the temperature dependent function of the subgroup interaction parameter $a_{m, n}$. Note that the subgroup interaction parameters are unsymmetrical, i.e. $a_{m, n} \neq a_{n, m}$. The sums are over all different subgroups. For a more detailed UNIFAC description, we refer to Fredenslund et al. (1975). The subgroup interaction parameters of non-electrolyte solutions have to be estimated using large data sets of binary and higher order mixtures, to distinguish the effective contributions of the different subgroups. In this study, we took the values of $a_{m, n}$ for the alcohol groups and water from the UNIFAC parametrisation of Marcolli and Peter (2005). For LIFAC, Yan et al. (1999) showed, that the model sensitivity to SR interaction parameters $a_{m, n}$ between ions and between ions and organic subgroups is rather small. Thus, in AIOMFAC we set all SR interaction parameters which involve ions to zero, as it is done in LIFAC. This also reduces the number of AIOMFAC fit parameters to those used in the MR part.

Since ions are treated like solvent components in the SR terms, resulting activity coefficients (Eq. 21) are with respect to the symmetrical convention on mole fraction basis. For ions $i$, the unsymmetrical normalised activity coefficient is determined from:

$\ln \gamma_{i}^{\mathrm{SR},(\mathrm{x}), \infty}=\ln \gamma_{i}^{\mathrm{SR},(\mathrm{x})}-\ln \gamma_{i}^{\mathrm{SR},(\mathrm{x}), \mathrm{ref}}$.

The symmetrically normalised value at the reference state is computed from Eqs. (22) and (28) by introducing the reference state conditions of the ions (setting $x_{w}=1, \sum_{s} x_{s}=0$ for $s \neq w$, and $\left.\sum_{i} x_{i}=0\right)$ :

$$
\begin{aligned}
\ln \gamma_{i}^{\mathrm{SR},(\mathrm{x}), \mathrm{ref}} & =\ln \frac{r_{i}}{r_{w}}+1-\frac{r_{i}}{r_{w}}+\frac{z}{2} q_{i}\left[\ln \left(\frac{r_{w} q_{i}}{r_{i} q_{w}}\right)\right. \\
& \left.-1+\frac{r_{i} q_{w}}{r_{w} q_{i}}\right]+q_{i}\left(1-\ln \Psi_{w, i}-\Psi_{i, w}\right)
\end{aligned}
$$

where subscript $w$ stands for the reference solvent (water). The last term on the right-hand side of Eq. (32), reflecting the residual part reference contribution, becomes zero as we defined the SR ion-solvent interactions to be zero.

\subsection{AIOMFAC activity coefficients}

Finally, according to Eqs. (1) and (7), the complete expression for the activity coefficient of solvent species $s$ is:

$\ln \gamma_{s}^{(x)}=\ln \gamma_{s}^{\mathrm{LR},(\mathrm{x})}+\ln \gamma_{s}^{\mathrm{MR},(\mathrm{x})}+\ln \gamma_{s}^{\mathrm{SR},(\mathrm{x})}$

with the specific contributions computed from Eqs. (8), (18), and (21). For the ions, the complete expression with regard to the unsymmetrical convention on molality basis is: 

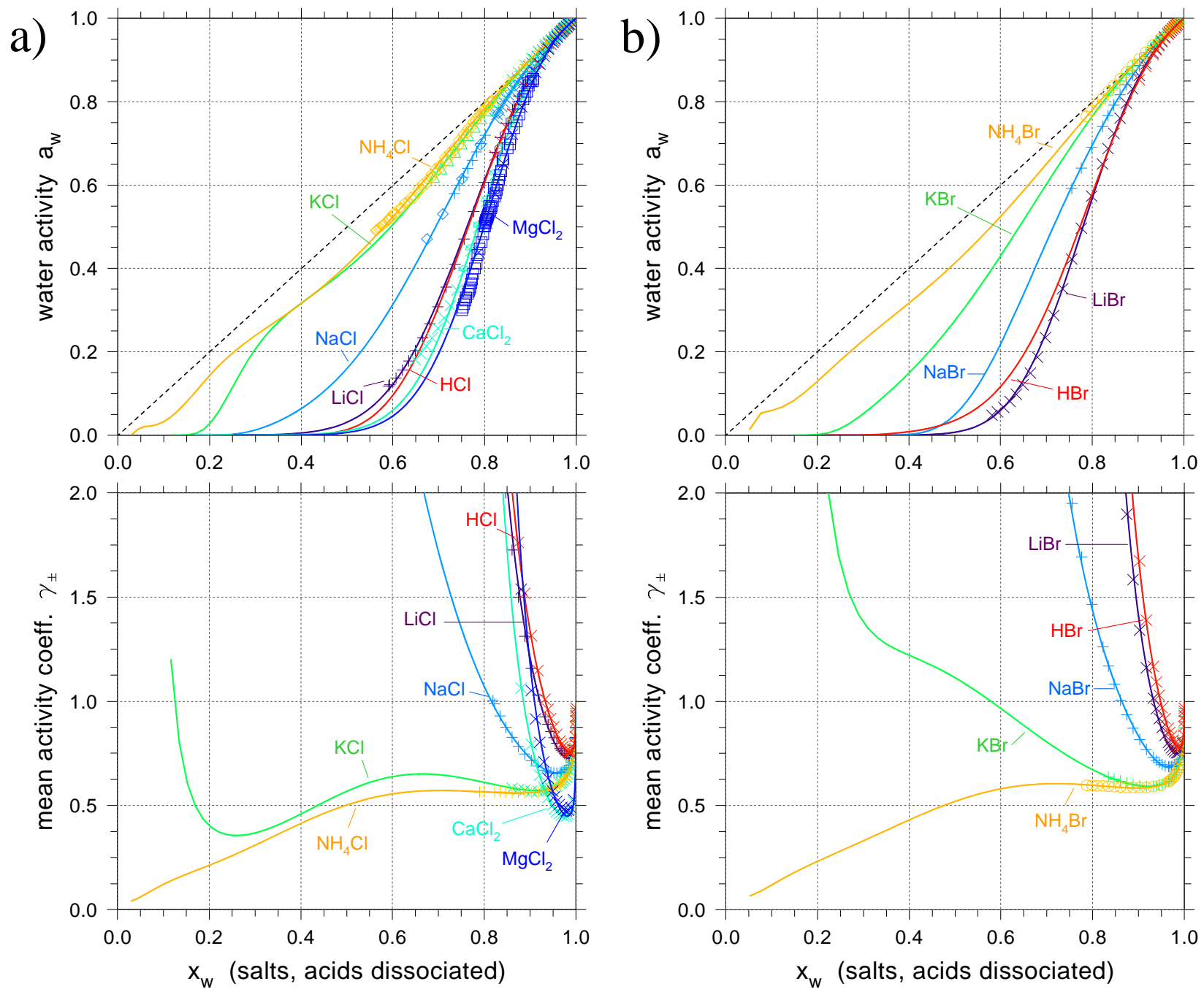

Fig. 3. Experimental (symbols) and modelled (solid lines) water activities and mean activity coefficients of the ions in binary aqueous salt (or acid) solutions at $298 \mathrm{~K}$. The $\mathrm{x}$-axis scale is the mole fraction of $\mathrm{H}_{2} \mathrm{O}$ in the solution with respect to completely dissociated salts and acids. (a) $\mathrm{Cl}^{-}$-electrolytes, (b) $\mathrm{Br}^{-}$-electrolytes; data from: Robinson and Stokes (2002) (×), Hamer and Wu (1972) (+), Ha et al. (2000) $(\diamond)$, Tang (1997) $(\triangle)$, Ha and Chan (1999) $(\square)$, Guendouzi et al. (2001) $(\bigcirc)$, and Covington and Irish (1972) $(\bigcirc)$. The diagonal, dashed line in the upper panels shows the water activity of an ideal mixture. At very high concentrations, beyond the efflorescence of supersaturated solutions, the curves are model predictions without direct experimental support.

$$
\begin{aligned}
\ln \gamma_{i}^{(m)}= & {\left[\ln \gamma_{i}^{\mathrm{LR},(\mathrm{x}), \infty}+\ln \gamma_{i}^{\mathrm{MR},(\mathrm{x}), \infty}+\ln \gamma_{i}^{\mathrm{SR},(\mathrm{x}), \infty}\right] } \\
& -\ln \left[\frac{M_{w}}{\sum_{s} x_{s}^{\prime} M_{s}}+M_{w} \sum_{i^{\prime}} m_{i^{\prime}}\right],
\end{aligned}
$$

where $M_{s}$ is the molar mass of solvent component $s, x_{s}^{\prime}$ its salt-free mole fraction, and $m_{i^{\prime}}$ is the molality of ion $i^{\prime}$. The contributions are from Eq. (9) for the LR, Eq. (19) or (20) for the MR (depending on whether $i$ is a cation or an anion), and Eq. (31) for the SR part. The last term on the right-hand side of Eq. (34) converts the activity coefficient $\ln \gamma_{i}^{(x), \infty}$ (infinitely diluted reference state on the mole fraction basis) to the activity coefficient on molality basis and infinitely diluted (in water) reference state. This term can be derived using the convention-independence of the chemical potentials $\left(\mu_{i}^{(m)}\left(p, T, n_{j}\right)=\mu_{i}^{(x)}\left(p, T, n_{j}\right)\right)$ and the definitions of the chosen reference states. While a model provides activity coefficients of cations and anions, in experiments one cannot distinguish between the individual interaction contributions of the ions in the mixture. Therefore the mean activity coefficient $\gamma_{ \pm}$of a salt $\mathbf{M}_{v^{+}} \mathbf{X}_{v^{-}}$, is defined as:

$$
\gamma_{ \pm}=\left[\gamma_{+}^{v^{+}} \cdot \gamma_{-}{ }^{v^{-}}\right]^{1 /\left(v^{+}+v^{-}\right)}
$$



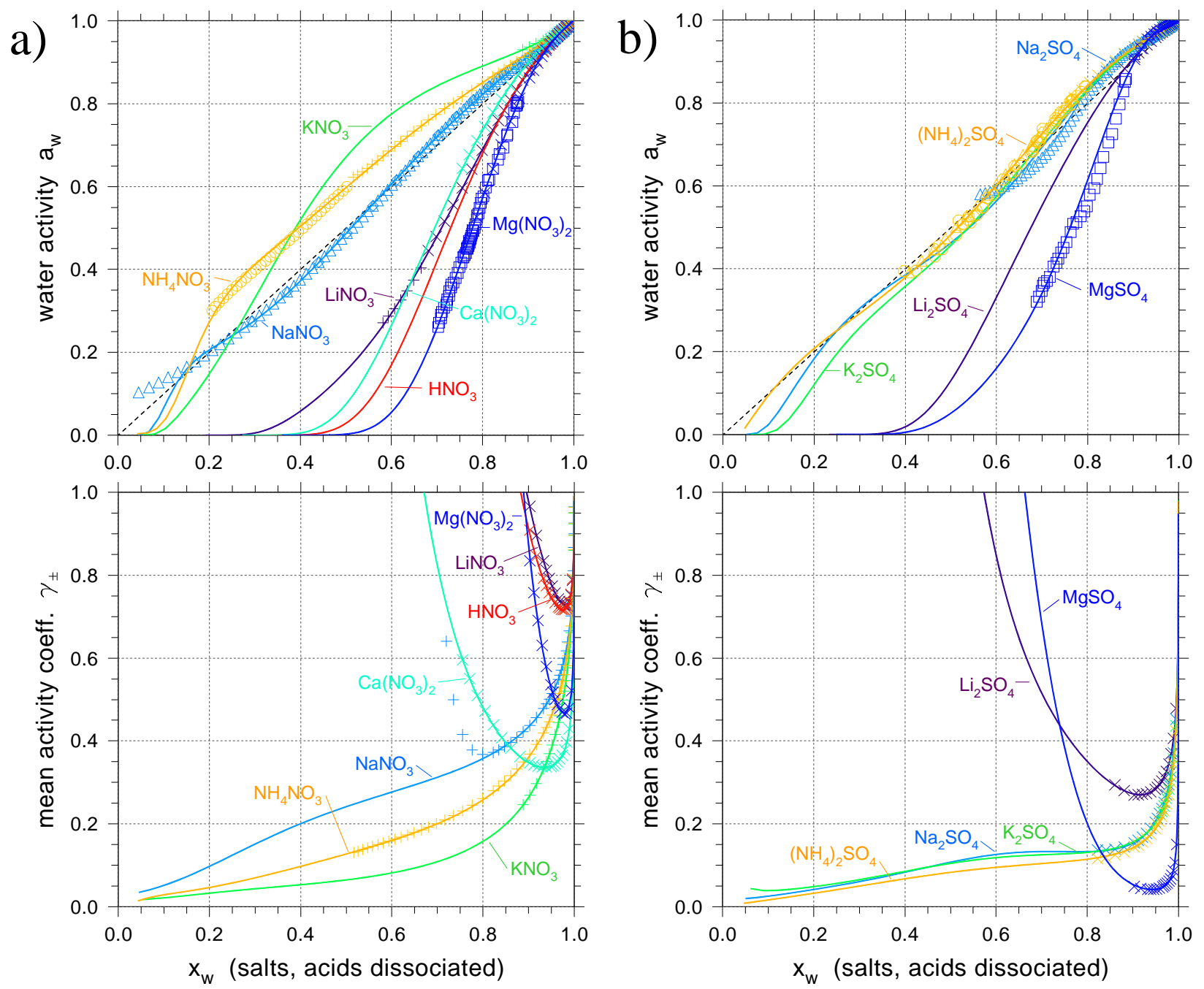

Fig. 4. Experimental (symbols) and modelled (solid lines) water activities and mean activity coefficients of the ions in binary aqueous salt (or acid) solutions at $298 \mathrm{~K}$. (a) $\mathrm{NO}_{3}^{-}$-electrolytes, (b) $\mathrm{SO}_{4}^{2-}$-electrolytes; data from: Robinson and Stokes (2002) ( $\times$ ), Hamer and $\mathrm{Wu}(1972)$

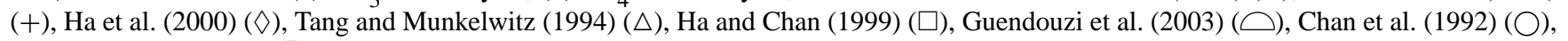
and Clegg et al. (1995) ( ). The diagonal, dashed line in the upper panels shows the water activity of an ideal mixture.

where $v^{+}$and $v^{-}$, are the stoichiometric numbers of cations $(+)$ and anions ( - ) respectively, assuming complete dissociation of the salt. Likewise, using the geometrical mean, the mean molal activity is obtained:

$$
\begin{aligned}
a_{ \pm}^{(m)} & =\left[\left(a_{+}^{(m)}\right)^{v^{+}} \cdot\left(a_{-}^{(m)}\right)^{v^{-}}\right]^{1 /\left(v^{+}+v^{-}\right)} \\
& =\left[\left(\frac{m_{+}}{m^{\circ}} \gamma_{+}^{(m)}\right)^{v^{+}} \cdot\left(\frac{m_{-}}{m^{\circ}} \gamma_{-}^{(m)}\right)^{v^{-}}\right]^{1 /\left(v^{+}+v^{-}\right)} \\
& =\frac{m_{ \pm}}{m^{\circ}} \cdot \gamma_{ \pm}^{(m)}
\end{aligned}
$$

with $m_{ \pm}=\left[m_{+} v^{+} \cdot m_{-}^{v^{-}}\right]^{1 /\left(v^{+}+v^{-}\right)}$.

\subsection{Estimation of model parameters}

The semi-empirical expressions of the MR part contain adjustable parameters, describing interactions between ions, organic functional groups and water. The Debye-Hückel (LR) part and the UNIFAC (SR) part contain no freely adjustable parameters for ions. Organic-organic and organic-water subgroup interactions are parametrized in the SR part. The UNIFAC parameters used here are taken from Marcolli and Peter (2005). Due to the many modifications in the MR part, all pertinent interaction parameters had to be recalculated by fitting the model to experimental data. In a first step, measurements of water activity and mean activity coefficients, 
Table 4. Data types, number of data points $(\mathrm{N})$, temperature range, and references of organic-inorganic-water mixtures used to fit or validate the AIOMFAC model.

\begin{tabular}{|c|c|c|c|c|}
\hline Salt + alcohol in mixture ${ }^{a}$ & Data type ${ }^{b}$ & $\mathrm{~N}$ & $\mathrm{~T}(\mathrm{~K})^{\mathrm{c}}$ & Reference \\
\hline \multirow[t]{2}{*}{$\mathrm{LiCl}+2$-propanol } & VLE & 30 & 348.25 & Sada et al. (1975) \\
\hline & VLE & 37 & $353-357$ & Lin et al. (1993) \\
\hline $\mathrm{LiBr}+$ ethanol & VLE & 19 & 333.15 & Rudakoff et al. (1972) \\
\hline \multirow{2}{*}{$\mathrm{LiBr}+2$-propanol } & VLE & 21 & 348.15 & Sada et al. (1975) \\
\hline & VLE & 37 & $353-357$ & Lin et al. (1993) \\
\hline \multirow[t]{6}{*}{$\mathrm{NaCl}+$ ethanol } & $\gamma_{ \pm}$ & 45 & 298 & Lopes et al. (2001) \\
\hline & $\gamma_{ \pm}$ & 123 & 298 & Esteso et al. (1989) \\
\hline & SLE & 7 & 298 & Pinho and Macedo (1996) \\
\hline & VLE & 14 & $316-332$ & Meyer et al. (1991) \\
\hline & VLE & 16 & $306-313$ & Meyer et al. (1991) \\
\hline & VLE & 13 & $350-361$ & Johnson and Furter (1965) \\
\hline $\mathrm{NaCl}+\mathrm{KCl}+$ ethanol & $\gamma_{ \pm}$ & 31 & 298 & Farelo et al. (2002) \\
\hline \multirow[t]{6}{*}{$\mathrm{NaCl}+$ 1-propanol } & VLE & 43 & $359-363$ & Morrison et al. (1990) \\
\hline & VLE & 10 & $362-375$ & Johnson and Furter (1965) \\
\hline & VLE & 36 & $360-365$ & Lin et al. (1993) \\
\hline & LLE & 11 & 298 & De Santis et al. (1976) \\
\hline & LLE & 8 & 298 & Chou et al. (1998) \\
\hline & LLE & 5 & 298 & Gomis et al. (1994) \\
\hline \multirow[t]{3}{*}{$\mathrm{NaCl}+2$-propanol } & VLE & 56 & $353-362$ & Rajendran et al. (1991) \\
\hline & LLE & 8 & 298 & De Santis et al. (1976) \\
\hline & LLE & 5 & 298 & Gomis et al. (1994) \\
\hline \multirow[t]{3}{*}{$\mathrm{NaCl}+$ 1-butanol } & LLE & 20 & 298 & De Santis et al. (1976) \\
\hline & LLE & 10 & 298 & Li et al. (1995) \\
\hline & LLE & 19 & 313.15 & De Santis et al. (1976) \\
\hline \multirow[t]{2}{*}{$\mathrm{NaCl}+2$-butanol } & LLE & 20 & 298 & De Santis et al. (1976) \\
\hline & LLE & 9 & 298 & Gomis et al. (1996) \\
\hline \multirow[t]{2}{*}{$\mathrm{NaCl}+$ isobutanol } & LLE & 9 & 298 & Gomis et al. (1996) \\
\hline & LLE & 20 & 298 & De Santis et al. (1976) \\
\hline \multirow[t]{2}{*}{$\mathrm{NaCl}+$ tert-butanol } & LLE & 14 & 298 & De Santis et al. (1976) \\
\hline & LLE & 8 & 298 & Gomis et al. (1996) \\
\hline $\mathrm{NaCl}+$ glycerol & $a_{w}$ & 10 & 298 & Marcolli and Krieger (2006) \\
\hline $\mathrm{NaCl}+1,4$-butanediol & $a_{w}$ & 10 & 298 & Marcolli and Krieger (2006) \\
\hline $\mathrm{NaCl}+1,2$-hexanediol & $a_{w}$ & 17 & 298 & Marcolli and Krieger (2006) \\
\hline \multirow[t]{2}{*}{$\mathrm{NaBr}+1$-propanol } & VLE & 30 & $360-364$ & Morrison et al. (1990) \\
\hline & LLE & 11 & 298 & Chou et al. (1998) \\
\hline $\mathrm{NaBr}+2$-propanol & VLE & 52 & $353-358$ & Morrison et al. (1990) \\
\hline \multirow[t]{2}{*}{$\mathrm{NaNO}_{3}+$ ethanol } & VLE & 122 & $351-373$ & Pena et al. (1996) \\
\hline & SLE & 10 & 303.15 & Taylor (1897) \\
\hline $\mathrm{Na}_{2} \mathrm{SO}_{4}+1,2$-ethanediol & SLE & 13 & 308.15 & Vener and Thompson (1949) \\
\hline \multirow[t]{2}{*}{$\mathrm{Na}_{2} \mathrm{SO}_{4}+1$-propanol } & SLE & 5 & 293.15 & Brenner et al. (1992) \\
\hline & LLE & 12 & $297-353$ & Brenner et al. (1992) \\
\hline \multirow[t]{4}{*}{$\mathrm{Na}_{2} \mathrm{SO}_{4}+2$-propanol } & SLE & 10 & 293.15 & Brenner et al. (1992) \\
\hline & SLE & 11 & 298 & Brenner et al. (1992) \\
\hline & LLE & 8 & $302-353$ & Brenner et al. (1992) \\
\hline & LLE & 8 & 308.15 & Lynn et al. (1996) \\
\hline \multirow[t]{3}{*}{$\mathrm{Na}_{2} \mathrm{SO}_{4}+$ tert-butanol } & SLE & 5 & 293.15 & Brenner et al. (1992) \\
\hline & LLE & 12 & 308.15 & Lynn et al. (1996) \\
\hline & LLE & 13 & $296-353$ & Brenner et al. (1992) \\
\hline \multirow[t]{2}{*}{$\mathrm{KCl}+$ ethanol } & VLE & 11 & $350-369$ & Johnson and Furter (1965) \\
\hline & $\gamma_{ \pm}$ & 60 & 298 & Lopes et al. (1999) \\
\hline \multirow[t]{4}{*}{$\mathrm{KCl}+1$-propanol } & VLE & 8 & $361-372$ & Johnson and Furter (1965) \\
\hline & VLE & 40 & $360-363$ & Lin et al. (1993) \\
\hline & LLE & 4 & 298 & Gomis et al. (1996) \\
\hline & LLE & 9 & 298 & Chou et al. (1998) \\
\hline
\end{tabular}


Table 4. Continued.

\begin{tabular}{|c|c|c|c|c|}
\hline Salt + alcohol in mixture ${ }^{a}$ & Data type ${ }^{b}$ & $\mathrm{~N}$ & $\mathrm{~T}(\mathrm{~K})^{\mathrm{c}}$ & Reference \\
\hline \multirow[t]{2}{*}{$\mathrm{KCl}+1$-butanol } & LLE & 8 & 298 & Li et al. (1995) \\
\hline & LLE & 9 & 298 & Gomis et al. (1996) \\
\hline $\mathrm{KCl}+2$-butanol & LLE & 9 & 298 & Gomis et al. (1996) \\
\hline $\mathrm{KCl}+$ isobutanol & LLE & 9 & 298 & Gomis et al. (1996) \\
\hline \multirow[t]{2}{*}{$\mathrm{KBr}+$ ethanol } & VLE & 40 & $354-357$ & Burns and Furter (1975) \\
\hline & SLE & 11 & 303.15 & Taylor (1897) \\
\hline $\mathrm{KBr}+1$-propanol & VLE & 36 & $359-362$ & Morrison et al. (1990) \\
\hline $\mathrm{KBr}+1$-butanol & LLE & 10 & 298 & Li et al. (1995) \\
\hline \multirow[t]{3}{*}{$\mathrm{KNO}_{3}$ + ethanol } & VLE & 13 & $351-369$ & Rieder and Thompson (1950) \\
\hline & VLE & 49 & $351-364$ & Vercher et al. (1996) \\
\hline & SLE & 10 & 303.15 & Bathrick (1896) \\
\hline $\mathrm{K}_{2} \mathrm{SO}_{4}+$ ethanol & SLE & 12 & 298 & Fox and Gauge (1910) \\
\hline $\mathrm{K}_{2} \mathrm{SO}_{4}+1$-propanol & SLE & 16 & 298 & Taboada et al. (2002) \\
\hline $\mathrm{K}_{2} \mathrm{SO}_{4}+2$-propanol & SLE & 26 & 293,303 & Mydlarz et al. (1989) \\
\hline \multirow[t]{3}{*}{$\mathrm{NH}_{4} \mathrm{Cl}+$ ethanol } & VLE & 10 & $350-366$ & Johnson and Furter (1965) \\
\hline & $\gamma_{ \pm}$ & 108 & 298 & Deyhimi et al. (2005) \\
\hline & SLE & 10 & 303.15 & Bathrick (1896) \\
\hline $\mathrm{NH}_{4} \mathrm{Cl}+1$-propanol & VLE & 9 & $362-383$ & Johnson and Furter (1965) \\
\hline $\mathrm{NH}_{4} \mathrm{Br}+$ ethanol & VLE & 43 & $355-358$ & Burns and Furter (1975) \\
\hline $\mathrm{NH}_{4} \mathrm{NO}_{3}+$ glycerol & $a_{w}$ & 9 & 298 & Marcolli and Krieger (2006) \\
\hline $\mathrm{NH}_{4} \mathrm{NO}_{3}+1,4$-butanediol & $a_{w}$ & 12 & 298 & Marcolli and Krieger (2006) \\
\hline $\mathrm{NH}_{4} \mathrm{NO}_{3}+1,2$-hexanediol & $a_{w}$ & 16 & 298 & Marcolli and Krieger (2006) \\
\hline$\left(\mathrm{NH}_{4}\right)_{2} \mathrm{SO}_{4}+$ glycerol & $a_{w}$ & 10 & 298 & Marcolli and Krieger (2006) \\
\hline$\left(\mathrm{NH}_{4}\right)_{2} \mathrm{SO}_{4}+1,2$-butanediol & $a_{w}$ & 8 & 298 & this study (bulk) \\
\hline$\left(\mathrm{NH}_{4}\right)_{2} \mathrm{SO}_{4}+1,4$-butanediol & $a_{w}$ & 12 & 298 & Marcolli and Krieger (2006) \\
\hline$\left(\mathrm{NH}_{4}\right)_{2} \mathrm{SO}_{4}+1,2,4$-butanetriol & $a_{w}$ & 9 & 298 & this study (bulk) \\
\hline$\left(\mathrm{NH}_{4}\right)_{2} \mathrm{SO}_{4}+2,4$-pentanediol & $a_{w}$ & 10 & 298 & this study (bulk) \\
\hline$\left(\mathrm{NH}_{4}\right)_{2} \mathrm{SO}_{4}+1,2$-hexanediol & $a_{w}$ & 12 & 298 & Marcolli and Krieger (2006) \\
\hline$\left(\mathrm{NH}_{4}\right)_{2} \mathrm{SO}_{4}+2,5$-hexanediol & $a_{w}$ & 8 & 298 & this study (bulk) \\
\hline$\left(\mathrm{NH}_{4}\right)_{2} \mathrm{SO}_{4}+1,7$-heptanediol & $a_{w}$ & 9 & 298 & this study (bulk) \\
\hline $\mathrm{CaCl}_{2}+$ ethanol & VLE & 13 & $307-321$ & Meyer et al. (1991) \\
\hline \multirow[t]{3}{*}{$\mathrm{CaCl}_{2}+2$-propanol } & VLE & 21 & 348.25 & Sada et al. (1975) \\
\hline & VLE & 42 & $356-368$ & Rajendran et al. (1991) \\
\hline & VLE & 12 & $354-356$ & Kato et al. (1971) \\
\hline $\mathrm{Ca}\left(\mathrm{NO}_{3}\right)_{2}+$ ethanol & VLE & 42 & $335-356$ & Polka and Gmehling (1994) \\
\hline $\mathrm{Ca}\left(\mathrm{NO}_{3}\right)_{2}+1$-propanol & VLE & 17 & $362-372$ & Miro and Gonzalez (1958) \\
\hline \multirow{2}{*}{$\mathrm{Ca}\left(\mathrm{NO}_{3}\right)_{2}+2$-propanol } & VLE & 23 & $355-361$ & Miro and Gonzalez (1958) \\
\hline & VLE & 41 & $335-354$ & Polka and Gmehling (1994) \\
\hline
\end{tabular}

a The mixtures contain water in addition to the stated components.

$\mathrm{b}$ The data types used to fit the model parameters. VLE data was translated into $\gamma_{o}, \gamma_{w}$ values, where $o$ indicates the organic compound, LLE data into $a_{w}, a_{o}, a_{ \pm}$, and SLE data into $a_{ \pm}$values.

$\mathrm{c}$ The temperature at which data was measured. For isobaric experiments, the approximate temperature range is shown.

comprising several single salt solutions at room temperature, were used to parametrise the inorganic interaction part of the model. In a second step, experimental data of ternary mixtures containing organics (alcohols and polyols), water and inorganic ions were used to fit the specific binary interaction coefficients between ions and organic functional groups. Vapour-liquid equilibria (VLE) data, as well as liquid-liquid equilibria (LLE) compositions, salt solubilities and electromotive force (EMF) measurements were used to establish a broad and reliable database. Subsequently, the two-step procedure to estimate MR parameters is described in more detail. 
Table 5. Fitted binary cation-anion MR interaction parameters.

\begin{tabular}{|c|c|c|c|c|c|c|}
\hline$c$ & $a$ & $\begin{array}{c}b_{c, a}^{(1)} \\
\left(\mathrm{kg} \mathrm{mol}^{-1}\right)\end{array}$ & $\begin{array}{c}b_{c, a}^{(2)} \\
\left(\mathrm{kg} \mathrm{mol}^{-1}\right)\end{array}$ & $\begin{array}{c}b_{c, a}^{(3)} \\
\left(\mathrm{kg}^{1 / 2} \mathrm{~mol}^{-1 / 2}\right)\end{array}$ & $\begin{array}{c}c_{c, a}^{(1)} \\
\left(\mathrm{kg}^{2} \mathrm{~mol}^{-2}\right)\end{array}$ & $\begin{array}{c}c_{c, a}^{(2)} \\
\left(\mathrm{kg}^{1 / 2} \mathrm{~mol}^{-1 / 2}\right)\end{array}$ \\
\hline $\mathrm{H}^{+}$ & $\mathrm{Cl}^{-}$ & 0.182003 & 0.243340 & 0.8 & 0.033319 & 0.504672 \\
\hline $\mathrm{H}^{+}$ & $\mathrm{Br}^{-}$ & 0.120325 & 0.444859 & 0.8 & 0.080767 & 0.596776 \\
\hline $\mathrm{H}^{+}$ & $\mathrm{NO}_{3}^{-}$ & 0.210638 & 0.122694 & 0.8 & -0.101736 & 1.676420 \\
\hline $\mathrm{H}^{+}$ & $\mathrm{SO}_{4}^{2-}$ & 0.097108 & -0.004307 & 1.0 & 0.140598 & 0.632246 \\
\hline $\mathrm{H}^{+}$ & $\mathrm{HSO}_{4}^{-}$ & 0.313812 & -4.895466 & 1.0 & -0.358419 & 0.807667 \\
\hline $\mathrm{Li}^{+}$ & $\mathrm{Cl}^{-}$ & 0.106555 & 0.206370 & 0.8 & 0.053239 & 0.535548 \\
\hline $\mathrm{Li}^{+}$ & $\mathrm{Br}^{-}$ & 0.106384 & 0.316480 & 0.8 & 0.057602 & 0.464658 \\
\hline $\mathrm{Li}^{+}$ & $\mathrm{NO}_{3}^{-}$ & 0.076313 & 0.300550 & 0.8 & 0.046701 & 0.664928 \\
\hline $\mathrm{Li}^{+}$ & $\mathrm{SO}_{4}^{2-}$ & 0.114470 & 0.035401 & 0.8 & -0.263258 & 1.316967 \\
\hline $\mathrm{Na}^{+}$ & $\mathrm{Cl}^{-}$ & 0.053741 & 0.079771 & 0.8 & 0.024553 & 0.562981 \\
\hline $\mathrm{Na}^{+}$ & $\mathrm{Br}^{-}$ & 0.180807 & 0.273114 & 0.8 & -0.506598 & 2.209050 \\
\hline $\mathrm{Na}^{+}$ & $\mathrm{NO}_{3}^{-}$ & 0.001164 & -0.102546 & 0.410453 & 0.002535 & 0.512657 \\
\hline $\mathrm{Na}^{+}$ & $\mathrm{SO}_{4}^{2-}$ & 0.001891 & -0.424184 & 0.8 & -0.223851 & 1.053620 \\
\hline $\mathrm{Na}^{+}$ & $\mathrm{HSO}_{4}^{-}$ & 0.021990 & 0.001863 & 0.8 & 0.019921 & 0.619816 \\
\hline $\mathrm{K}^{+}$ & $\mathrm{Cl}^{-}$ & 0.016561 & -0.002752 & 0.8 & 0.020833 & 0.670530 \\
\hline $\mathrm{K}^{+}$ & $\mathrm{Br}^{-}$ & 0.033688 & 0.060882 & 0.8 & 0.015293 & 0.565063 \\
\hline $\mathrm{K}^{+}$ & $\mathrm{NO}_{3}^{-}$ & 0.000025 & -0.413172 & 0.357227 & -0.000455 & 0.242244 \\
\hline $\mathrm{K}^{+}$ & $\mathrm{SO}_{4}^{2-}$ & 0.004079 & -0.869936 & 0.8 & -0.092240 & 0.918743 \\
\hline $\mathrm{NH}_{4}^{+}$ & $\mathrm{Cl}^{-}$ & 0.001520 & 0.049074 & 0.116801 & 0.011112 & 0.653256 \\
\hline $\mathrm{NH}_{4}^{+}$ & $\mathrm{Br}^{-}$ & 0.002498 & 0.081512 & 0.143621 & 0.013795 & 0.728984 \\
\hline $\mathrm{NH}_{4}^{+}$ & $\mathrm{NO}_{3}^{-}$ & -0.000057 & -0.171746 & 0.260000 & 0.005510 & 0.529762 \\
\hline $\mathrm{NH}_{4}^{+}$ & $\mathrm{SO}_{4}^{2-}$ & 0.000373 & -0.906075 & 0.545109 & -0.000379 & 0.354206 \\
\hline $\mathrm{NH}_{4}^{+}$ & $\mathrm{HSO}_{4}^{-}$ & 0.009054 & 0.214405 & 0.228956 & 0.017298 & 0.820465 \\
\hline $\mathrm{Mg}^{2}+$ & $\mathrm{Cl}^{-}$ & 0.195909 & 0.332387 & 0.8 & 0.072063 & 0.397920 \\
\hline $\mathrm{Mg}^{2+}$ & $\mathrm{NO}_{3}^{-}$ & 0.430671 & 0.767242 & 0.8 & -0.511836 & 1.440940 \\
\hline $\mathrm{Mg}^{2+}$ & $\mathrm{SO}_{4}^{2-}$ & 0.122364 & -3.425876 & 0.8 & -0.738561 & 0.864380 \\
\hline $\mathrm{Ca}^{2+}$ & $\mathrm{Cl}^{-}$ & 0.104920 & 0.866923 & 0.8 & 0.072063 & 0.365747 \\
\hline $\mathrm{Ca}^{2+}$ & $\mathrm{NO}_{3}^{-}$ & 0.163282 & 0.203681 & 0.8 & -0.075452 & 1.210906 \\
\hline
\end{tabular}

Table 6. Additional aqueous electrolyte interaction parameters $R_{c, c^{\prime}}$ and $Q_{c, c^{\prime}, a}$ (set to 0.0 if not specified).

\begin{tabular}{lllll}
\hline$c$ & $c^{\prime}$ & $a$ & $\begin{array}{l}R_{c, c^{\prime}} \\
\left(\mathrm{kg} \mathrm{mol}^{-1}\right)\end{array}$ & $\begin{array}{l}Q_{c, c^{\prime}, a} \\
\left(\mathrm{~kg}^{2} \mathrm{~mol}^{-2}\right)\end{array}$ \\
\hline $\mathrm{NH}_{4}^{+}$ & $\mathrm{H}^{+}$ & & -0.220938 & \\
$\mathrm{NH}_{4}^{+}$ & $\mathrm{H}^{+}$ & $\mathrm{HSO}_{4}^{-}$ & & 0.002414 \\
\hline
\end{tabular}

\subsubsection{Step 1: Aqueous inorganic mixtures}

In a first step, data sets of binary aqueous salt or inorganic acid solutions were used to fit the MR parameters $b_{c, a}^{(1)}, b_{c, a}^{(2)}$, $b_{c, a}^{(3)}, c_{c, a}^{(1)}$, and $c_{c, a}^{(2)}$ simultaneously, whereas $b_{c, a}^{(3)}$ was fixed in most cases to a value of $0.8 \mathrm{~kg}^{1 / 2} \mathrm{~mol}^{-1 / 2}$. These MR parameters were determined using the Downhill-Simplex method (Nelder and Mead, 1965) to minimize the following objec- tive function:

$$
F=\sum_{d} \sum_{p} w_{d, p}\left[Q_{d, p}^{\text {calc }}-Q_{d, p}^{\exp }\right]^{2}
$$

where $p$ refers to a specific point in data set $d$, weighted by factor $w_{d, p}$. The quantity $Q_{d, p}^{\text {calc }}$ represents the calculated and $Q_{d, p}^{\exp }$ the experimentally determined value of $a_{w}$ or $\gamma_{ \pm}$at the same mixture composition. Stoichiometric osmotic coefficients $(\Phi)$ were converted to water activities by:

$$
\ln a_{w}=-\Phi M_{w} \sum_{i} m_{i}
$$

where the sum is over the molality of the ions.

Equilibrium relative humidity $(\mathrm{RH})$ measurements by means of an electrodynamic balance (EDB) can be used to determine water activities of solutions, which are supersaturated with respect to their associated salts. Thus, this method provides data for low $\mathrm{RH}$ conditions (low $a_{w}$ ) and is very helpful for model extrapolations to very high ionic strengths 

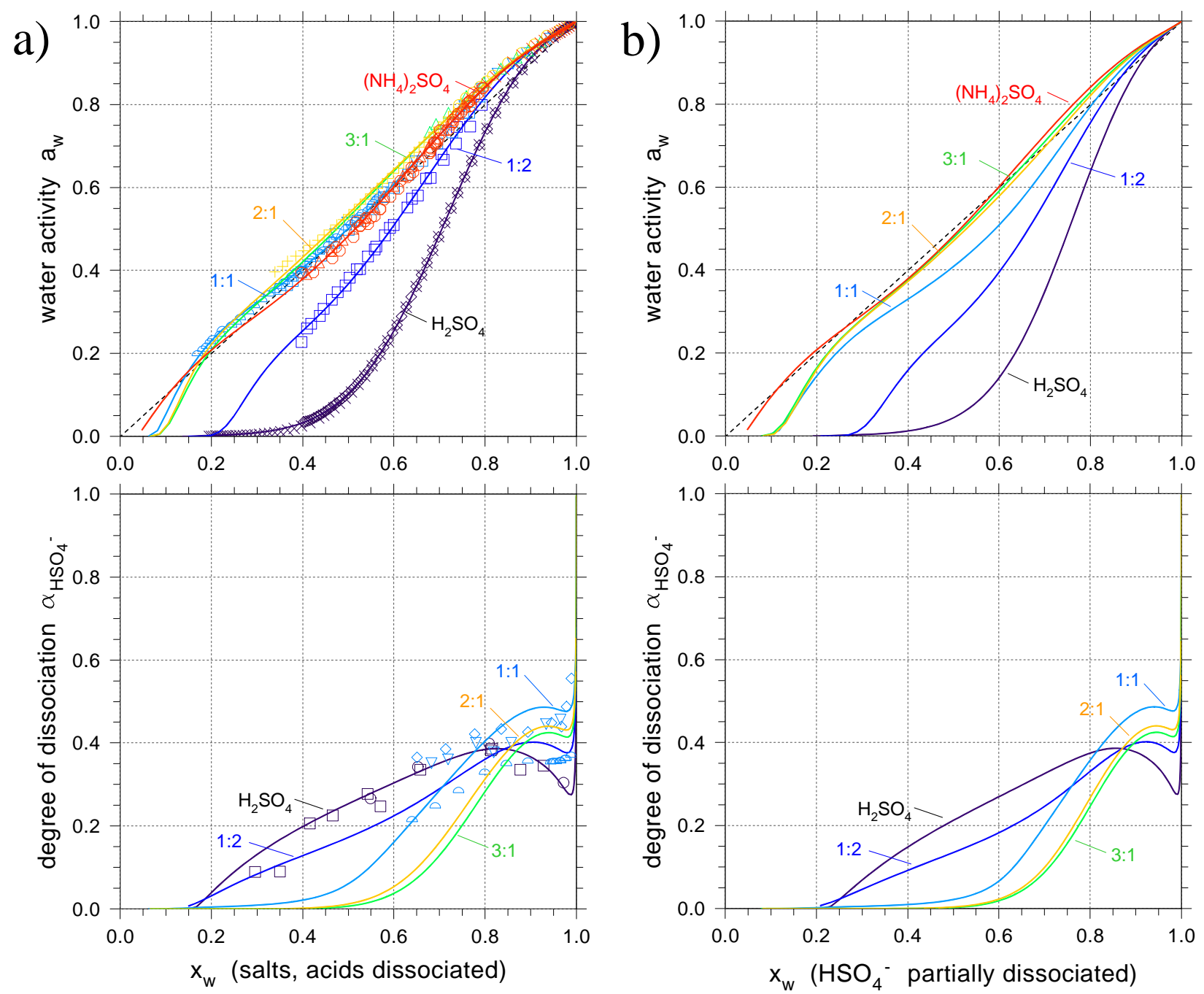

Fig. 5. Experimental (symbols) and modelled (solid lines) water activities of aqueous sulphuric acid, ammonium sulphate, and mixtures of both, indicated by the molar ratio of $\left(\mathrm{NH}_{4}\right)_{2} \mathrm{SO}_{4}: \mathrm{H}_{2} \mathrm{SO}_{4}$. The corresponding degrees of bisulphate dissociation, $\alpha_{\mathrm{HSO}_{4}^{-}}$, are plotted in the lower panels. In (b) $x_{w}$ on the x-axis is taking the modelled partial dissociation of bisulphate into account, while in (a) complete dissociation is assumed. (a) upper panel data from: Robinson and Stokes (2002) (×), Staples (1981) ( $\diamond)$, Kim et al. (1994) ( $\square$ ), Tang and Munkelwitz $(1977)(\nabla)$, Clegg et al. (1995) $(\bigcirc)$, Spann (1984) $(\bigcirc)$, Tang and Munkelwitz (1994) $(\triangle)$, this study (bulk) $(\bigcirc)$, this study $($ EDB) $(+)$. Lower panel data from: Knopf et al. (2003) ( $\bigcirc)$, Myhre et al. (2003) ( $\square$ ), Young et al. (1959) ( $\diamond)$, Dawson et al. (1986) ( $\nabla)$, Irish and Chen (1970) ( $\bigcirc)$.

(often highly supersaturated). To obtain reasonable model results for such extrapolated conditions, we applied one additional constraint, namely that of a monotonically decreasing $a_{w}$ with increasing ionic strength (and decreasing $x_{w}$ ) during the minimisation of $F$. Thermodynamic consistency between different $a_{w}$ and $\gamma_{ \pm}$data points of the same mixture can be checked by applying the Gibbs-Duhem relation. As the AIOMFAC expressions satisfy the Gibbs-Duhem relation, plots of modelled and measured $a_{w}$ and $\gamma_{ \pm}$disclose disagreements between data sets. On the other hand, a consistent data set of $a_{w}$ and $\gamma_{ \pm}$of a mixture can be used to detect model code deficiencies or inconsistencies.
For the aqueous sulphuric acid-ammonium sulphate system, the binary cation-cation interaction parameter $R_{c, c^{\prime}}$ of $\left(\mathrm{NH}_{4}^{+}, \mathrm{H}^{+}\right)$and the ternary cation-cation-anion interaction parameter $Q_{c, c^{\prime}, a}$ of $\left(\mathrm{NH}_{4}^{+}, \mathrm{H}^{+}, \mathrm{HSO}_{4}^{-}\right)$were determined. For all other systems, these interaction types are not necessary to describe the mixtures and therefore set to zero. The data sets used for parameter estimation and model validation of the considered 28 inorganic substances are referenced in Table 3 and results are discussed in graphical form in Sect. 3. 

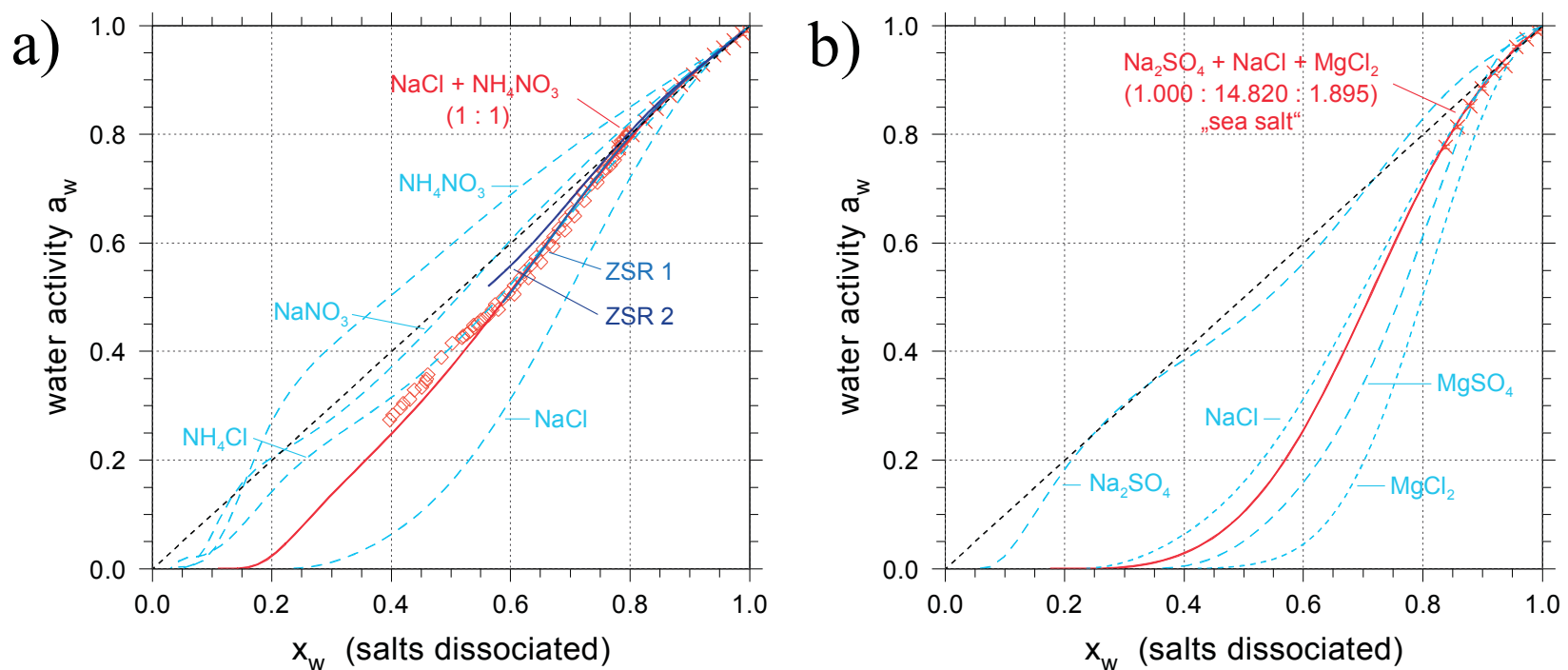

Fig. 6. Predictions and measurements of multi-salt mixtures. (a) salt mixture containing the four ions $\mathrm{Na}^{+}, \mathrm{NH}_{4}^{+}, \mathrm{Cl}^{-}$, and $\mathrm{NO}_{3}^{-} \cdot \mathrm{Symbols}$ : $(\diamond)$ EDB measurements (Ha et al., 2000), $(\times)$ bulk $a_{w}$ measurements (this study). The red line is the AIOMFAC $a_{w}$ prediction, the dashed lines show the model curves of the related binary salts. ZSR predictions are plotted for comparison using the polynomials given in Ha et al. (2000), assuming that the mixture is a solution of $\mathrm{NaCl}+\mathrm{NH}_{4} \mathrm{NO}_{3}$ (ZSR 1) and $\mathrm{NaNO}_{3}+\mathrm{NH}_{4} \mathrm{Cl}$ (ZSR 2), respectively. (b) "sea salt"-like mixture of $\mathrm{Na}^{+}, \mathrm{Mg}^{2+}, \mathrm{SO}_{4}^{2-}$, and $\mathrm{Cl}^{-}$. Experimental $a_{w}$ data $(\times)$ from this study, AIOMFAC prediction (red solid line) and the AIOMFAC binary salts (dashed lines) for comparison.

Table 7. Fitted binary MR parameters of organic-inorganic interactions between the functional main groups $\mathrm{CH}_{\mathrm{n}}$ and $\mathrm{OH}$, and the ions.

\begin{tabular}{llrr}
\hline$k$ & $i$ & \multicolumn{1}{c}{$\begin{array}{c}b_{k, i}^{(1)} \\
\left(\mathrm{kg} \mathrm{mol}^{-1}\right)\end{array}$} & \multicolumn{1}{c}{$\begin{array}{c}b_{k, i}^{(2)} \\
\left(\mathrm{kg} \mathrm{mol}^{-1}\right)\end{array}$} \\
\hline $\mathrm{CH}_{\mathrm{n}}$ & $\mathrm{Li}^{+}$ & 0.242840 & 0.004770 \\
$\mathrm{OH}$ & $\mathrm{Li}^{+}$ & -0.029646 & -1.033024 \\
$\mathrm{CH}_{\mathrm{n}}$ & $\mathrm{Na}^{+}$ & 0.124972 & -0.031880 \\
$\mathrm{OH}$ & $\mathrm{Na}^{+}$ & 0.080254 & 0.002201 \\
$\mathrm{CH}$ & $\mathrm{K}^{+}$ & 0.121449 & 0.015499 \\
$\mathrm{OH}$ & $\mathrm{K}^{+}$ & 0.065219 & -0.170779 \\
$\mathrm{CH}$ & $\mathrm{NH}_{4}^{+}$ & 0.103096 & -0.006344 \\
$\mathrm{OH}$ & $\mathrm{NH}_{4}^{+}$ & 0.039373 & 0.001083 \\
$\mathrm{CH}$ & $\mathrm{Ca}^{2+}$ & 0.000019 & -0.060807 \\
$\mathrm{OH}$ & $\mathrm{Ca}^{2+}$ & 0.839628 & -0.765776 \\
$\mathrm{CH}$ & $\mathrm{Cl}^{-}$ & 0.014974 & 0.142574 \\
$\mathrm{OH}$ & $\mathrm{Cl}^{-}$ & -0.042460 & -0.128063 \\
$\mathrm{CH}$ & $\mathrm{Br}^{-}$ & 0.000042 & -0.025473 \\
$\mathrm{OH}$ & $\mathrm{Br}^{-}$ & -0.007153 & 0.483038 \\
$\mathrm{CH}$ & $\mathrm{NO}_{3}^{-}$ & 0.018368 & 0.669086 \\
$\mathrm{OH}$ & $\mathrm{NO}_{3}^{-}$ & -0.128216 & -0.962408 \\
$\mathrm{CH}$ & $\mathrm{SO}_{4}^{2-}$ & 0.101044 & -0.070253 \\
$\mathrm{OH}$ & $\mathrm{SO}_{4}^{2-}$ & -0.164709 & 0.574638 \\
\hline & & &
\end{tabular}

\subsubsection{Step 2: Organic-inorganic mixtures}

Given the binary cation-anion MR interactions determined in step 1 and the LR and SR contributions, the organicinorganic $\mathrm{MR}$ interactions were assumed to be responsible for model deviations from measurements for organicinorganic mixtures. Therefore, in a second step, the MR interaction parameters $b_{k, i}^{(1)}$ and $b_{k, i}^{(2)}$ between solvent main groups $k$ and ions $i$ were fitted using data sets of ternary aqueous organic-inorganic mixtures. In contrast to step 1, where MR parameters of every binary mixture type could be fitted independently, the organic-inorganic interaction parameters are ion specific. Consequently, all ternary mixture data were subjected to a simultaneous fit of $b_{k, i}^{(1)}$ and $b_{k, i}^{(2)}$ to determine ion specific activity coefficients from mixtures containing salts. Although computationally more demanding, the benefit of this model approach is the potential to predict mixtures containing ions and a wide range of organic compounds consisting of the same main groups as the ones used to estimate the parameters. This is one of the fundamental advantages of a group contribution method over substance specific methods. It also shows the need for a wide variety of data involving the same ions and functional groups in different combinations, to assign unambiguously non-idealities of a system to specific organic-inorganic interactions.

In this step, the following case dependent objective function was minimized: 

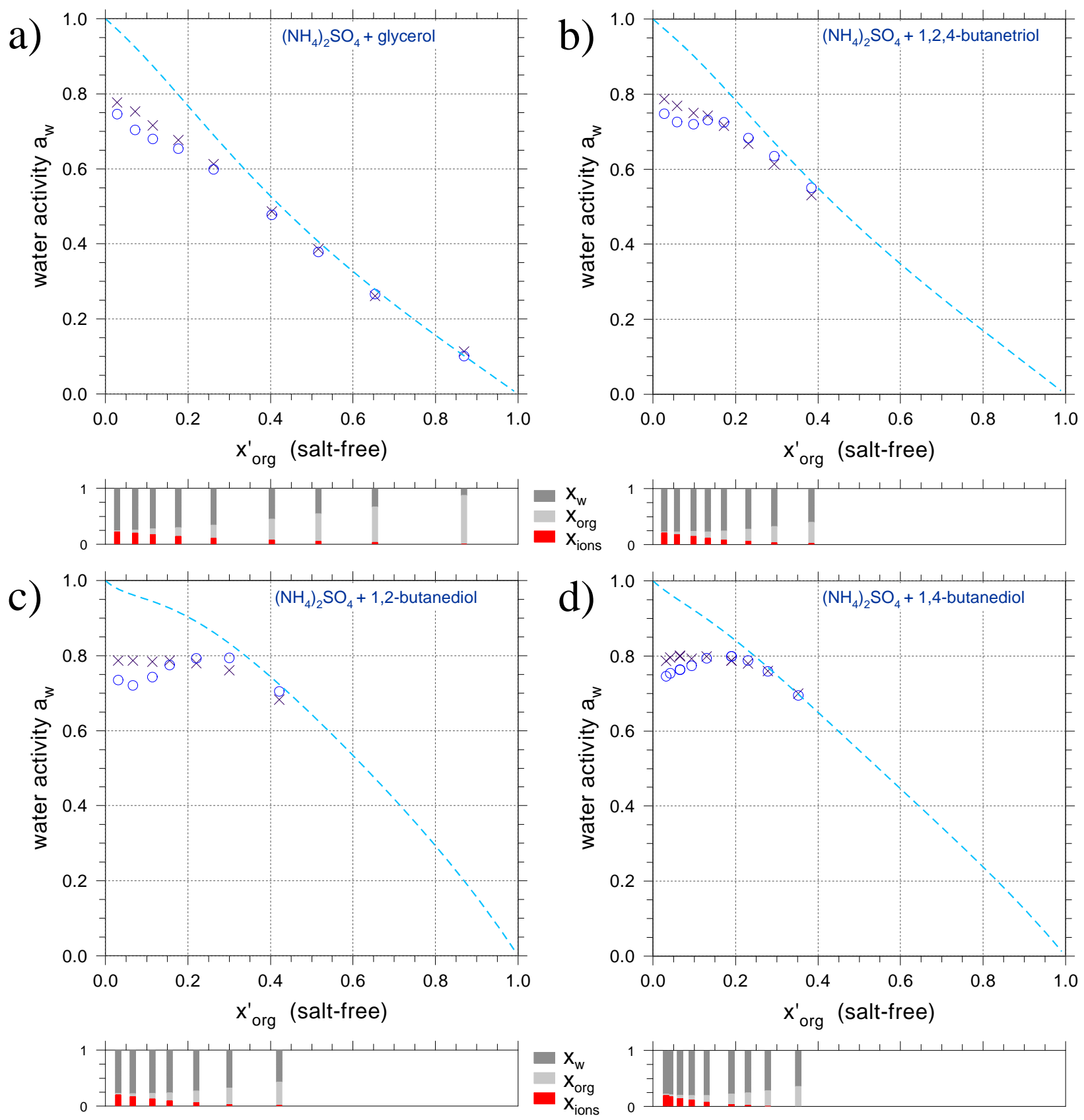

Fig. 7. Water activities of ternary polyol-water-ammonium sulphate mixtures at $298 \mathrm{~K} .(\times)$ are experimental $a_{w}$ data, (O) AIOMFAC results. The dashed line is the AIOMFAC $a_{w}$ of the salt-free solvent mixture. The ternary mixture compositions with respect to completely dissociated $\left(\mathrm{NH}_{4}\right)_{2} \mathrm{SO}_{4}$, are shown in the bar graphs (ions summed up). Polyols: (a) glycerol, (b) 1,2,4-butanetriol, (c) 1,2-butanediol, (d) 1,4-butanediol. Data from: Marcolli and Krieger (2006) (a) and (d), (this study) (b) and (c). 

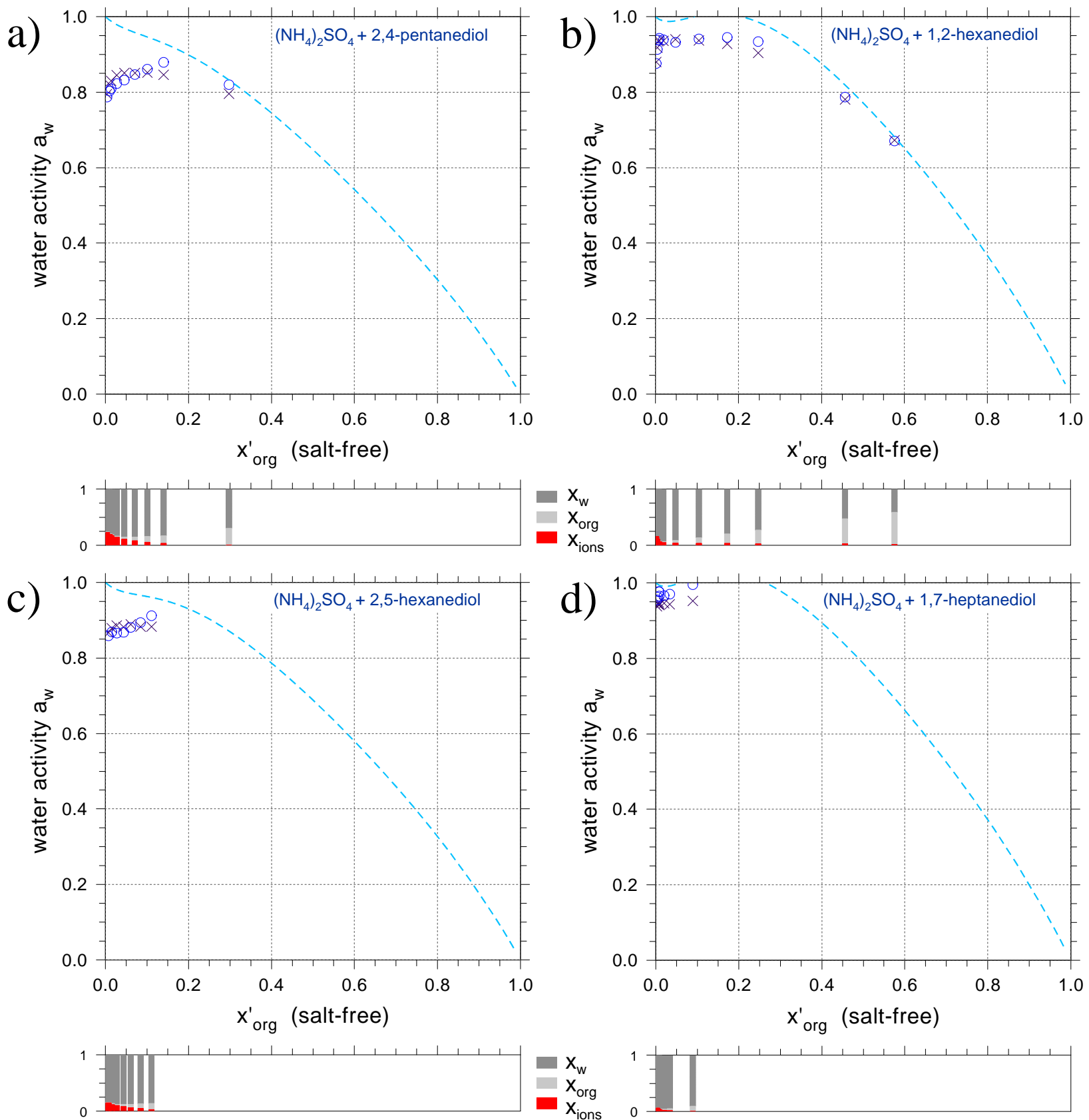

Fig. 8. Water activities of ternary polyol-water-ammonium sulphate mixtures at $298 \mathrm{~K} .(\times)$ are experimental $a_{w}$ data, (O) AIOMFAC results. The dashed line is the AIOMFAC $a_{w}$ of the salt-free solvent mixture. Polyols: (a) 2,4-pentanediol, (b) 1,2-hexanediol, (c) 2,5-hexanediol, (d) 1,7-heptanediol. Data from: Marcolli and Krieger (2006) (b), (this study) (a), (c), and (d).

$F=\sum_{d} \sum_{p} \begin{cases}w_{d, p}\left[\frac{Q_{d, p}^{\text {calc }}-Q_{d, p}^{\text {exp }}}{Q_{d, p}^{\text {exp }}}\right]^{2} & \text { if: } a_{w}, \text { VLE, } \\ w_{d, p}\left[\frac{\left(a_{j}^{\alpha}\right)_{d, p}-\left(a_{j}^{\beta}\right)_{d, p}}{0.5\left(\left(a_{j}^{\alpha}\right)_{d, p}+\left(a_{j}^{\beta}\right)_{d, p}\right)}\right]^{2} \text { or } \gamma_{ \pm} \text {data, LLE data, } \\ w_{d, p}\left[\left(a_{ \pm}^{\text {calc }}\right)_{d, p}-\left(a_{ \pm}^{\text {ref }}\right)_{d, p}\right]^{2} & \text { if: SLE data, }\end{cases}$

where $a_{j}^{\alpha}, a_{j}^{\beta}$ denote the calculated activities of component $j$ in the two liquid phases $\alpha$ and $\beta . a_{ \pm}^{\text {ref }}$ refers to the calculated mean molal ionic activity of the corresponding salt in a binary saturated aqueous salt solution set as the reference value for comparisons with ternary saturated solutions of the same salt.

VLE data of gas- and liquid-mixture compositions were transformed into activity coefficients of water and the related alcohol for the model fit. Non-ideality of the gas phase was 

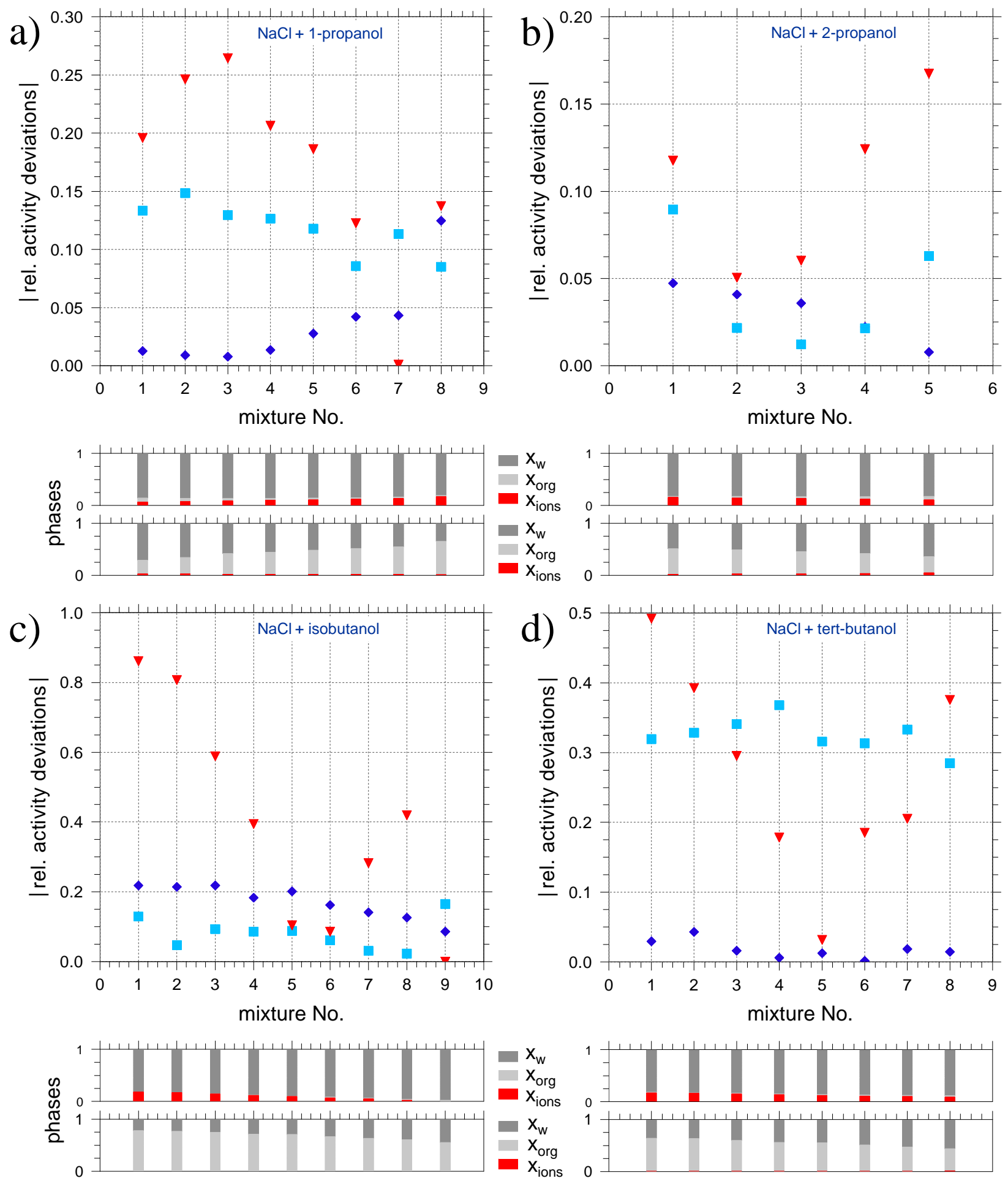

Fig. 9. Plots of the relative activity deviations between the two coexisting phases of alcohol-water-NaCl mixtures in LLE at $298 \mathrm{~K}$. Plotted are the modelled relative deviations between the activities of the components in the two coexisting liquid phases. Symbols $(\square)$ alcohol, $(\diamond)$ water, and $(\nabla)$ mean ionic activities. The alcohols are: (a) 1-propanol, (b) 2-propanol, (c) isobutanol, (d) tert-butanol. The bar graphs show the corresponding phase compositions measured by: Chou et al. (1998) (a), Gomis et al. (1994) (b), Gomis et al. (1996) (c) and (d). 

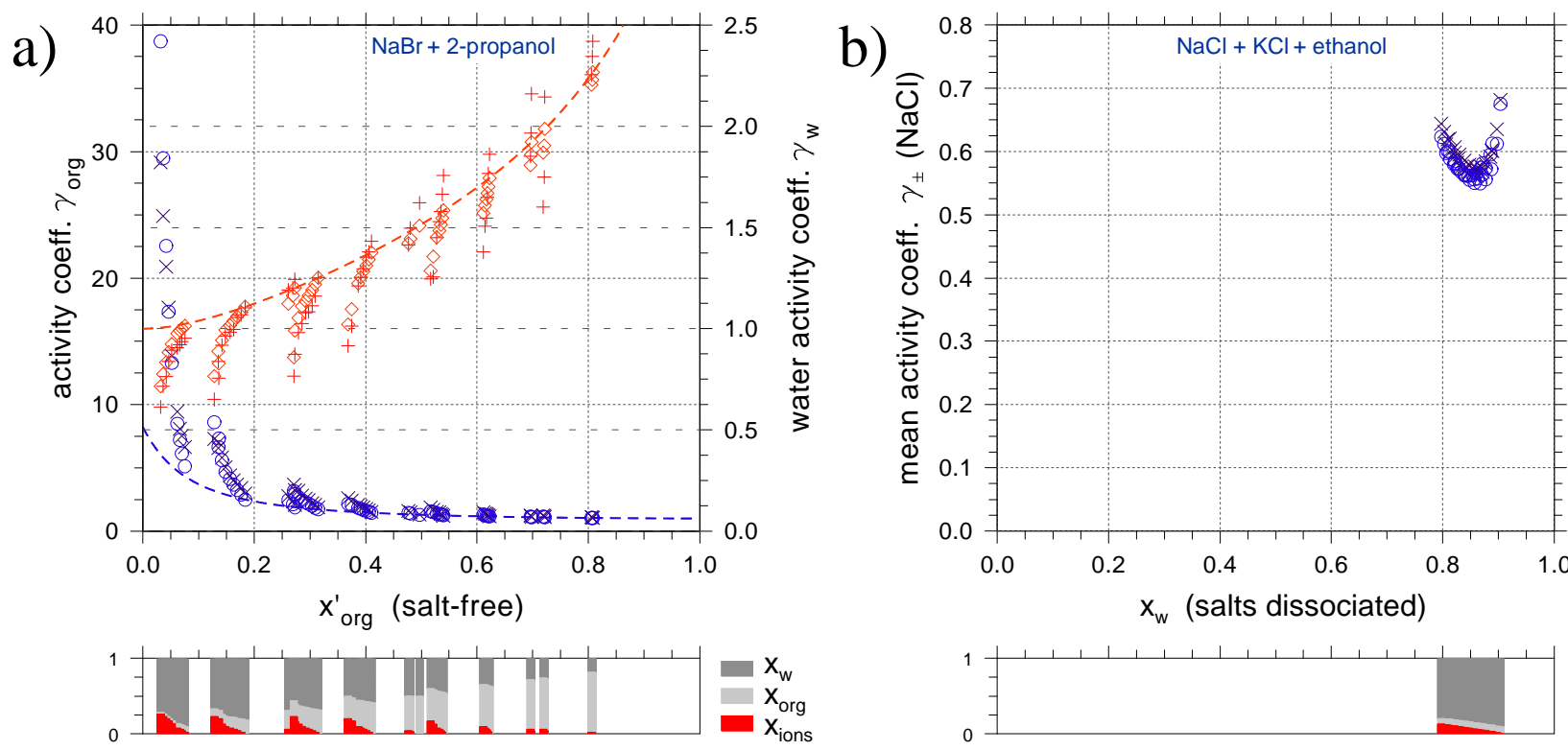

Fig. 10. (a) activity coefficients of isobaric 2-propanol-water-NaBr mixtures in VLE at 353-358 K. Blue symbols: the measured ( $\times$ ) and calculated $(\bigcirc)$ activity coefficients of 2-propanol. In red: measured $(+)$ and calculated $(\diamond)$ water activity coefficients. The dashed curves are the model results of the salt-free solvent mixtures. (b) Mean molal activity coefficients of $\mathrm{NaCl}$ in quaternary ethanol-water-NaCl-KCl mixtures from EMF measurements at $298 \mathrm{~K}$. Symbols $(\bigcirc)$ and $(\times)$ are AIOMFAC predictions and experimental data respectively. Data from: Morrison et al. (1990) (a), Farelo et al. (2002) (b).

thereby taken into account by applying a fugacity correction (Tsonopoulos, 1974; Zemp and Francesconi, 1992). In LLE, the components exhibit the same activities in coexisting liquid phases. This data type was implemented in the model fit by minimising the relative differences between the activities of the components in the two phases. SLE data was used in a similar way by minimising the difference between mean molal ionic activities $\left(a_{ \pm}\right)$of the same salt in saturated solutions with different solvent compositions. To provide data of aqueous-polyol-salt solutions, our own measurements of water activities at room temperature were performed using an AquaLab water activity meter (Model 3TE, Decagon Devices, USA) with the method described in Marcolli and Peter (2005) and Marcolli and Krieger (2006). A description of the experimental procedure and the measured water activities are given in Appendix A. EMF data from the literature are commonly listed in terms of molal mean activity coefficients, normalised to the reference state of infinite dilution in the solvent mixture. Because the raw data of EMF measurements was often not obtainable, the listed mean molal activity data was only used for model validation, to check whether the model can reproduce the activity coefficients when the reference state is converted to the mixed solvent case. Data at other temperatures than room temperature, were used with a low weighting factor or just for comparison. Table 4 lists the data sources of ternary alcohol/polyol+water+salt mixtures used for parameter determination and model validation.
Figure 2 shows the binary species combinations, for which the specific MR parameters have been determined so far. Some of the ionic species are of minor importance with respect to their occurrence in atmospheric aerosols, but are helpful to determine unambiguously the individual ionic interaction contributions from salt solution data. Mean interactions between ions and water are indirectly represented by the parameters of the cation-anion interaction pairs, since the aqueous solution is defined as the reference system as in conventional Pitzer models (Pitzer, 1991). Activities predicted by the AIOMFAC model show significantly larger deviations from measurements for salt-free water-alcohol mixtures than for aqueous electrolyte solutions. This is a consequence and drawback of the group-contribution approach of UNIFAC that has to be accepted, if a model should be applicable to a large variety of organic substances.

Since the organic-ion interaction parameters should not compensate for deviations related to inaccuracies in the modelled and measured organic-organic SR (UNIFAC) interactions, the weighting factor for a specific data point was computed as: 

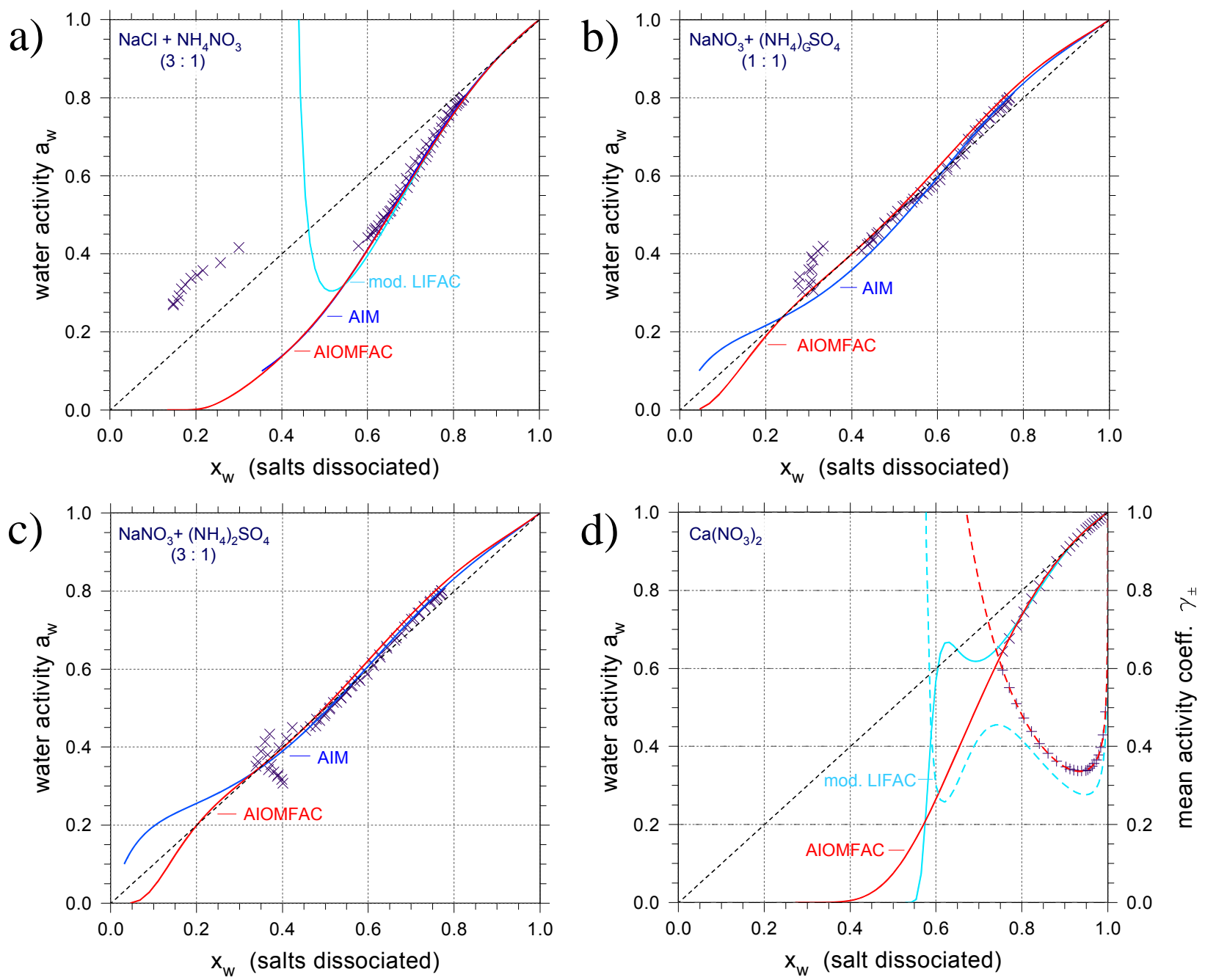

Fig. 11. Measurements of aqueous electrolyte solutions (symbols $\times,+$ ) and corresponding calculations of the models AIM III (Clegg et al., 1998b), mod. LIFAC (Kiepe et al., 2006), and AIOMFAC at $298 \mathrm{~K}$. Salts: (a) $\mathrm{NaCl}+\mathrm{NH}_{4} \mathrm{NO}_{3}$ at a molar salt mixing ratio of (3:1), (b) and (c) $\mathrm{NaNO}_{3}+\left(\mathrm{NH}_{4}\right)_{2} \mathrm{SO}_{4}(1: 1)$ and (3:1), respectively, and (d) $\mathrm{Ca}\left(\mathrm{NO}_{3}\right)_{2}$. Since $\left(\mathrm{NH}_{4}\right)_{2} \mathrm{SO}_{4}$ is not parametrised in mod. LIFAC, (b) and (c) show only AIM and AIOMFAC water activities. $\mathrm{Ca}\left(\mathrm{NO}_{3}\right)_{2}$ is not available in the AIM, therefore (d) shows mod. LIFAC and AIOMFAC water activities (solid curves) and mean molal activity coefficients (dashed curves). Data from: Ha et al. (2000) (a), (b), and (c), Robinson and Stokes (2002) (d).

$w_{d, p}=w_{d, p}^{i}\left[x_{o}(d, p) \sum_{i} x_{i}(d, p)\right]^{1 / 3}$

where $w_{d, p}^{i}$ is the initial weighting of the data set, $x_{o}$ the mole fraction of the organic compound, and the sum is over the ions. This empirical formula ensures that those data points are weighted high, which contain large contributions of both, salt and organics. Together with a wide data base, this approach helps to avoid fitting model parameters to other effects than the desired interactions.

\section{Results and discussion}

\subsection{Binary aqueous electrolyte solutions}

The AIOMFAC model is aimed at predicting activities in organic-inorganic multicomponent mixtures up to high ionic strength, since the aqueous phase of an aerosol can contain high amounts of inorganic ions. In addition, a well performing inorganic model part is desirable to avoid problems when fitting organic-inorganic interaction parameters. The LIFAC model is only parametrised up to salt saturation and fails to predict activities of supersaturated solutions. For these reasons we redetermined the MR interaction parameters of AIOMFAC for binary aqueous electrolyte solutions 
a)
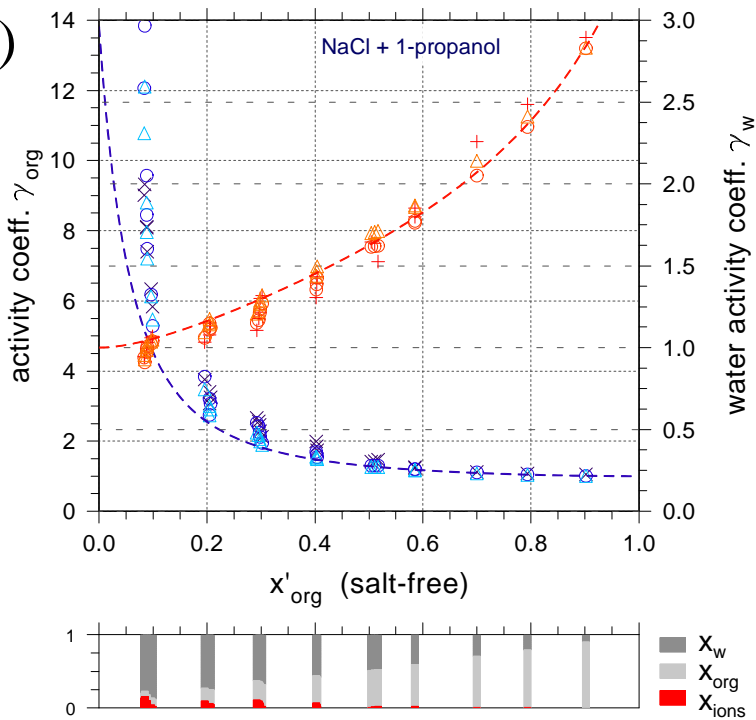

c)

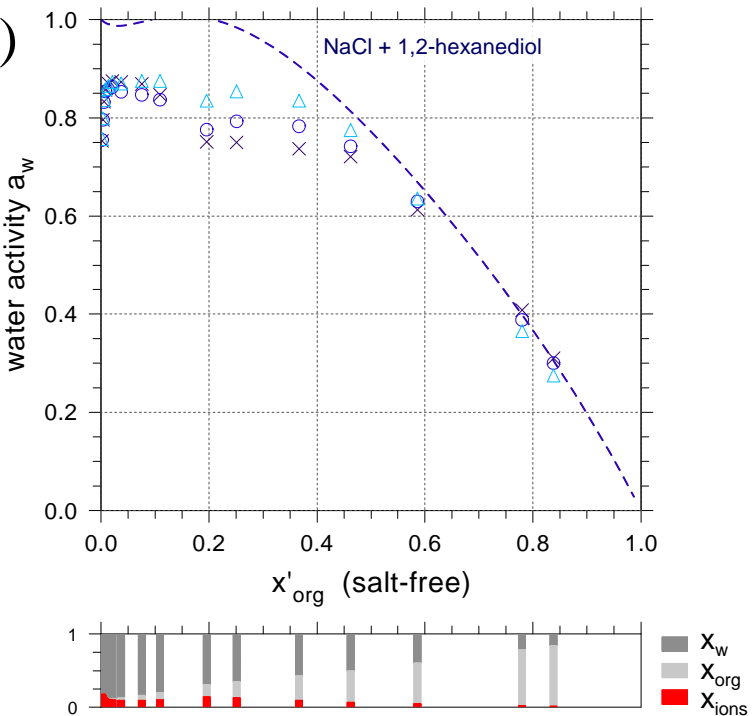

b)
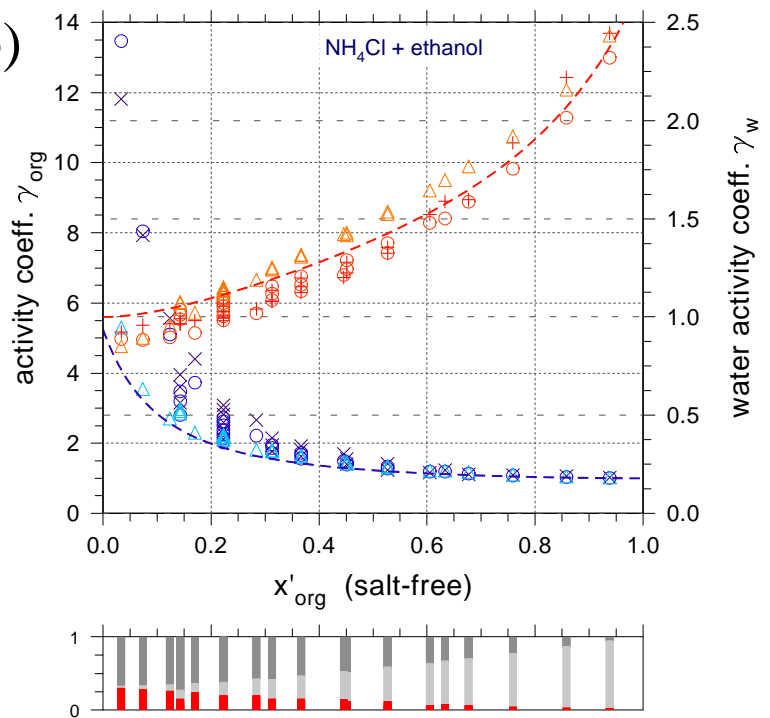

d)

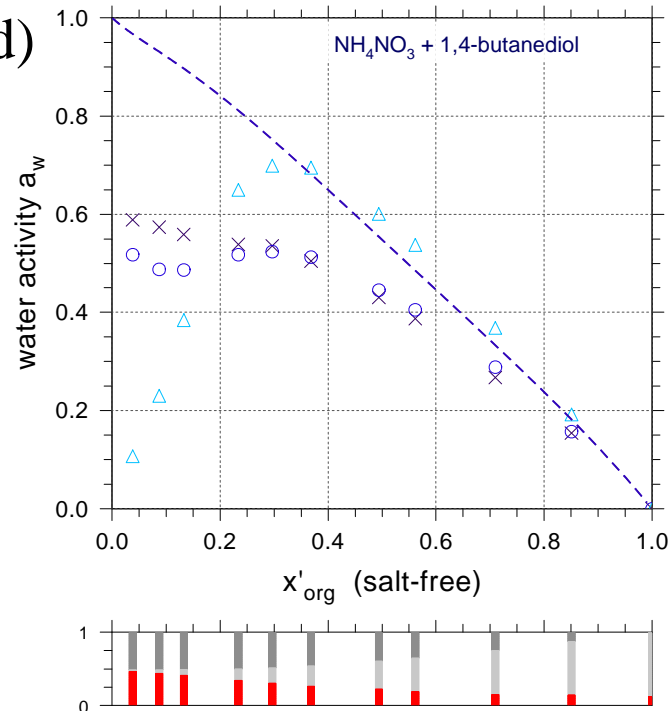

Fig. 12. Comparison of mod. LIFAC with AIOMFAC calculations for ternary alcohol/polyol-water-salt mixtures. Upper panels show alcohol and water activity coefficients from isobaric $\mathrm{VLE}$ data of (a) 1-propanol-water- $\mathrm{NaCl}$ mixtures at $360-365 \mathrm{~K}$ and (b) ethanol-water- $\mathrm{NH} \mathrm{H}_{4} \mathrm{Cl}$ mixtures at 350-366 K. Symbols: measurements $(\times,+)$ and calculations of mod. LIFAC $(\triangle)$ and AIOMFAC $(\bigcirc)$; in blue for the activity coefficients of the alcohols, in red for the activity coefficients of water. The dashed curves are the AIOMFAC results of the salt-free solvent mixtures. Panels (c) and (d) show measured and calculated water activities of 1,2-hexanediol-water-NaCl and 1,4-butanediol-water- $\mathrm{NH}_{4} \mathrm{NO}_{3}$ mixtures, respectively, at 298 K. Symbols as in the upper panels. Data from: Lin et al. (1993) (a), Johnson and Furter (1965) (b), Marcolli and Krieger (2006) (c) and (d).

with Eq. (38). The parameters for aqueous solutions of the 28 investigated inorganic electrolyte species are listed in Table 5 .

Panels (a) and (b) of Fig. 3 show the AIOMFAC results for water activities and corresponding mean ionic activity coefficients of salts/acids containing the anions $\mathrm{Cl}^{-}$and $\mathrm{Br}^{-}$, respectively. Figure 4 gives the analogous presentation for the nitrates and sulphates. The abscissa is mole fraction of the solvent, i.e. water, with respect to completely dissociated salts/acids into cations and anions. Model comparison with the experiments shows in general excellent agreement to very high ionic strengths and low water activities (low RH). Bulk measurements agree very well with each other, whereas measurements in the supersaturated regions show slightly higher variance, likely due to the less accurate experimental methods. The Gibbs-Duhem relation between water activities and the mean activity coefficients is fulfilled for most data sets, since $a_{w}$ and $\gamma_{ \pm}$can be fitted accurately using the same model parametrisation as can be seen from the upper and lower figure panels. One exception is $\mathrm{NaNO}_{3}$ which shows 
a)
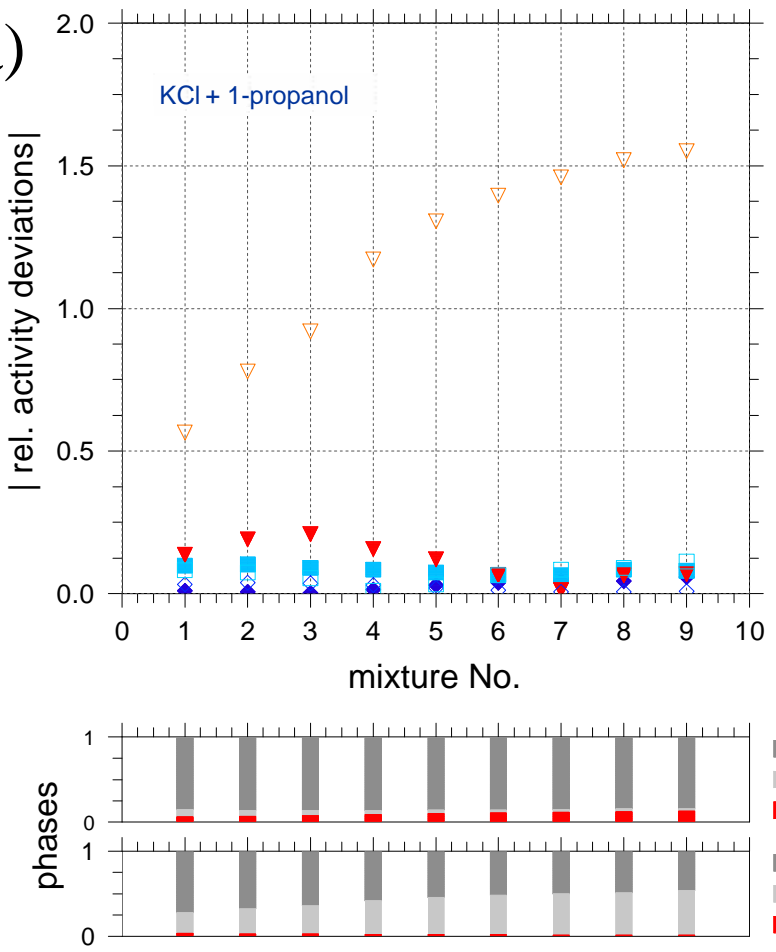

c)

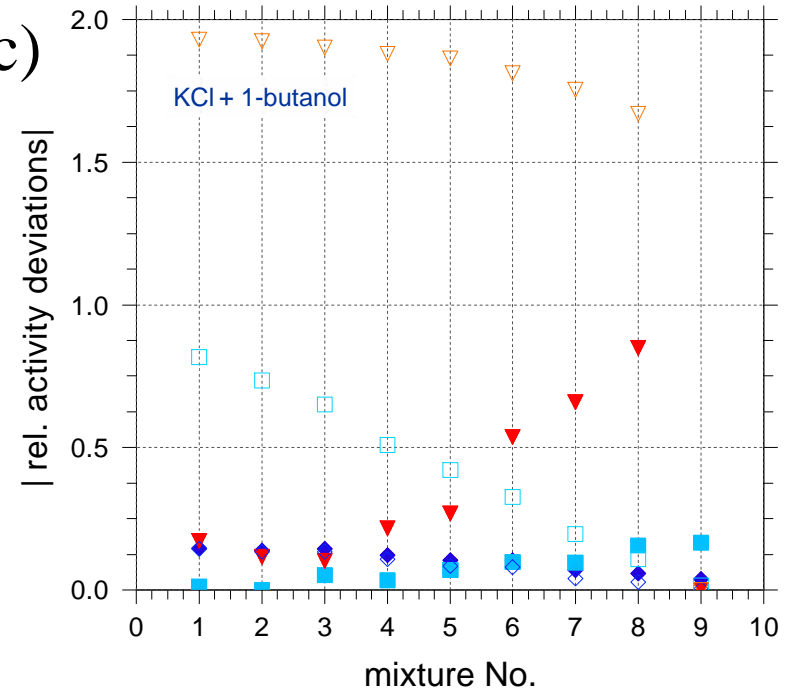

b)

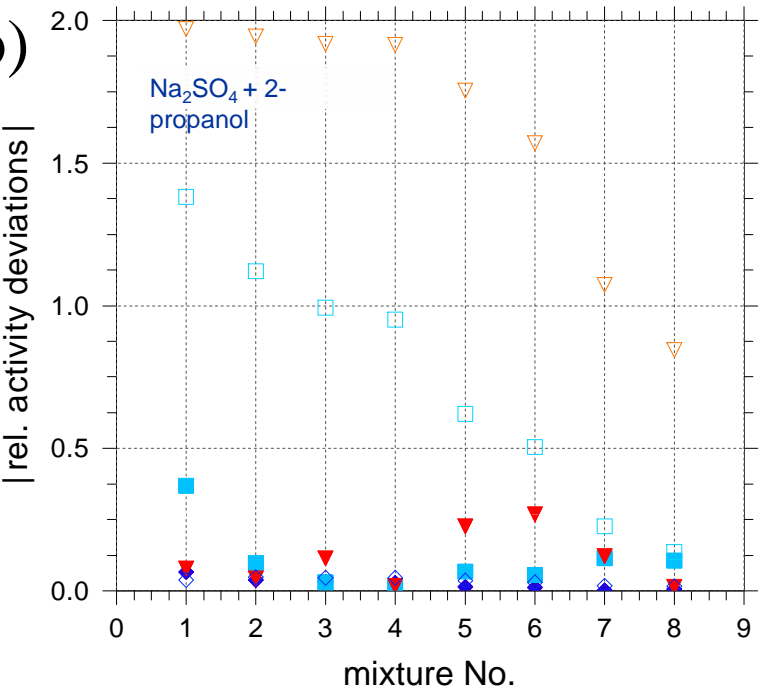

$x_{\mathrm{w}}$
$x_{\text {org }}$
$x_{\text {ions }}$
$x_{\mathrm{w}}$
$x_{\text {org }}$
$x_{\text {ions }}$

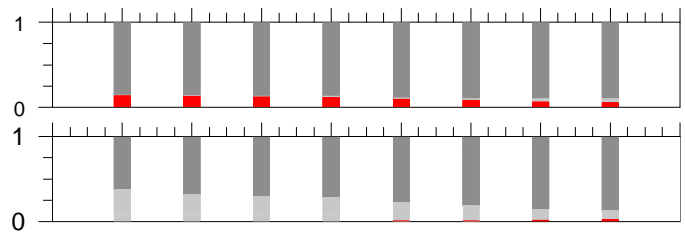

d)

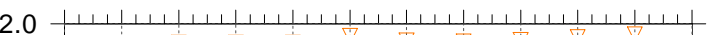

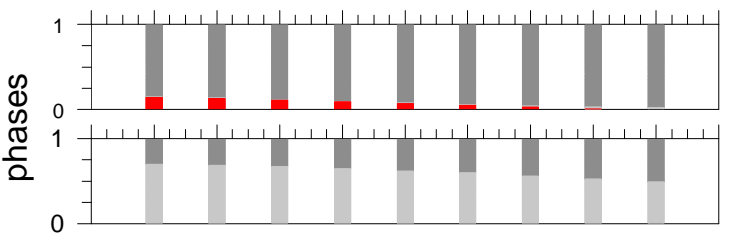
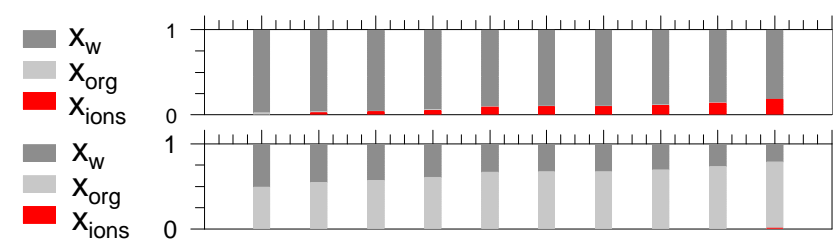

Fig. 13. Comparison of mod. LIFAC and AIOMFAC calculations for different alcohol-water-salt mixtures in LLE at 298 K. Plotted are the modelled relative deviations between the activities of the components in the two coexisting liquid phases. Symbols $(\square)$ alcohol, $(\diamond)$ water, and $(\nabla)$ mean ionic activities. Solid symbols show AIOMFAC, open symbols mod. LIFAC results. Mixtures: (a) 1-propanol-water-KCl, (b) 2-propanol-water- $\mathrm{Na}_{2} \mathrm{SO}_{4}$, (c) 1-butanol-water-KCl, (d) 1-butanol-water-NaCl. The bar graphs show the corresponding phase compositions measured by: Chou et al. (1998) (a), Lynn et al. (1996) (b), Gomis et al. (1996) (c), and Li et al. (1995) (d). 
incompatible water and mean ionic activities. Here it was decided to follow the water activity data at high concentrations. Deviations from ideal mixing behaviour are higher for the mixtures containing cations with higher surface charge density (e.g. $\mathrm{Mg}^{2+}, \mathrm{Li}^{+}, \mathrm{H}^{+}$) than for mixtures of cations with chaotropic character (e.g. $\mathrm{NH}_{4}^{+}$).

Model predictions beyond the concentration range of EDB data are not expected to be important for single-salt aerosol particles since they would effloresce. However, for multi-salt particles, this area maybe of some importance even for subsaturated salt mixtures because the model expressions are based on the ionic strength of the solution. Ternary and higher order mixtures are therefore used to validate the AIOMFAC parametrisation obtained from binary solution data. For example, the ionic strength of aqueous $\mathrm{MgCl}_{2}$ described by EDB measurements ranges up to $I=18.4 \mathrm{~mol} \mathrm{~kg}^{-1}$ while EDB measurements of aqueous solutions containing $\mathrm{MgCl}_{2}+\mathrm{Mg}\left(\mathrm{NO}_{3}\right)_{2}+\mathrm{MgSO}_{4}$ with a $1: 1: 5$ molar ratio range up to $I=47.8 \mathrm{~mol} \mathrm{~kg}^{-1}$. Thus, AIOMFAC needs to describe (extrapolate) aqueous $\mathrm{MgCl}_{2}$ solutions beyond measured binary solutions data. In the case of aqueous $\mathrm{MgCl}_{2}$, AIOMFAC describes the solution up to $I=165.0 \mathrm{~mol} \mathrm{~kg}^{-1}$. This demonstrates that AIOMFAC can be used up to very high ionic strength and that a thermodynamically reasonable prediction is made, whereas classical extended Debye-Hückel approaches as used in some extended UNIFAC models are applicable only in a range of $I<0.1 \mathrm{~mol} \mathrm{~kg}^{-1}$ (Robinson and Stokes, 2002). The concentration range of application of AIOMFAC is comparable to the one of the AIM III model by Clegg et al. (1998b), one of the most commonly used models to calculate activities of aqueous electrolyte solutions at room temperature.

\subsection{Activities in multicomponent electrolyte solutions}

\subsubsection{Sulphuric acid-ammonium sulphate mixtures}

Sulphuric acid and ammonium sulphate are two of the most common solutes in inorganic aerosols. The dissociation of aqueous sulphuric acid $\left(\mathrm{H}_{2} \mathrm{SO}_{4}\right)$ is a two-step process:

$$
\begin{aligned}
& \mathrm{H}_{2} \mathrm{SO}_{4} \rightleftharpoons \mathrm{H}^{+}+\mathrm{HSO}_{4}^{-}, \\
& \mathrm{HSO}_{4}^{-} \rightleftharpoons \mathrm{H}^{+}+\mathrm{SO}_{4}^{2-} .
\end{aligned}
$$

The first dissociation step Reaction (R1) has been shown to be essentially complete at atmospheric conditions (Young et al., 1959; Seinfeld and Pandis, 1998). On the other hand, the dissociation Reaction (R2) of the bisulphate ion $\left(\mathrm{HSO}_{4}^{-}\right)$ is strongly temperature dependent and can only be assumed to be complete for very low sulphuric acid concentrations (Young et al., 1959; Dawson et al., 1986; Knopf et al., 2003). In AIOMFAC, the first dissociation step is considered to be complete, the second step is explicitly taken into consideration. This is done by computation of the equilibrium dissociation constant $K_{\mathrm{II}}(T)$ with Eq. (42) and iterative adjustment of the ionic molalities until the literature value is met:

$$
\begin{aligned}
K_{\mathrm{II}}(T) & =\frac{a_{\mathrm{H}^{+}}(T) a_{\mathrm{SO}_{4}^{2-}}(T)}{a_{\mathrm{HSO}_{4}^{-}}(T)} \\
& =\frac{m_{\mathrm{H}^{+}} m_{\mathrm{SO}_{4}^{2-}} \gamma_{\mathrm{H}^{+}}(T) \gamma_{\mathrm{SO}_{4}^{2-}}(T)}{m_{\mathrm{HSO}_{4}^{-}} \gamma_{\mathrm{HSO}_{4}^{-}}(T)} .
\end{aligned}
$$

At $298 \mathrm{~K}, K_{\mathrm{II}}=0.01031 \mathrm{~kg} \mathrm{~mol}^{-1}$ (Knopf et al., 2003). The degree of dissociation, $\alpha_{\mathrm{HSO}_{4}^{-}}$, of the $\mathrm{HSO}_{4}^{-}$ion is in general calculated from the molal ratio of actual bisulphate to potential bisulphate amounts:

$\alpha_{\mathrm{HSO}_{4}^{-}}=1-\frac{m_{\mathrm{HSO}_{4}^{-}}}{m_{\mathrm{HSO}_{4}^{-}}^{\max },}$

where superscript max indicates the maximum possible molality of bisulphate, when the equilibrium of Reaction (R2) would be completely on the $\mathrm{HSO}_{4}^{-}$side and available $\mathrm{SO}_{4}^{2-}$ and $\mathrm{H}^{+}$(from other sources) would associate to bisulphate:

$m_{\mathrm{HSO}_{4}^{-}}^{\max }=m_{\mathrm{HSO}_{4}^{-}}+\min \left[m_{\mathrm{SO}_{4}^{2-}}, m_{\mathrm{H}^{+}}\right]$.

For pure aqueous sulphuric acid, $m_{\mathrm{HSO}_{4}^{-}}^{\max }$ equals the initial bisulphate molality before dissociation, but in mixtures including other sources for sulphate ions the additional contributions have to be considered. Mixtures of $\left(\mathrm{NH}_{4}\right)_{2} \mathrm{SO}_{4}+\mathrm{H}_{2} \mathrm{SO}_{4}+\mathrm{H}_{2} \mathrm{O}$ contain the following ions: $\mathrm{NH}_{4}^{+}$, $\mathrm{SO}_{4}^{2-}, \mathrm{HSO}_{4}^{-}, \mathrm{H}^{+}$(and probably also ions like $\mathrm{NH}_{4} \mathrm{SO}_{4}^{-}$). Thus, they include at least 4 binary cation-anion interactions, for which $12 \mathrm{MR}$ parameters have to be fitted simultaneously. At the same time, the equilibrium condition given by Eq. (42) has to be fulfilled. A good description of activities in aqueous sulphuric acid-ammonium sulphate solutions, involving various mixing ratios, was achieved after introducing the ad-

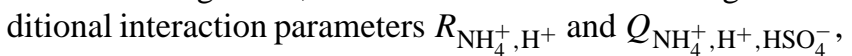
listed in Table 6. Water activities as modelled by AIOMFAC are shown in the upper panels of Fig. 5 together with the experimental data used for the model fit. The corresponding degrees of bisulphate dissociation are plotted in the lower panels.

A mixture with $\left(\mathrm{NH}_{4}\right)_{2} \mathrm{SO}_{4}: \mathrm{H}_{2} \mathrm{SO}_{4}$ ratio of $1: 1$ corresponds to a solution of $\mathrm{NH}_{4} \mathrm{HSO}_{4}$ and a $3: 1$ mixture reflects the composition of letovicite, $\left(\mathrm{NH}_{4}\right)_{3} \mathrm{H}\left(\mathrm{SO}_{4}\right)_{2}$. All curves in Fig. 5a) with a mixing ratio of $1: 1$ or higher are close to or even above the ammonium sulphate $a_{w}$ curve at the same $x_{w}$. This behaviour of the modelled $a_{w}$ is a consequence of the abscissa scale assuming complete salt and acid dissociation. Panel b) of Fig. 5 shows the same model curves plotted against a $x_{w}$-axis taking the modelled partial dissociation of the bisulphate ion into account, while $\left(\mathrm{NH}_{4}\right)_{2} \mathrm{SO}_{4}$ is still assumed to be completely dissociated. With this different scaling, all ternary ammonium sulphate-sulphuric acid mixtures lie in between the curves of pure ammonium sulphate 
and sulphuric acid. Such scale-effects are in principal expected for the plots of other mixtures too, although perhaps less prominent, depending on the real degree of dissociation of an electrolyte.

\subsubsection{Aqueous multi-salt mixtures}

The non-ideality of aqueous multi-salt mixtures is in general a result of the interactions between all components. Therefore the AIOMFAC model expressions consider all possible binary cation-anion interactions to compute the overall effect on water and ion activities. Higher order interactions between three or more different ions are neglected, to keep the number of fit parameters low. Figure 6 shows two examples of AIOMFAC water activity predictions. In a) experimental data of an aqueous mixture containing the ions $\mathrm{Na}^{+}, \mathrm{NH}_{4}^{+}, \mathrm{Cl}^{-}$, and $\mathrm{NO}_{3}^{-}$in a $(1: 1: 1: 1)$ molar ratio are compared with AIOMFAC and ZSR predictions. The ZSR relation (Zdanovskii, 1936, 1948; Stokes and Robinson, 1966) is an expression that can be used to calculate water activities of mixtures based on data from the corresponding binary aqueous salt solutions. The ZSR relation is widely used due to its simple form and generally good performance. For comparison, two ZSR predictions are plotted, assuming that the mixture is a solution of $\mathrm{NaCl}+\mathrm{NH}_{4} \mathrm{NO}_{3}$ for $\mathrm{ZSR} 1$ and $\mathrm{NaNO}_{3}+\mathrm{NH}_{4} \mathrm{Cl}$ for ZSR 2. Polynomials tabulated in $\mathrm{Ha}$ et al. (2000) were used to describe the water activities of binary salt solutions in the recommended $a_{w}$ range. In the concentration range of the bulk mixture, AIOMFAC and ZSR 1 predict the water activity quite well, while ZSR 2 slightly deviates. At supersaturated conditions AIOMFAC and ZSR 1 are still in good agreement with each other and the data, while ZSR 2 overpredicts $a_{w}$. EDB data has higher variation than bulk data and AIOMFAC predictions become less accurate at higher concentrations due to the lack of binary data at high ionic strength. This explains the deviations between model and experiments at $a_{w}<0.45$ at least partly. One advantage of AIOMFAC, compared with the ZSR relation, is the unambiguous and consistent computation of all mixture component activities - a necessary condition for LLE predictions.

An artificial sea salt mixture was measured and compared to the AIOMFAC prediction as shown in Fig. 6b). The mixture is composed of $\mathrm{Na}_{2} \mathrm{SO}_{4}, \mathrm{NaCl}, \mathrm{MgCl}_{2}$, and water with a (salt) molar ratio of (1.000:14.820:1.895) according to the recipe given in Lewis and Schwartz (2004). Again, binary ion combinations like $\mathrm{Mg}^{2+}-\mathrm{SO}_{4}^{2-}$ form in the solution and have to be considered in addition to the salts describing the mixture. AIOMFAC $a_{w}$ predictions and bulk data agree well. As expected from the composition, $\mathrm{NaCl}$ dominates the solution's $a_{w}$. The generally good performance of AIOMFAC and the ZSR models to predict water activities in multi-salt mixtures shows that binary cation-anion interaction parametrisations seem to be indeed sufficient to describe the mixed solutions, even at supersaturated conditions.

\subsection{Alcohol-water-salt mixtures}

For the parametrisation of the organic-inorganic MR interactions, a comprehensive compilation of ternary (alcohol+water+salt) data sets were used as described in Sect. 2.6.2. The fitted MR parameters for the calculation of $B_{k, i}(I)$ are listed in Table 7. The inclusion of organicinorganic MR interaction parameters led to a distinct improvement of the model performance, showing that this type of interactions is indeed important to determine ion and alcohol/polyol activities. In the following, we will present the model performance for selected systems.

Figures 7 and 8 show modelled and measured water activities of polyol-water-ammonium sulphate mixtures. Increase of the salt content decreases the water activity for a given salt-free mole fraction and may even induce the formation of a liquid-liquid phase separation in case of the longer chain diols. AIOMFAC underestimates the water activity of salt-rich polyol-water mixtures, while it slightly overestimates $a_{w}$ at moderate and low salt content. The effect of a dissolved salt on the water activity is apparent as the deviation from the salt-free mixture curve. In all cases ammonium sulphate exerts a salting-out effect on the polyols. Note that the MR part of AIOMFAC does not distinguish between 1,2-butanediol and 1,4-butanediol, while the SR part does. Inclusion of organic-inorganic MR parameters leads to an improvement of the water activity predictions by $32-60 \%$ for Fig. 7 and $26-73 \%$ for Fig. 8. Note that in the panels (b) and (d) of Fig. 8 the predicted salt-free solution curves show water activities exceeding 1.0 because we did not allow for the formation of a LLE in the model calculations.

LLE data is very useful to determine MR parameters for two reasons: (i) the composition measurements of the coexisting phases can be used to compare the activities of the organic compound, of water and of the ions in the two liquid phases simultaneously and (ii) the data is often measured at room temperature. Figure 9 shows a selection of LLE data sets, all containing $\mathrm{NaCl}$ as inorganic salt.

Plotted are the relative activity deviations of the components between the two phases:

$\mid$ rel. activity deviation $\mid=\frac{\left|a_{j}^{\alpha}-a_{j}^{\beta}\right|}{0.5\left(a_{j}^{\alpha}+a_{j}^{\beta}\right)}$

where $\alpha, \beta$ denote the two different liquid phases. The mean activity coefficient was used in the case of ions. The ions are essentially found in the water rich, polar phase, while the organics are salted-out to the more nonpolar, almost salt-free phase. Good agreement of the activities in the two phases is reached for water, which is present in both phases as a major fraction. The activity deviations of organics and ions are larger, because the model tends to overpredict/underpredict activities when one component is available only in very small amounts in one phase. The introduction of organic-inorganic 
MR interaction parameters leads to significant improvements of the relative activity deviations $\left(\Delta a_{j}^{\alpha, \beta}\right)$ of LLE containing $\mathrm{NaCl}$ in the ranges of $4-43 \%$ for $\Delta a_{w}^{\alpha, \beta}, 93-96 \%$ for $\Delta a_{o}^{\alpha, \beta}$ (where $o$ indicates the organic compound), and $77-94 \%$ for $\Delta a_{ \pm}^{\alpha, \beta}$. Similar improvements are obtained for LLE systems containing $\mathrm{KCl}$ and $\mathrm{Na}_{2} \mathrm{SO}_{4}$.

VLE data, although often measured at temperatures different from room temperature, offer a useful quality check for salting-out and salting-in effects. To compare AIOMFAC predictions of alcohol and water activity coefficients with VLE measurements, the actual measurement temperatures were used in the SR and LR part of AIOMFAC (without adapting densities and dielectric constants in the LR part). While the MR parametrisation in the present form does not include temperature dependence. Figure 10 shows an example in panel (a) for mixtures of ethanol-water- $\mathrm{NaBr}$. The presence of $\mathrm{NaBr}$ increases the activity of ethanol and decreases water activity compared with the salt-free system. If the organic-inorganic interaction parameters were set to zero, the ethanol activity coefficients would show no salting-out effect and instead lie below the dashed curve. This highlights the importance of organic-inorganic interaction parameters for an accurate prediction of gas/particle partitioning. Panel (b) of Fig. 10 shows a rare example of EMF data for the case of a quaternary system containing more than one salt. The published mean activity coefficients are given with respect to the unsymmetrical solvent mixture reference state for ions. Computing the AIOMFAC activity coefficients with respect to this reference state resulted in an excellent agreement with the EMF measurements.

\subsection{Comparison with other activity models}

In the past, many models were parametrised to compute activity coefficients of either aqueous electrolyte solutions or aqueous organic, electrolyte-free systems. Only a few models combine organic and inorganic approaches to a single framework and only very few of them are aimed at atmospheric aerosol systems. Raatikainen and Laaksonen (2005) showed a comparison of the most established organicinorganic models suitable for activity calculations of aerosol solutions. One can classify these models into (i) groupcontribution and (ii) organic substance specific methods. Both model types have general assets and drawbacks. Groupcontribution approaches (e.g. extended UNIFAC models) offer the potential to predict activities of a large fraction of organic compounds using parametrisations for only a few functional groups. Substance specific models (e.g. extended UNIQUAC models) in contrast, need individual parametrisations for each organic compound. The accuracy of activity coefficient predictions from organic compound specific models are, as a consequence of the custom-made parametrisation, usually better than the predictions of group-contribution models. On the other hand, the compound specific mod- els need experimental data for the parametrisation of every considered mixture and are therefore highly limited in their application compared to group-contribution models. In general, these two model types show a trade-off between desired accuracy for specific systems using parametrisations for every compound and desired overall organic-inorganic system application and predictability using a small number of functional group specific parameters. The AIOMFAC model represents a type (i) model.

Atmospheric aerosols contain a large number of often poorly characterised organic compounds, which are dominated by a relatively small number of functional groups. This circumstance favours group-contribution models over substance specific models when used for aerosol modelling. Keeping this in mind, we focus here on the comparison of AIOMFAC with other group-contribution activity models rather than on a comparison with substance specific organicinorganic activity models like extended UNIQUAC (Thomsen et al., 2004) or mod. LIQUAC (Kiepe et al., 2006).

In contrast to most models compared by Raatikainen and Laaksonen (2005), AIOMFAC offers an excellent aqueous electrolyte representation up to high ionic strength. Only the model of Ming and Russell (2002), which includes the AIM model (Clegg et al., 1998a,b) for the inorganic part, yields a comparable accuracy for aqueous electrolyte solutions. Most other models are limited to the concentration range of dilute to, at maximum, saturated electrolyte solutions. One disadvantage in this context is the limitation of AIOMFAC to systems at room temperature. The incomplete dissociation of bisulphate in aqueous sulphuric acid-ammonium sulphate systems is explicitly considered in AIOMFAC, other group-contribution models, besides the Ming and Russell model, assume always complete bisulphate dissociation or do not implement the related ions at all. Another advantage of AIOMFAC is the consistent model design, able to predict VLE, LLE, and SLE with the same parametrisation. As Raatikainen and Laaksonen pointed out, this is not the case for some models considered in their comparison (e.g. LIFAC). Recently, an improved and modified version of LIFAC (mod. LIFAC) has been published by Kiepe et al. (2006), that is able to predict VLE and LLE. In contrast to AIOMFAC, which has been parametrised using a variety of data types, including LLE and SLE data, organic-inorganic MR interaction parameters of mod. LIFAC have been obtained from VLE, osmotic coefficients, and mean ionic activity coefficient data.

To describe ion induced liquid-liquid phase separations, models have to explicitly treat interactions between ions and organics. The occurrence of such phase separations has consequences for the gas/particle partitioning of atmospheric aerosols, because in the case of two liquid phases, partitioning of semi-volatile organics to the particulate phase is enhanced compared with the situation of particles consisting of one liquid phase (Erdakos and Pankow, 2004). This increases the amount of particle bound organic mass and decreases the 
gas phase fraction of semi-volatile components.

AIOMFAC shares the advantage of an explicit organicinorganic MR interaction part with other models based on LIQUAC/LIFAC, e.g., with the X-UNIFAC models (Erdakos et al., 2006; Chang and Pankow, 2006). In contrast to the other models with a UNIFAC part, AIOMFAC includes the new UNIFAC parametrisation by Marcolli and Peter (2005), which represents better the SR contribution of alcohols/polyols found in atmospheric aerosols.

Methods based on ZSR mixing rules are comparably accurate in predicting water activities of mixtures, but do not consistently predict activity coefficients of all mixture components and can become ambiguous in multi-salt solutions.

Figure 11 shows experimental water activity data of four different aqueous electrolyte solutions at $298 \mathrm{~K}$ and corresponding model calculations of AIM III (Aerosol Inorganics Model, http://mae.ucdavis.edu/ sclegg/aim.html) (Clegg et al., 1998b), mod. LIFAC, and AIOMFAC. Panels (a), (b), and (c) of Fig. 11 show that the water activities calculated by AIM III and AIOMFAC are in good agreement with the measurements up to high salt concentrations $\left(a_{w}<0.6\right)$. The experimental data at very high concentrations $\left(a_{w}<0.45\right)$ in panels (a) and (b) indicate the formation of a solid salt (or hydrate) out of the supersaturated solution. This is not reproduced by the models as the formation of solids was not enabled in the model calculations. Panels (a) and (d) show the comparison of mod. LIFAC with AIOMFAC. At low and moderate concentrations the calculated water activities of both models agree well with each other and the measurements. At high salt concentrations mod. LIFAC strongly deviates from AIOMFAC and shows in (a) a steep $a_{w}$ increase and in (d) an increase followed by a sharp decrease, features that have to be rated as artefacts of the mod. LIFAC parametrisation. Because mod. LIFAC was not parametrised for supersaturated electrolyte solutions, such artefacts can appear for predictions of highly concentrated (supersaturated) solutions. Panel (d) also suggests that for the $\mathrm{Ca}\left(\mathrm{NO}_{3}\right)_{2}$ parametrisation in mod. LIFAC only water activity data of bulk measurements were used. The smooth AIOMFAC curves show that the use of EMF data covering high solution concentrations and measurements of ternary mixtures as well as a reasonable constraint on the $a_{w}$ curve gradient enable much better descriptions and predictions up to high concentrations.

The similarity of mod. LIFAC and AIOMFAC facilitates the comparison between the two models as the AIOMFAC framework can be easily adapted to the model equations and parameters given by Kiepe et al. (2006). Figures 12 and 13 show comparisons between the two models for ternary alcohol/polyol-water-salt mixtures. Panels (a) and (b) of Fig. 12 show two examples of activity coefficient comparisons for isobaric VLE data. The agreement of both models with experimental VLE data is overall similar. However, panels (c) and (d) of Fig. 12 show that AIOMFAC represents polyol-water-salt mixtures much better than mod. LI-
FAC. There the use of further data types besides VLE for the model parametrisations are crucial. Figure 13 shows for four different LLE systems that the AIOMFAC calculations are much more accurate than mod. LIFAC for all LLE datasets. Particularly mean molal activities of the salts in the coexisting phases show large deviations when calculated with mod. LIFAC, which indicates that mod. LIFAC will not be able to predict LLE accurately. These examples show the importance of a wide database covering different experimental methods and data types as well as different organic compounds containing the same functional groups to parametrise an activity model over a wide composition range.

\section{Conclusions}

AIOMFAC, a semi-empirical group-contribution model for computing activity coefficients of organic-inorganic solutions was presented. The thermodynamic framework of AIOMFAC considers explicitly the different Gibbs excess contributions from long-, middle-, and short-range interactions between all mixture species. Water as the fixed reference solvent for inorganic ions allows the prediction and description of multicomponent LLE, VLE, SLE, and EMF data within the same model. Seven cations, five anions and two organic functional groups, the alkane and the hydroxyl group, were considered using a total of over 150 different data sets. The determination of 28 cation-anion and 18 organic main group-ion interaction parameters in the middle-range part led to a good overall description of mixed alcohol/polyol-water-salt systems. Aqueous electrolyte solutions are predicted very well within the range of available data including high supersaturations. In compliance with the Gibbs-Duhem relation, consistency between mean ionic activity coefficients and water activity predictions was assured. Aqueous mixtures of salts are well predicted by only considering binary cation-anion interaction parameters. Ternary alcohol-water-salt mixtures are described with good agreement to experiments. Although in some cases the data could be more accurately predicted by an organic substance specific model, the group-contribution approach offers much more flexibility with a manageable number of groups/species. In principle, the model allows also the calculation of substance specific mixtures if a high accuracy for a specific system is needed. Since other inorganic salts are easily implemented, AIOMFAC is not restricted to atmospheric systems and could be applied in other research fields as well.

In this study we have shown the proof of concept of our model approach. In future, we will extend the AIOMFAC parametrisation to further functional groups and apply it to predict the stable phases and thermodynamic behaviour for multicomponent mixtures of atmospheric relevance. However, for an extension to further functional groups, more experimental data of ternary and higher order organic-inorganic mixtures are requested. 
Table A1. Water activities from bulk measurements of aqueous ammonium sulphate-sulphuric acid mixtures at $298.15 \mathrm{~K}$ with a $\left(\mathrm{NH}_{4}\right)_{2} \mathrm{SO}_{4}: \mathrm{H}_{2} \mathrm{SO}_{4}$ molar ratio of $2: 1$. Concentrations of the electrolytes are given in mass fractions.

\begin{tabular}{ccc}
\hline \multicolumn{3}{c}{ Composition of aqueous solutions (mass fractions) } \\
\cline { 1 - 2 }$\left(\mathrm{NH}_{4}\right)_{2} \mathrm{SO}_{4}$ & $\mathrm{H}_{2} \mathrm{SO}_{4}$ & $a_{w}{ }^{\mathrm{a}}$ \\
\hline 0.0247 & 0.0092 & 0.995 \\
0.0611 & 0.0227 & 0.978 \\
0.0977 & 0.0362 & 0.966 \\
0.1340 & 0.0497 & 0.945 \\
0.1704 & 0.0633 & 0.924 \\
0.2068 & 0.0768 & 0.900 \\
0.2433 & 0.0903 & 0.870 \\
0.2583 & 0.0958 & 0.856 \\
0.2733 & 0.1014 & 0.843 \\
0.2882 & 0.1070 & 0.829 \\
0.3036 & 0.1127 & 0.816 \\
0.3181 & 0.1181 & 0.799 \\
\hline
\end{tabular}

a The accuracy is specified to be $\pm 0.003 a_{w}$.

\section{Appendix A}

Tables A1 and A3-A9 show data of our own water activity measurements at room temperature using an AquaLab water activity meter (Model 3TE, Decagon Devices, USA) for bulk measurements. This instrument allows us to perform measurements in the temperature range from 289 to $313 \mathrm{~K}$. The inorganic aqueous electrolyte solutions were measured with the standard sample block, for which an accuracy of \pm 0.003 $a_{w}$ is specified by the manufacturer. For the measurements of organic-inorganic mixtures containing polyols, the volatile sample block available as an accessory to the instrument was used. With this sample block, the water activity in the presence of other semi-volatile components can be determined. Experimental errors for the volatile sample block are specified to be $\pm 0.015 a_{w}$. To correct for instrument drifts and offsets, the performance of the sample block was frequently controlled and readjusted with reference samples. All measurements were performed at $298 \pm 1 \mathrm{~K}$. The operating principle of this instrument is described in more detail in Marcolli and Peter (2005) and Marcolli and Krieger (2006).

The inorganic salts were purchased from Sigma-Aldrich with purities of $99 \%$ or higher. Sulphuric acid was purchased from Merck with a concentration of $96.06 \%$. The polyols were purchased from Fluka with purities ranging from $\geq 95 \%$ to $\geq 98 \%$ ( $\geq 95 \%$ : 1,7-heptanediol, 1,2,4-butanetriol; $\geq 97 \%$ : 2,5-hexanediol; $\geq 98 \%$ : 1,2-butanediol, and 2,4pentanediol). The substances were used without further purification. The solutions were prepared by mass percent with ultrapure water (Millipore Simplicity 185) using an analyti-
Table A2. Water activities from EDB measurements of aqueous ammonium sulphate-sulphuric acid mixtures at $288 \mathrm{~K}$ with a $\left(\mathrm{NH}_{4}\right)_{2} \mathrm{SO}_{4}: \mathrm{H}_{2} \mathrm{SO}_{4}$ molar ratio of $2: 1$. Concentrations of the electrolytes are given in mass fractions.

\begin{tabular}{ccc}
\hline \multicolumn{2}{c}{ Composition of aqueous solutions (mass fractions) } \\
\cline { 1 - 2 }$\left(\mathrm{NH}_{4}\right)_{2} \mathrm{SO}_{4}$ & $\mathrm{H}_{2} \mathrm{SO}_{4}$ & $a_{w}{ }^{\mathrm{a}}$ \\
\hline 0.3137 & 0.1164 & 0.803 \\
0.3296 & 0.1223 & 0.783 \\
0.3398 & 0.1261 & 0.770 \\
0.3489 & 0.1295 & 0.758 \\
0.3583 & 0.1330 & 0.746 \\
0.3678 & 0.1365 & 0.733 \\
0.3765 & 0.1397 & 0.721 \\
0.3852 & 0.1430 & 0.709 \\
0.3940 & 0.1462 & 0.697 \\
0.4031 & 0.1496 & 0.684 \\
0.4110 & 0.1526 & 0.672 \\
0.4206 & 0.1561 & 0.659 \\
0.4289 & 0.1592 & 0.647 \\
0.4374 & 0.1623 & 0.635 \\
0.4468 & 0.1658 & 0.622 \\
0.4544 & 0.1687 & 0.610 \\
0.4624 & 0.1716 & 0.597 \\
0.4718 & 0.1751 & 0.585 \\
0.4798 & 0.1781 & 0.572 \\
0.4875 & 0.1809 & 0.559 \\
0.4955 & 0.1839 & 0.547 \\
0.5029 & 0.1866 & 0.535 \\
0.5106 & 0.1895 & 0.522 \\
0.5193 & 0.1927 & 0.510 \\
0.5273 & 0.1957 & 0.497 \\
0.5359 & 0.1989 & 0.485 \\
0.5434 & 0.2017 & 0.473 \\
0.5532 & 0.2053 & 0.460 \\
0.5606 & 0.2081 & 0.448 \\
0.5697 & 0.2114 & 0.435 \\
0.5793 & 0.2150 & 0.422 \\
0.5847 & 0.2170 & 0.409 \\
0.5930 & 0.2201 & 0.396 \\
\hline & &
\end{tabular}

a The accuracy is assumed to be $\pm 0.016 a_{w}$. 
Table A3. Bulk water activity measurements of aqueous sodium chloride-ammonium nitrate mixtures at $298.15 \mathrm{~K}$ with a $\mathrm{NaCl}$ : $\mathrm{NH}_{4} \mathrm{NO}_{3}$ molar ratio of $1: 1$.

\begin{tabular}{ccc}
\hline \multicolumn{3}{c}{ Composition of aqueous solutions (mass fractions) } \\
\cline { 1 - 2 } $\mathrm{NaCl}$ & $\mathrm{NH}_{4} \mathrm{NO}_{3}$ & $a_{w}{ }^{\mathrm{a}}$ \\
\hline 0.0038 & 0.0052 & 0.991 \\
0.0093 & 0.0127 & 0.985 \\
0.0207 & 0.0283 & 0.973 \\
0.0338 & 0.0462 & 0.959 \\
0.0456 & 0.0624 & 0.946 \\
0.0591 & 0.0809 & 0.928 \\
0.0709 & 0.0971 & 0.910 \\
0.0844 & 0.1156 & 0.891 \\
0.0967 & 0.1323 & 0.872 \\
0.1102 & 0.1508 & 0.847 \\
0.1220 & 0.1670 & 0.824 \\
0.1351 & 0.1849 & 0.799 \\
0.1478 & 0.2022 & 0.775 \\
\hline
\end{tabular}

a The accuracy is specified to be $\pm 0.003 a_{w}$.

Table A4. Bulk water activity measurements of aqueous sodium chloride-magnesium sulphate mixtures at $298.15 \mathrm{~K}$ with a $\mathrm{NaCl}$ : $\mathrm{MgSO}_{4}$ molar ratio of $1: 1$.

\begin{tabular}{ccc}
\hline \multicolumn{3}{c}{ Composition of aqueous solutions (mass fractions) } \\
\cline { 1 - 2 } $\mathrm{NaCl}$ & $\mathrm{MgSO}_{4}$ & $a_{w}{ }^{\mathrm{a}}$ \\
\hline 0.0088 & 0.0173 & 0.989 \\
0.0131 & 0.0259 & 0.987 \\
0.0289 & 0.0571 & 0.971 \\
0.0404 & 0.0796 & 0.956 \\
0.0559 & 0.1101 & 0.934 \\
0.0670 & 0.1320 & 0.908 \\
0.0828 & 0.1632 & 0.865 \\
0.0939 & 0.1851 & 0.825 \\
\hline
\end{tabular}

a The accuracy is specified to be $\pm 0.003 a_{w}$.
Table A5. Bulk water activity measurements of aqueous "sea salt"like sodium chloride-sodium sulphate-magnesium chloride mixtures at $298.15 \mathrm{~K}$ with a $\mathrm{NaCl}: \mathrm{Na}_{2} \mathrm{SO}_{4}: \mathrm{MgCl}_{2}$ molar ratio of 14.820: $1.000: 1.895$.

\begin{tabular}{cccc}
\hline \multicolumn{3}{c}{ Composition of aqueous solutions (mass fractions) } \\
\cline { 1 - 3 } $\mathrm{NaCl}$ & $\mathrm{Na}_{2} \mathrm{SO}_{4}$ & $\mathrm{MgCl}_{2}$ & $a_{w}{ }^{\mathrm{a}}$ \\
\hline 0.0029 & 0.0005 & 0.0006 & 0.994 \\
0.0102 & 0.0017 & 0.0021 & 0.989 \\
0.0321 & 0.0053 & 0.0067 & 0.975 \\
0.0532 & 0.0087 & 0.0111 & 0.961 \\
0.0743 & 0.0122 & 0.0155 & 0.926 \\
0.0962 & 0.0158 & 0.0200 & 0.913 \\
0.1180 & 0.0194 & 0.0246 & 0.884 \\
0.1399 & 0.0229 & 0.0291 & 0.852 \\
0.1618 & 0.0265 & 0.0337 & 0.814 \\
0.1822 & 0.0299 & 0.0380 & 0.777 \\
\hline
\end{tabular}

a The accuracy is specified to be $\pm 0.003 a_{w}$.
Table A6. Bulk water activity measurements of aqueous sodium sulphate-magnesium chloride-magnesium sulphate mixtures at $298.15 \mathrm{~K}$ with a $\mathrm{Na}_{2} \mathrm{SO}_{4}: \mathrm{MgCl}_{2}: \mathrm{MgSO}_{4}$ molar ratio of 1.490 : 1.000: 1.263 .

\begin{tabular}{cccc}
\hline \multicolumn{3}{c}{ Composition of aqueous solutions (mass fractions) } \\
\cline { 1 - 2 } $\mathrm{Na}_{2} \mathrm{SO}_{4}$ & $\mathrm{MgCl}_{2}$ & $\mathrm{MgSO}_{4}$ & $a_{w}{ }^{\mathrm{a}}$ \\
\hline 0.0037 & 0.0017 & 0.0026 & 0.992 \\
0.0175 & 0.0079 & 0.0126 & 0.987 \\
0.0309 & 0.0139 & 0.0222 & 0.978 \\
0.0438 & 0.0197 & 0.0315 & 0.968 \\
0.0577 & 0.0259 & 0.0414 & 0.955 \\
0.0701 & 0.0315 & 0.0503 & 0.94 \\
0.0849 & 0.0382 & 0.0609 & 0.919 \\
0.0987 & 0.0444 & 0.0709 & 0.895 \\
0.1121 & 0.0504 & 0.0805 & 0.867 \\
\hline
\end{tabular}

a The accuracy is specified to be $\pm 0.003 a_{w}$. 
Table A7. Bulk water activity measurements of ammonium sulphate-polyol-water mixtures at $298.15 \mathrm{~K}$. Concentrations are given in mass fractions of $\left(\mathrm{NH}_{4}\right)_{2} \mathrm{SO}_{4}$ and polyols.

\begin{tabular}{cccc}
\hline \multicolumn{3}{c}{ Composition of aqueous solutions (mass fractions) } & \\
\cline { 1 - 2 }$\left(\mathrm{NH}_{4}\right)_{2} \mathrm{SO}_{4}$ & 1,2 -butanediol & $1,2,4$-butanetriol & $a_{w}{ }^{\mathrm{a}}$ \\
\hline 0.0150 & 0.7726 & & 0.683 \\
0.0304 & 0.6613 & & 0.761 \\
0.0797 & 0.5384 & & 0.780 \\
0.1355 & 0.4149 & & 0.787 \\
0.1980 & 0.3142 & & 0.784 \\
0.2821 & 0.1875 & & 0.787 \\
0.3540 & 0.0888 & & 0.787 \\
0.4320 & 0.0000 & & 0.802 \\
0.0158 & & 0.7737 & 0.531 \\
0.0364 & & 0.6845 & 0.614 \\
0.0680 & & 0.5961 & 0.668 \\
0.1055 & & 0.4922 & 0.716 \\
0.1580 & & 0.3992 & 0.743 \\
0.2249 & & 0.3030 & 0.750 \\
0.2966 & & 0.1872 & 0.769 \\
0.3615 & & 0.0903 & 0.787 \\
0.4320 & & 0.0000 & 0.802
\end{tabular}

a The accuracy is specified to be $\pm 0.015 a_{w}$.

Table A8. Bulk water activity measurements of ammonium sulphate-polyol-water mixtures at $298.15 \mathrm{~K}$. Concentrations are given in mass fractions of $\left(\mathrm{NH}_{4}\right)_{2} \mathrm{SO}_{4}$ and polyols.

\begin{tabular}{cccc}
\hline \multicolumn{3}{c}{ Composition of aqueous solutions (mass fractions) } & \\
\cline { 1 - 2 }$\left(\mathrm{NH}_{4}\right)_{2} \mathrm{SO}_{4}$ & 2,4-pentanediol & 2,5-hexanediol & $a_{w}{ }^{\mathrm{a}}$ \\
\hline 0.0073 & 0.7051 & & 0.796 \\
0.0461 & 0.4627 & & 0.846 \\
0.0900 & 0.3592 & & 0.852 \\
0.1373 & 0.2649 & & 0.851 \\
0.1971 & 0.1731 & & 0.851 \\
0.2575 & 0.1046 & & 0.845 \\
0.3304 & 0.0507 & & 0.830 \\
0.3608 & 0.0342 & & 0.820 \\
0.4190 & 0.0121 & & 0.795 \\
0.4320 & 0.0000 & & 0.802 \\
0.0433 & & 0.4299 & 0.883 \\
0.0736 & & 0.3488 & 0.883 \\
0.1083 & & 0.2654 & 0.889 \\
0.1480 & & 0.1955 & 0.882 \\
0.1902 & & 0.1241 & 0.886 \\
0.2302 & & 0.0725 & 0.879 \\
0.2911 & & 0.0338 & 0.867 \\
0.4320 & & 0.0000 & 0.802 \\
\hline
\end{tabular}

a The accuracy is specified to be $\pm 0.015 a_{w}$.
Table A9. Bulk water activity measurements of ammonium sulphate-1,7-heptanediol-water mixtures at $298.15 \mathrm{~K}$. Concentrations are given in mass fractions of $\left(\mathrm{NH}_{4}\right)_{2} \mathrm{SO}_{4}$ and 1,7heptanediol.

\begin{tabular}{ccc}
\hline \multicolumn{3}{c}{ Composition of aqueous solutions (mass fractions) } \\
\cline { 1 - 2 }$\left(\mathrm{NH}_{4}\right)_{2} \mathrm{SO}_{4}$ & 1,7-heptanediol & $a_{w}{ }^{\mathrm{a}}$ \\
\hline 0.0144 & 0.4111 & 0.952 \\
0.0327 & 0.1983 & 0.943 \\
0.0477 & 0.1218 & 0.946 \\
0.0453 & 0.0511 & 0.948 \\
0.0480 & 0.0536 & 0.943 \\
0.0765 & 0.0507 & 0.941 \\
0.0981 & 0.0320 & 0.944 \\
0.1338 & 0.0160 & 0.938 \\
0.4320 & 0.0000 & 0.802 \\
\hline
\end{tabular}

a The accuracy is specified to be $\pm 0.015 a_{w}$.

cal balance. The compositions of the aqueous electrolyte solutions were corrected to include the water which was present in the salts as purchased.

Table A2 shows water activity data from our EDB measurements. The electrodynamic balance used in our experiments is described in detail elsewhere (Colberg et al., 2004; Marcolli and Krieger, 2006). An electrically charged particle (typically $2-7 \mu \mathrm{m}$ in radius) is balanced in an electrodynamic trap where the temperature is kept constant and the relative humidity within the EDB-chamber is increased or decreased continuously by changing the $\mathrm{N}_{2} / \mathrm{H}_{2} \mathrm{O}$ ratio in the gas phase, using automatic mass flow controllers. The relative humidity is registered by a sensor in the trap with an accuracy of $\pm 1.5 \%$ RH between 10 and $90 \%$ RH. The mass of the particle is calculated from the DC voltage compensating the gravitational force. A change in DC voltage is therefore a direct measurement for the mass change of the particle. The experiments in the EDB were performed at $288 \mathrm{~K}$. The measured ammonium sulphate-sulphuric acid solutions were prepared with the same procedure as for the AquaLab bulk measurements. 
Acknowledgements. This work was supported by the Swiss National Foundation under project No. 200020-103651. We would like to thank A. A. Zardini and U. K. Krieger of our group, for conducting helpful EDB measurements.

Edited by: G. McFiggans

\section{References}

Abrams, D. S. and Prausnitz, J. M.: Statistical Thermodynamics of Liquid Mixtures: A New Expression for the Excess Gibbs Energy of Partly or Completely Miscible Systems, AIChE J., 21, 116-128, 1975.

Achard, C., Dussap, C. G., and Gros, J. B.: Representation of vapor-liquid equilibria in water-alcohol-electrolyte mixtures with a modified UNIFAC group-contribution method, Fluid Phase Equilib., 98, 71-89, 1994.

Bathrick, E.: Precipitation of Salts, J. Phys. Chem., 1, 157-169, 1896.

Brenner, D. K., Anderson, E. W., Lynn, S., and Prausnitz, J. M.: Liquid-Liquid Equilibria for Saturated Aqueous Solutions of Sodium Sulfate + 1-Propanol, 2-Propanol, or 2-Methylpropan2-ol, J. Chem. Eng. Data, 37, 419-422, 1992.

Burns, J. A. and Furter, W. F.: Thermodynamic behavior of electrolytes in mixed solvents, a symposium: 170th meeting of the American Chemical Society, Chicago, American Chemical Society, 1975.

Carslaw, K. S., Clegg, S. L., and Brimblecombe, P.: A Thermodynamic Model of the System $\mathrm{HCl}-\mathrm{HNO}_{3}-\mathrm{H}_{2} \mathrm{SO}_{4}-\mathrm{H}_{2} \mathrm{O}$, Including Solubilities of $\mathrm{HBr}$, from $<200$ to $328 \mathrm{~K}$, J. Phys. Chem., 99, 11 557-11 574, 1995.

Chan, C. K., Flagan, R. C., and Seinfeld, J. H.: Water Activities of $\mathrm{NH}_{4} \mathrm{NO}_{3} /\left(\mathrm{NH}_{4}\right)_{2} \mathrm{SO}_{4}$ Solutions, Atmos. Environ. A, 26, 16611673, 1992.

Chan, C. K., Ha, Z. Y., and Choi, M. Y.: Study of water activities of aerosols of mixtures of sodium and magnesium salts, Atmos. Environ., 34, 4795-4803, 2000.

Chang, E. I. and Pankow, J. F.: Prediction of activity coefficients in liquid aerosol particles containing organic compounds, dissolved inorganic salts, and water-Part 2: Consideration of phase separation effects by an X-UNIFAC model, Atmos. Environ., 40, 6422-6436, doi:10.1016/j.atmosenv.2006.04.031, 2006.

Chou, T. J., Tanioka, A., and Tseng, H. C.: Salting Effect on the Liquid-Liquid Equilibria for the Partially Miscible Systems of nPropanol-Water and i-Propanol-Water, Ind. Eng. Chem. Res., 37, 2039-2044, 1998.

Clegg, S. L., Ho, S. S., Chan, C. K., and Brimblecombe, P.: Thermodynamic Properties of Aqueous $\left(\mathrm{NH}_{4}\right)_{2} \mathrm{SO}_{4}$ to High Supersaturation as a Function of Temperature, J. Chem. Eng. Data, 40, 1079-1090, 1995.

Clegg, S. L., Milioto, S., and Palmer, D. A.: Osmotic and Activity Coefficients of Aqueous $\left(\mathrm{NH}_{4}\right)_{2} \mathrm{SO}_{4}$ as a Function of Temperature, and Aqueous $\left(\mathrm{NH}_{4}\right)_{2} \mathrm{SO}_{4}-\mathrm{H}_{2} \mathrm{SO}_{4}$ Mixtures at $298.15 \mathrm{~K}$ and 323.15 K, J. Chem. Eng. Data, 41, 455-467, 1996.

Clegg, S. L., Brimblecombe, P., and Wexler, A. S.: Thermodynamic Model of the System $\mathrm{H}^{+}-\mathrm{NH}_{4}^{+}-\mathrm{SO}_{4}^{2-}-\mathrm{NO}_{3}^{-}-\mathrm{H}_{2} \mathrm{O}$ at Tropospheric Temperatures, J. Phys. Chem. A, 102, 2137-2154, $1998 \mathrm{a}$.
Clegg, S. L., Brimblecombe, P., and Wexler, A. S.: Thermodynamic Model of the System $\mathrm{H}^{+}-\mathrm{NH}_{4}^{+}-\mathrm{Na}^{+}-\mathrm{SO}_{4}^{2-}-\mathrm{NO}_{3}^{-}-\mathrm{Cl}^{-}-\mathrm{H}_{2} \mathrm{O}$ at 298.15 K, J. Phys. Chem. A, 102, 2155-2171, 1998 b.

Colberg, C. A., Krieger, U. K., and Peter, T.: Morphological Investigations of Single Levitated $\mathrm{H}_{2} \mathrm{SO}_{4} / \mathrm{NH}_{3} / \mathrm{H}_{2} \mathrm{O}$ Aerosol Particles during Deliquescence/Efflorescence Experiments, J. Phys. Chem. A, 108, 2700-2709, doi:10.1021/jp037628r, 2004.

Covington, A. K. and Irish, D. E.: Osmotic and Activity Coefficients of Aqueous Ammonium Bromide Solutions at $25^{\circ} \mathrm{C}$, J. Chem. Eng. Data, 17, 175-176, 1972.

Dawson, B. S. W., Irish, D. E., and Toogood, G. E.: Vibrational Spectral Studies of Solutions at Elevated Temperatures and Pressures. 8. A Raman Spectral Study of Ammonium Hydrogen Sulfate Solutions and the $\mathrm{HSO}_{4}^{-}-\mathrm{SO}_{4}^{2-}$ Equilibrium, J. Phys. Chem., 90, 334-341, 1986.

De Santis, R., Marrelli, L., and Muscetta, P. N.: Liquid-Liquid Equilibria in Water-Aliphatic Alcohol Systems in the Presence of Sodium Chloride, Chem. Eng. J., 11, 207-214, 1976.

Debye, P. and Hückel, E.: Zur Theorie der Elektrolyte, Physikalische Zeitschrift, 24, 185-206, 1923.

Decesari, S., Facchini, M. C., Fuzzi, S., and Tagliavini, E.: Characterization of water-soluble organic compounds in atmospheric aerosol: A new approach, J. Geophys. Res. Atmos., 105, 14811489, doi:10.1029/1999JD900950, 2000.

Deyhimi, F., Ghalami-Choobar, B., and Salamat-Ahangari, R.: Activity coefficients for $\mathrm{NH}_{4} \mathrm{Cl}$ in ethanol-water mixed solvents by electromotive force measurements, J. Mol. Liq., 116, 93-97, 2005.

Dinane, A.: Thermodynamic properties of $(\mathrm{NaCl}+\mathrm{KCl}+\mathrm{LiCl}+$ $\mathrm{H}_{2} \mathrm{O}$ ) at $\mathrm{T}=298.15 \mathrm{~K}$ : Water activities, osmotic and activity coefficients, J. Chem. Thermodyn., 39, 96-103, doi:10.1016/j.jct. 2006.05.011, 2007.

Erdakos, G. B. and Pankow, J. F.: Gas/particle partitioning of neutral and ionizing compounds to single- and multi-phase aerosol particles. 2. Phase separation in liquid particulate matter containing both polar and low-polarity organic compounds, Atmos. Environ., 38, 1005-1013, doi:10.1016/j.atmosenv.2003.10.038, 2004.

Erdakos, G. B., Chang, E. I., Pankow, J. F., and Seinfeld, J. H.: Prediction of activity coefficients in liquid aerosol particles containing organic compounds, dissolved inorganic salts, and water - Part 3: Organic compounds, water, and ionic constituents by consideration of short-, mid-, and long-range effects using X-UNIFAC.3, Atmos. Environ., 40, 6437-6452, doi:10.1016/j. atmosenv.2006.04.001, 2006.

Esteso, M. A., Gonzalez-Diaz, O. M., Hernandez-Luis, F. F., and Fernandez-Merida, L.: Activity Coefficients for $\mathrm{NaCl}$ in Ethanol-Water Mixtures at $25^{\circ} \mathrm{C}$, J. Solution Chem., 18, 277288, 1989.

Farelo, F., Lopes, A., and Ferra, M. I. A.: Activity Coefficients of Potassium Chloride and Sodium Chloride in the Quaternary System KCl-NaCl-water-ethanol, J. Solution Chem., 31, 845860, 2002.

Fowler, R. H. and Guggenheim, E. A.: Statistical Thermodynamics, Cambridge University Press, 2 edn., 1949.

Fox, J. J. and Gauge, A. J. H.: The Solubility of Potassium Sulphate in Concentrated Aqueous Solutions of Non-Electrolytes, J. Chem. Soc., 97, 377-385, 1910.

Fredenslund, A., Jones, R. L., and Prausnitz, J. M.: Group- 
Contribution Estimation of Activity Coefficients in Nonideal Liquid Mixtures, AIChE J., 21, 1086-1099, 1975.

Gomis, V., Ruiz, F., Devera, G., Lopez, E., and Saquete, M. D.: Liquid-liquid-solid equilibria for the ternary systems watersodium chloride or potassium chloride-1-propanol or 2-propanol, Fluid Phase Equilib., 98, 141-147, 1994.

Gomis, V., Ruiz, F., Asensi, J. C., and Saquete, M. D.: Liquid-Liquid-Solid Equilibria for the Ternary Systems Butanols+Water+Sodium Chloride or+Potassium Chloride, J. Chem. Eng. Data, 41, 188-191, 1996.

Guendouzi, M. E., Dinane, A., and Mounir, A.: Water activities, osmotic and activity coefficients in aqueous chloride solutions at $\mathrm{T}=298.15 \mathrm{~K}$ bythe hygrometric method, J. Chem. Thermodyn., 33, 1059-1072, 2001.

Guendouzi, M. E., Mounir, A., and Dinane, A.: Water activity, osmotic and activity coefficients of aqueous solutions of $\mathrm{Li}_{2} \mathrm{SO}_{4}, \mathrm{Na}_{2} \mathrm{SO}_{4}, \mathrm{~K}_{2} \mathrm{SO}_{4},\left(\mathrm{NH}_{4}\right)_{2} \mathrm{SO}_{4}, \mathrm{MgSO}_{4}, \mathrm{MnSO}_{4}$, $\mathrm{NiSO}_{4}, \mathrm{CuSO}_{4}$, and $\mathrm{ZnSO}_{4}$ at $\mathrm{T}=298.15 \mathrm{~K}$, J. Chem. Thermodyn., 35, 209-220, 2003.

Ha, Z. Y. and Chan, C. K.: The Water Activities of $\mathrm{MgCl}_{2}$, $\mathrm{Mg}\left(\mathrm{NO}_{3}\right)_{2}, \mathrm{MgSO}_{4}$, and Their Mixtures, Aerosol Sci. Technol., 31, 154-169, 1999.

Ha, Z. Y., Choy, L., and Chan, C. K.: Study of water activities of supersaturated aerosols of sodium and ammonium salts, J. Geophys. Res. Atmos., 105, 11 699-11 709, 2000.

Hamer, W. J. and Wu, Y.: Osmotic Coefficients and Mean Activity Coefficients of Uni-univalent Electrolytes in Water at $25^{\circ} \mathrm{C}, \mathrm{J}$. Phys. Chem. Ref. Data, 1, 1047-1099, 1972.

Hansen, H. K., Rasmussen, P., Fredenslund, A., Schiller, M., and Gmehling, J.: Vapor-Liquid Equilibria by UNIFAC Group Contribution. 5. Revision and Extension, Ind. Eng. Chem. Res., 30, 2352-2355, 1991.

Heyrovska, R.: Ionic Concentrations and Hydration Numbers of "Supporting Electrolytes", 18, 351-361, doi:10.1002/elan. 200503416, 2006.

Iliuta, M. C., Thomsen, K., and Rasmussen, P.: Extended UNIQUAC model for correlation and prediction of vapourliquid-solid equilibria in aqueous salt systems containing nonelectrolytes. Part A. Methanol-water-salt systems, Chem. Eng. Sci., 55, 2673-2686, 2000.

Irish, D. E. and Chen, H.: Equilibria and Proton Transfer in the Bisulfate-Sulfate System, J. Phys. Chem., 74, 3796-3801, 1970.

Johnson, A. I. and Furter, W. F.: Vapor-Liquid Equilibrium in Systems Containing Dissolved Salts, Can. J. Chem. Eng., 43, 356, 1965.

Kanakidou, M., Seinfeld, J. H., Pandis, S. N., Barnes, I., Dentener, F. J., Facchini, M. C., Van dingenen, R., Ervens, B., Nenes, A., Nielsen, C. J., Swietlicki, E., Putaud, J. P., Balkanski, Y., Fuzzi, S., Horth, J., Moortgat, G. K., Winterhalter, R., Myhre, C. E. L., Tsigaridis, K., Vignati, E., Stephanou, E. G., and Wilson, J.: Organic aerosol and global climate modelling: a review, Atmos. Chem. Phys., 5, 1053-1123, 2005,

http://www.atmos-chem-phys.net/5/1053/2005/.

Kato, M., Sato, T., and Hirata, M.: Measurement of Salt Effect on Vapor-Liquid Equilibria by Bubble and Condensation Point Method, J. Chem. Eng. Jpn., 4, 308-311, 1971.

Kiepe, J., Noll, O., and Gmehling, J.: Modified LIQUAC and Modified LIFAC-A Further Development of Electrolyte Models for the Reliable Prediction of Phase Equilibria with Strong Elec- trolytes, Ind. Eng. Chem. Res., 45, 2361-2373, doi:10.1021/ ie0510122, 2006.

Kim, Y. P., Pun, B. K. L., Chan, C. K., Flagan, R. C., and Seinfeld, J. H.: Determination of Water Activity in Ammonium Sulfate and Sulfuric Acid Mixtures Using Levitated Single Particles, Aerosol Sci. Technol., 20, 275-284, 1994.

Kiriukhin, M. Y. and Collins, K. D.: Dynamic hydration numbers for biologically important ions, Biophys. Chem., 99, 155-168, 2002.

Knopf, D. A., Luo, B. P., Krieger, U. K., and Koop, T.: Thermodynamic Dissociation Constant of the Bisulfate Ion from Raman and Ion Interaction Modeling Studies of Aqueous Sulfuric Acid at Low Temperatures, J. Phys. Chem. A, 107, 4322-4332, doi: 10.1021/jp027775+, 2003.

Lee, S. H., Murphy, D. M., Thomson, D. S., and Middlebrook, A. M.: Chemical components of single particles measured with Particle Analysis by Laser Mass Spectrometry (PALMS) during the Atlanta SuperSite Project: Focus on organic/sulfate, lead, soot, and mineral particles, J. Geophys. Res. Atmos., 107, 4003, doi:10.1029/2000JD000011, 2002.

Lewis, E. R. and Schwartz, S. E.: Sea Salt Aerosol Production: Mechanism, Methods, Measurements, and Models: a critical review., American Geophysical Union, Washington DC, 2004.

Li, J. D., Polka, H. M., and Gmehling, J.: A $\mathrm{g}^{E}$ model for single and mixed solvent electrolyte systems. 1. Model and results for strong electrolytes, Fluid Phase Equilib., 94, 89-114, 1994.

Li, Z. C., Tang, Y. P., Liu, Y., and Li, Y. G.: Salting effect in partially miscible systems of n-butanol-water and butanone-water, 1. Determination and correlation of liquid-liquid equilibrium data, Fluid Phase Equilib., 103, 143-153, 1995.

Lin, C. L., Lee, L. S., and Tseng, H. C.: Phase Equilibria for Propan-1-ol + Water + Sodium Chloride and + Potassium Chloride and Propan-2-ol + Water + Lithium Chloride and + Lithium Bromide, J. Chem. Eng. Data, 38, 306-309, 1993.

Lopes, A., Farelo, F., and Ferra, M. I. A.: Activity Coefficients of Potassium Chloride in Water-Ethanol Mixtures, J. Solution Chem., 28, 117-131, 1999.

Lopes, A., Farelo, F., and Ferra, M. I. A.: Activity Coefficients of Sodium Chloride in Water-Ethanol Mixtures: A Comparative Study of Pitzer and PitzerSimonson Models, J. Solution Chem., 30, 757-770, 2001.

Lynn, S., Schiozer, A. L., Jaecksch, W. L., Cos, R., and Prausnitz, J. M.: Recovery of Anhydrous $\mathrm{Na}_{2} \mathrm{SO}_{4}$ from $\mathrm{SO}_{2}$-Scrubbing Liquor by Extractive Crystallization: Liquid-Liquid Equilibria for Aqueous Solutions of Sodium Carbonate, Sulfate, and/or Sulfite Plus Acetone, 2-Propanol, or tert-Butyl Alcohol, Ind. Eng. Chem. Res., 35, 4236-4245, 1996.

Marcolli, C. and Krieger, U. K.: Phase Changes during Hygroscopic Cycles of Mixed Organic/Inorganic Model Systems of Tropospheric Aerosols, J. Phys. Chem. A, 110, 1881-1893, doi: 10.1021/jp0556759, 2006.

Marcolli, C. and Peter, T.: Water activity in polyol/water systems: new UNIFAC parameterization, Atmos. Chem. Phys., 5, 15451555, 2005, http://www.atmos-chem-phys.net/5/1545/2005/.

Marcolli, C., Luo, B. P., Peter, T., and Wienhold, F. G.: Internal mixing of the organic aerosol by gas phase diffusion of semivolatile organic compounds, Atmos. Chem. Phys., 4, 2593 2599, 2004, 
http://www.atmos-chem-phys.net/4/2593/2004/.

Maria, S. F., Russell, L. M., Gilles, M. K., and Myneni, S. C. B.: Organic Aerosol Growth Mechanisms and Their Climate-Forcing Implications, Science, 306, 1921-1924, doi:10.1126/science. 1103491, 2004.

Meyer, T., Polka, H. M., and Gmehling, J.: Low-Pressure Isobaric Vapor-Liquid Equilibria of Ethanol/Water Mixtures Containing Electrolytes, J. Chem. Eng. Data, 36, 340-342, 1991.

Middlebrook, A. M., Murphy, D. M., and Thomson, D. S.: Observations of organic material in individual marine particles at Cape Grim during the First Aerosol Characterization Experiment (ACE 1), J. Geophys. Res. Atmos., 103, 16 475- 16 483, 1998.

Ming, Y. and Russell, L. M.: Thermodynamic Equilibrium of Organic-Electrolyte Mixtures in Aerosol Particles., AIChE J., 48, 1331-1348, 2002.

Miro, A. R. and Gonzalez, J. R. A.: Efecto Salino en los Diagramas de Equilibrio Liquido-Vapor. III. Sistemas n-propanol-agua isopropanol-agua con nitrato calcio, Anales de Fisica y Quimica, pp. 797-802, 1958.

Morrison, J. F., Baker, J. C., Meredith, H. C., Newman, K. E., Walter, T. D., Massie, J. D., Perry, R. L., and Cummings, P. T.: Experimental Measurement of Vapor-Liquid Equilibrium in Alcohol/Water/Salt Systems, J. Chem. Eng. Data, 35, 395-404, 1990.

Murphy, D. M. and Thomson, D. S.: Chemical composition of single aerosol particles at Idaho Hill: Negative ion measurements, J. Geophys. Res. Atmos., 102, 6353-6368, 1997.

Murphy, D. M., Cziczo, D. J., Froyd, K. D., Hudson, P. K., Matthew, B. M., Middlebrook, A. M., Peltier, R. E., Sullivan, A., Thomson, D. S., and Weber, R. J.: Single-particle mass spectrometry of tropospheric aerosol particles, J. Geophys. Res. Atmos., 111, D23S32, doi:10.1029/2006JD007340, 2006.

Mydlarz, J., Jones, A. G., and Millan, A.: Solubility and Density Isotherms for Potassium Sulfate-Water-2-Propanol, J. Chem. Eng. Data, 34, 124-126, 1989.

Myhre, C. E. L., Christensen, D. H., Nicolaisen, F. M., and Nielsen, C. J.: Spectroscopic Study of Aqueous $\mathrm{H}_{2} \mathrm{SO}_{4}$ at Different Temperatures and Compositions: Variations in Dissociation and Optical Properties, J. Phys. Chem. A, 107, 1979-1991, doi: 10.1021/jp026576n, 2003.

Nelder, J. A. and Mead, R.: A Simplex Method for Function Minimization, Comput. J., 7, 308-313, 1965.

Pena, M. P., Vercher, E., and Martinez-Andreu, A.: Isobaric VaporLiquid Equilibrium for Ethanol + Water + Sodium Nitrate, J. Chem. Eng. Data, 41, 1097-1100, 1996.

Pinho, S. P. and Macedo, E. A.: Representation of salt solubility in mixed solvents: A comparison of thermodynamic models, Fluid Phase Equilib., 116, 209-216, 1996.

Pitzer, K. S.: Activity Coefficients in Electrolyte Solutions, CRC Press, Roca Raton, FL, USA, 1991.

Polka, H. M. and Gmehling, J.: Effect of Calcium Nitrate on the Vapor-Liquid Equilibria of Ethanol + Water and 2-Propanol + Water, J. Chem. Eng. Data, 39, 621-624, 1994.

Raatikainen, T. and Laaksonen, A.: Application of several activity coefficient models to water-organic-electrolyte aerosols of atmospheric interest, Atmos. Chem. Phys., 5, 2475-2495, 2005, http://www.atmos-chem-phys.net/5/2475/2005/.

Rajendran, M., Renganarayanan, S., and Srinivasan, D.: Salt effect in phase equilibria and heat of mixing: effect of dissolved inorganic salts on the liquid-liquid equilibria of ethyl acetate-2- propanol-water system and the vapor-liquid equilibria and heat of mixing of its constituent binaries, Fluid Phase Equilib., 70, 65-106, 1991.

Rieder, R. M. and Thompson, A. R.: Salt Effect in Vapor-Liquid Equilibria. Ethanol-Water Saturated With Potassium Nitrate, Ind. Eng. Chem., 42, 379-382, 1950.

Robinson, R. A. and Stokes, R. H.: Electrolyte Solutions, Dover Publications Inc., New York, USA, 2nd, revised edn., 2002.

Rogge, W. F., Mazurek, M. A., Hildemann, L. M., Cass, G. R., and Simoneit, B. R. T.: Quantification of Urban Organic Aerosols at a Molecular Level: Identification, Abundance and Seasonal Variation, Atmos. Environ., 27, 1309-1330, 1993.

Rudakoff, G., Hahn, R., and Decker, U.: Zur Berechnung von Aktivitätskoeffizienten in ternären Systemen mit einer nichtflüchtigen Komponente aus Messungen des Gesamtdampfdruckes, Z. Chem., 12, 467-470, 1972.

Sada, E., Morisue, T., and Miyahara, K.: Salt Effects on VaporLiquid Equilibrium of Isopropanol-Water system, J. Chem. Eng. Jpn., 8, 196-201, 1975.

Seinfeld, J. H. and Pandis, S. N.: Atmospheric Chemistry and Physics: From Air Pollution to Climate Change, J. Wiley \& Sons, New York, USA, 1998.

Spann, J. F.: A laboratory study of single sulfate aerosols using electrodynamic suspension, Ph.D. thesis, Fayetteville, 1984.

Staples, B. R.: Activity and Osmotic Coefficients of Aqueous Sulfuric Acid at 298.15 K, J. Phys. Chem. Ref. Data, 10, 779-798, doi:10.1063/1.555648, 1981.

Stokes, R. H. and Robinson, R. A.: Interactions in Aqueous Nonelectrolyte Solutions. I. Solute-Solvent Equilibria., J. Phys. Chem., 70, 2126-2130, 1966.

Taboada, M. E., Veliz, D. M., Galleguillos, H. R., and Graber, T. A.: Solubilities, Densities, Viscosities, Electrical Conductivities, and Refractive Indices of Saturated Solutions of Potassium Sulfate in Water + 1-Propanol at 298.15, 308.15, and 318.15 K, J. Chem. Eng. Data, 47, 1193-1196, 2002.

Tang, I. N.: Thermodynamic and optical properties of mixed-salt aerosols of atmospheric importance, J. Geophys. Res. Atmos., 102, 1883-1893, 1997.

Tang, I. N. and Munkelwitz, H. R.: Aerosol Growth StudiesIII. Ammonium Bisulfate Aerosols in a Moist Atmosphere, J. Aerosol Sci., 8, 321-330, 1977.

Tang, I. N. and Munkelwitz, H. R.: Water activities, densities, and refractive indices of aqueous sulfates and sodium nitrate droplets of atmospheric importance, J. Geophys. Res. Atmos., 99, 18 801-18 808, 1994.

Taylor, E.: Precipitation of Salts, J. Phys. Chem., 1, 718-733, 1897.

Thomsen, K., Iliuta, M. C., and Rasmussen, P.: Extended UNIQUAC model for correlation and prediction of vapor-liquidliquid-solid equilibria in aqueous salt systems containing nonelectrolytes. Part B. Alcohol (ethanol, propanols, butanols)water-salt systems, Chem. Eng. Sci., 59, 3631-3647, doi:10. 1016/j.ces.2004.05.024, 2004.

Tsonopoulos, C.: An Empirical Correlation of Second Virial Coefficients, AIChE J., 20, 263-272, 1974.

Vener, R. E. and Thompson, A. R.: Solubility and Density Isotherms for Sodium Sulfate-Ethylene Glycol-Water, Ind. Eng. Chem., 41, 2242-2247, 1949.

Vercher, E., Pena, M. P., and Martinez-Andreu, A.: Isobaric VaporLiquid Equilibrium for Ethanol + Water + Potassium Nitrate., J. 
Chem. Eng. Data, 41, 66-69, 1996.

Yan, W. D., Topphoff, M., Rose, C., and Gmehling, J.: Prediction of vapor-liquid equilibria in mixed-solvent electrolyte systems using the group contribution concept, Fluid Phase Equilib., 162, 97-113, 1999.

Young, T. F., Maranville, L. F., and Smith, H. M.: Raman spectral investigations of ionic equilibria in solutions of strong electrolytes. In: The Structure of Electrolytic Solutions, New York, USA, 1959.

Zdanovskii, A. B.: Zakonomernosti v izmeneniyakh svoistv smeshannykh rastvorov: Trudy solyanoi laboratorii (Fundamental
Aspects of Variation of Properties of Mixed Solutions: Works of Salt Laboratory), Tr. Solyanoi Lab. Akad. Nauk SSSR, 5-70, 1936.

Zdanovskii, A. B.: Novyi metod rascheta rastvorimostei elektrolitov $\mathrm{v}$ mnogokomponentny sistema, 1. (New methods of calculating solubilities of electrolytes in multicomponent systems, 1.), Zh. Fiz. Khim., 22, 1478-1485, 1948.

Zemp, R. J. and Francesconi, A. Z.: Salt Effect on Phase Equilibria by a Recirculating Still, J. Chem. Eng. Data, 37, 313-316, 1992. 